\title{
The role of microRNA miR-196 in the Hox dependant maturation of lumbar motor neurons
}

\author{
Doctoral Thesis \\ In partial fulfillment of the requirements for the degree 'Doctor of Philosophy \\ (PhD)' in the Molecular Biology Program at the George-August University \\ Goettingen, Faculty of Biology
}

Submitted by:

Naisana Seyed Asli

Born in

Tehran, Iran

Goettingen, July2008 


\section{AFFIDAVIT}

Here I declare that my doctoral thesis entitled " The role of microRNA miR-196 in the HOX dependant maturation of lumbar motor neurons " has been written independently with no other sources and aids than quoted.

Naisana Seyed Asli, Goettingen, July2008 
.... I express my heartfelt thanks to Prof. Michael Kessel for his continuous support during my years of PhD studies and for the advices that have taught me a lot both in science and life .........

My gratitude to the PhD committee members Prof. Tomas Pieler and Prof. Reinhard Luehrmann for the advices and comments during the PhD committee meetings.

My thanks to Dr. Till Marquardt for the helpful advices to get me into the business of motor neurons .....

My thanks to the current and previous members of the "Kessel group" for the great atmosphere and for the moments of joy we shared

My thanks to the members of the MCB department for the help during my work

My deep love and faith to my family for the warm support they gave me at each and every moment from "far far away"

..... and my everlasting love to the person whose patience made all this distance short enough....... 


\section{TABLE OF CONTENTS}

LIST OF FIGURES

SUMMARY iii

INTRODUCTION _ 1

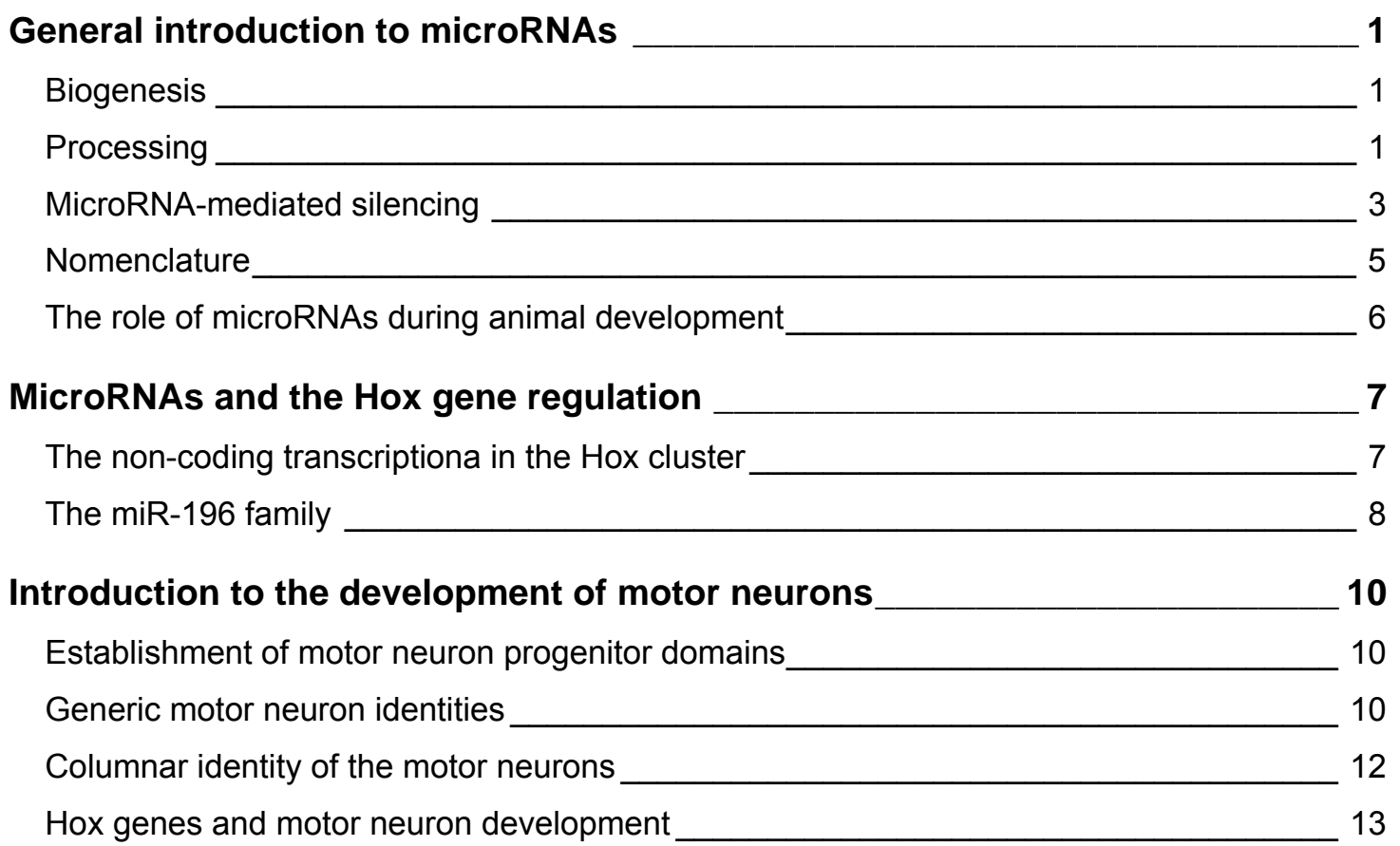

Aims and scopes of this study

HOXB8 and miR-196 are expressed in a mutually exclusive pattern along the anteroposterior axis _ 15

miR-196 represses the HOXB8 translation by targeting its 3'UTR___ 18

miR-196 expression vectors__ 18

miR-196 suppresses the endogenous HOXB8 protein _ـ 20

miR-196 inhibitor, relieves the HOXB8 repression in CEF cells___ 21

miR-196 targets the gga-HOXB8 3'-UTR___ 21

The interplay of HOXB8 and miR-196 is shortly before motor neuron generation in the lumbar neural tube

Misexpression of hoxb8 in the lumbar neural tube results in delayed motor neuron development 
gga-HOXB8 expression vector 23

HOXB8 misexpression in the lumbar neural tube, results in an increase in motor neuron precursors at the expense of post-mitotic and differentiated motor neurons 24 The generation of axonal projections is impaired in HOXB8 misexpressing lumbar motor neurons 26

Knockdown of miR-196 results in delayed motor neuron development similar to HOXB8 misexpression 27

miR-196-depleted lumbar neural tube shows a delayed motor neuron differentiation pattern, with more precursor cells at the expense of post-mitotic motor neurons 27 miR-196-depleted lumbar LMC neurons show little defects in the development of axonal projections 30

Change of miR-196 expression dosage or domain, does not result in any defects in motor neuron development

miR-196 overexpression in the lumbar neural tube, results in no significant change in motor neuron differentiation

miR-196 misexpression in the brachial neural tube, results in no significant change in motor neuron differentiation

Ectopic miR-196 does neither affect the antero-posterior positioning of the lumbar LMCs, nor the ability of these cells in developing axonal projections 34

The developmental delay in HOXB8 misexpressing motor neurons does not result from altered progenitor domains 35

The developmental delay in HOXB8 misexpressing motor neurons results from a failure in expressing pan motor neuron factors and a defect in the cell cycle exit

HOXB8 misexpression negatively affects the expression of the pan motor neuron factor MNR2

HOXB8 misexpression results in an increase in BrdU-positive cycling cells in the lumbar neural tube 38

\section{DISCUSSION}

Mutually exclusive expression domains of miR-196 and HOXB8 along the antero-posterior axis

Repressive effect of miR-196 on HOXB8 translation by targeting the 3'UTR of its mRNA 41 Delayed lumbar motor neuron development upon HOXB8 misexpression and miR-196 knockdown

The negative effect of HOXB8 on the expression of motor neuron fate determinants and cell cycle exit in lumbar neural tube 43 
MATERIALS \& METHODS 46

RNA analysis 46

Whole mount in situ hybridization for chick embryos ${ }^{76}$ 46

In situ hybridization on cryosections using LNA antisense probes ${ }^{78}$ 49

Total RNA extraction from tissue culture cells 50

Total RNA extraction from embryos 51

Northern blot analysis for small RNA visualization ${ }^{79}$ 51

Protein analysis 54

Total Protein extraction from cells 54

Total Protein extraction from embryos 54

SDS-PAGE separation of protein samples 54

Western blot analysis 55

Histological techniques _ـ 56

Vibratome sectioning of whole embryos___ 56

Embedding the embryos for cryosectioning __ 57

Immunohistochemistry _

Immunostaining of the frozen sections___ 58

Luciferase reporter assay__ 59

Vector designs $\quad 59$

miR-196 expression vectors _ 59

miR-196 knockdown oligonucleotides __ 62

miR-196-targeted sensor constructs __ 62

miR-196 GFP sensor $\quad 62$

miR-196 luciferase sensor __ 63

GFP-gga HOXB8 3'UTR 64

gga-HOXB8 expression vector___ 64

Generation of the ISH probes _ 65

In ovo electroporation

Retrograde labeling of axonal tracts

BrdU labeling of chick embryos __ 69

Immunostaining with anti-BrdU antibody __ 70

Cell culture experiments__ 71

Transfection methods__ 71 


\section{Quantitative approaches} 71

Quantitation of western blot signals 71

Quantitation of cell numbers in immuno-stained embryos 72

REFERENCES 73

CURRICULUM VITAE 80 


\section{LIST OF FIGURES}

Fig.1 The processing of microRNA precursor transcripts to mature microRNAs ..................

Fig.2 Different mechanisms of microRNA-mediated gene silencing ...........................

Fig.3 The structure of the Hox cluster as shown in human, mouse and chicken................... 8

Fig.4 Sonic hedgehog-induced progenitor domains in the ventral neural tube and the formation

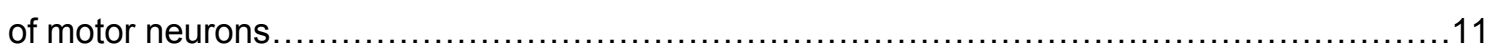

Fig.5 Motor neurons cluster into different motor columns along the antero-posterior axis.........13

Fig.6 Expression patterns of HOXB8 and miR-196 along the antero-posterior axis of stage $\mathrm{HH} 16$

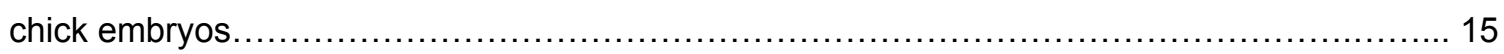

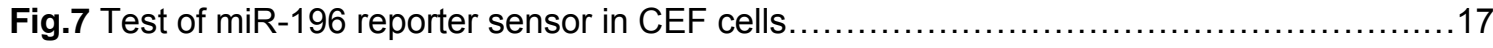

Fig.8 miR-196 expression domain shown by sensor reporter analysis.........................18

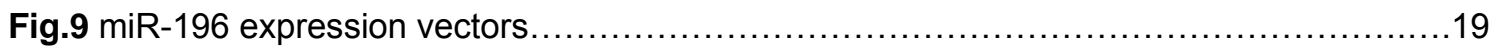

Fig.10 Effects of ectopic miR-196 on the endogenous HOXB8 protein.........................20

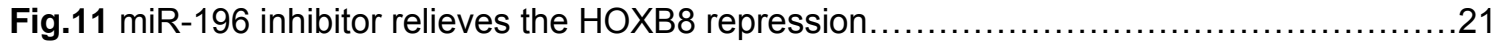

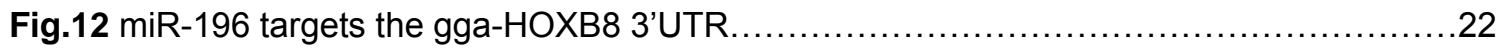

Fig.13 Generation of motor neuron precursors in the chick neural tube .........................23

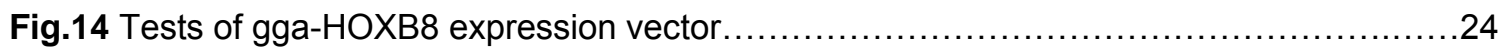

Fig.15 HOXB8 misexpression delays the differentiation of lumbar motor neurons...............25

Fig.16 Axonal projections from lumbar LMCs Upon HOXB8/GFP electroporation.................27 
Fig.17 miR-196 depletion delays lumbar motor neuron maturation. 29

Fig.18 Axonal projections from lumbar LMCs upon miR-196 knockdown.... .30

Fig.19 miR-196 overexpression in the lumbar neural tube. 32

Fig.20 miR-196 misexpression in the brachial neural tube. .33

Fig.21 The antero-posterior patterning of the lumbar LMC upon expression of miR196. .34

Fig.22 The formation of lumbar motor neuron progenitor domains upon HOXB8 misexpression.

Fig. 23 Expression of MNR2 and Lim3 in HOXB8-electroporated lumbar neural tube .37

Fig.24 Proliferation status of HOXB8- electroporated lumbar neural tube 39

Fig.25 Structure of the bicistronic vector used for the expression of the miR-196 60

Fig.26 In ovo electroporation in chick neural tube 67

Fig.27 Schematic illustration of retrograde axonal labeling .68 


\section{SUMMARY}

Small, non-coding microRNAs regulate the translation of many mRNAs through imperfect base pairing in the 3' untranslated region. Three conserved genes, encoding three miR-196 RNAs are located in the mammalian and avian Hoxa, Hoxb and Hoxd gene clusters, respectively. Based on bioinformatics and reporter gene studies, the three murine genes Hoxa7, b8 and c8 were identified as targets of miR-196. Overexpression of miR-196 impaired the ectopic induction of HOXB8 by retinoic acid in the chick forelimbs. Hox genes are involved in antero-posterior patterning of vertebrate embryos, from gastrulation to organogenesis. In the developing spinal cord they are determinants of motor neurons identity, and in particular important for their columnar organisation. The current study investigates the function of miR-196 in the development of the lumbar spinal cord.

By RNA in situ hybridization and double sensor-tracer analysis, it is shown here that miR-196 and HOXB8 adopt mutually exclusive expression domains along the anteroposterior axis of the chick spinal cord. HOXB8 is expressed in the cervical and thoracic region of the neural tube, whereas miR-196 is expressed in the lumbar region adjacent to the posterior boundary of the HOXB8 domain. miR-196 specifically repressed translation of HOXB8 via interaction with its 3'UTR both in cultured cells and in the living embryo. This regulatory effect was further confirmed by knockdown approaches relieving HOXB8 from repression. Interfering with the balance between HOXB8 and miR-196 by the misexpression of HOXB8 in the lumbar neural tube, or by inhibition of miR-196 activity, affected the timing of motor neuron development. The number of progenitor cells was increased, and their exit from the cell cycle delayed, so that the development of postmitotic motor neurons and their axonal projections were impaired. These data suggest a requirement for HOXB8 downregulation from the lumbar neural tube in a developmental phase, when motor neuron progenitors are supposed to exit the cell cycle and neurons are born. miR-196 is expressed at the right time in the right cells to mediate the absence of HOXB8 protein via a direct interaction with HOXB8 mRNA. Previous studies had emphasized the importance of anterior Hox gene expression boundaries, indicating a combinatorial mechanism and/or a posterior prevalence. The present study provides evidence for a microRNA mediated definition of the posterior expression boundary of a Hox gene, as an additional mechanism to define cellular identities along the body axis. 


\section{INTRODUCTION}

\section{General introduction to microRNAs}

MicroRNAs are small non-coding RNAs of 21-24 nucleotides, which are involved in indirect regulation of genes upon exerting their effects on the 3'UTR of their target mRNAs. There are certain features which make microRNAs a distinct group from other non-coding small RNAs which include their biogenesis, processing and also the mechanism by which they affect the target mRNA.

\section{Biogenesis}

MicroRNAs are synthesized by RNA polymerase II, as big primary transcripts that like any normal mRNA, are capped and polyadenylated ${ }^{2,3}$. The few identified microRNA promoter regions show sequence motifs, which are bound by polll-specific transcription factors ${ }^{4}$. According to their genomic context, the microRNA genes are found in three different groups ${ }^{5}$ :

- Exonic microRNAs in non-coding transcription units (e.g. intergenic regions)

- Intronic microRNAs in non-coding transcription units

- Intronic microRNAs in protein-coding transcription units

\section{Processing}

MicroRNAs are first transcribed as large primary transcripts, the pri-microRNAs, which can have a length of more than $1 \mathrm{~kb}$. A pri-microRNA needs to pass through the first processing step, which results in the formation of a 70nt length hairpin (Fig-1a). The responsible Drosha enzyme, is a member of the RNAselll family of endonucleases. The pri-microRNA cleavage is performed via a complex of Drosha together with its regulatory subunit DGCR8 (Digeorge syndrome catalytic subunit 8 ) in humans and Pasha in drosophila. The DGCR8/Pasha is a protein of around $120 \mathrm{kDa}$, containing two dsRBDs (double stranded RNA binding domains). According to the current understandings, the Drosha/DGCR8 complex, also known as the microprocessor complex, is able to recognize the tertiary structure of the pri-microRNAs, in particular the stem region and the terminal loop ${ }^{5}$. A terminal loop of more than 10 nucleotides is 
preferred by Drosha, indicating that the enzyme prefers a more relaxed structure at the end of the stem region ${ }^{4}$. Moreover, the single stranded flanking regions at the base of the stem-loop structure are also of significant function, as in their absence, the primicroRNA would be inefficiently processed ${ }^{4}$. The Drosha/DGCR8 processing seems not to use the 5'- Cap and 3'-polyA structures of the primary transcript, and the primicroRNA processing can therefore take place before the transcription is completely finished ${ }^{4}$. After recognizing the tertiary structure of the pri-microRNA, the Drosha/DGCR8 complex, binds the ssRNA-dsRNA junction at the base of the stem loop and cuts the transcript, at a distance of one helical RNA turn ( $\approx 11$ bases), hence leaving a stem loop structure of around 70 nucleotides which has a 5 ' phosphate and a 2 nucleotides overhang at the $3^{\prime}-\mathrm{OH}$ end ${ }^{6,7}$. The product of Drosha processing, known as pre-microRNA, is exported out of the nucleus by binding to Ran-GTP and using the export receptor, exportin- $5^{8}$. A structural motif known as the 'minihelix motif' which consists of a $>14 \mathrm{bp}$ stem and 3-8 nucleotides overhang at the 3'end is necessary for the pre-microRNA to be recognized and subsequently transported by Exportin- $5^{5}$. The 70 nucleotides length pre-microRNA enters the next processing step, by another RNAselll type enzyme, 'Dicer', which cleaves the hairpin structure and yields a dsRNA of 21-24 base pairs, with a typical feature of 2 nucleotides overhang at the 3' end (Fig1b). Dicer homologues, typically have two RNAsell domains and a double strand RNA binding domain (dsRBD), together with a long $\mathrm{N}$-terminal segment, containing a DEADbox RNA helicase domain and a PAZ domain which recognizes the 3' single stranded RNA overhangs in Drosha products ${ }^{5}$. The PAZ domain is a common domain between Dicer homologues and a family of highly conserved proteins known as Argonautes (AGO) that are involved in different steps of RNA interference. Upon recognition of the 3 ' overhang by the PAZ domain, the two RNAselll domains form an active catalytic center in the center of the pre-microRNA and the hairpin is cut at a distance of around 20 nucleotides from its free end. The product of Dicer would hence be a double stranded RNA of around 22 pairs with a feature of two nucleotides 3'overhang ${ }^{4}$. From the double stranded Dicer product, the microRNA strand with lesser energy at its 5 ' end is selectively stabilized and used as the guide strand in the microRNA-mediated gene silencing and the complementary strand is subsequently degraded ${ }^{4}$. The mature microRNA strand is passed by to Dicer-interacting AGO proteins and would from then on be used as a guide strand for the silencing machinery. 
Fig.1 The processing of microRNA precursor transcripts to mature microRNAs; a) The complex of Drosha/DGCR8 cuts the primary microRNA to a $70 \mathrm{nt}$ pre-microRNA. b) The exported pre-microRNA is further processed by Dicer to make the mature microRNA, which incorporates into the RISC complex.

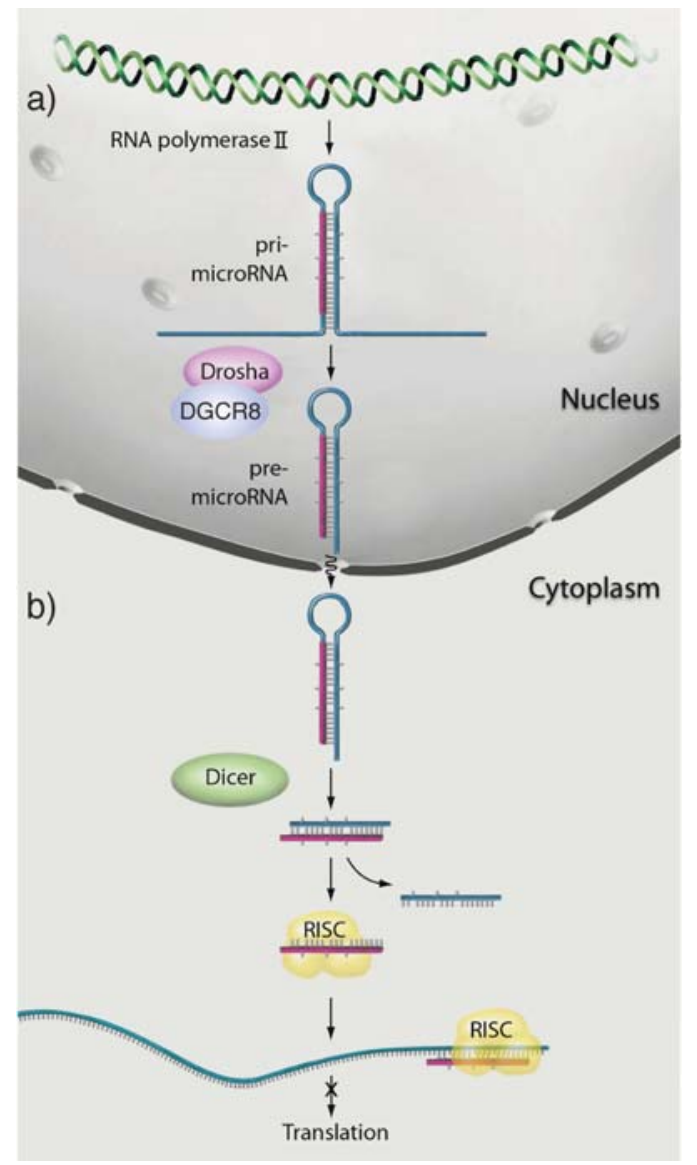

\section{MicroRNA-mediated silencing}

MicroRNAs exert their function within a ribonucleoprotein complex, known as microRNA-induced silencing complex (miRISC), which includes the mature microRNA together with a number of Argonaute family proteins ${ }^{9}$. The target recognition occurs through a limited base-pairing between the nucleotides 2-8 at the 5' end of the microRNA (seed region) and the complementary sequence in the 3'UTR of the target mRNA. The microRNA effect depends to a large extent on the degree by which the microRNA is complementary to its target mRNA. Upon binding of the microRNA to its target sequence, the mRNA is translationally repressed. The translational repression of the target mRNA could occur at different steps of translation and through distinct mechanisms (Fig.2). MicroRNA-mediated inhibition of translation can occur at the 
translation initiation step, by impairing the cap recognition process ${ }^{9-12}$. There is also evidence for inhibition of translation via premature termination of translation or cotranslational protein degradation ${ }^{10-12}$. Apart from the role of microRNAs in translational repression of their target mRNAs, there is also evidence for microRNA-mediated destabilization of target transcripts. The destabilization process seems to involve the deadenylation and subsequently decapping of the target mRNA which would finally result in the mRNA degradation in special cytoplasmic foci, known as processing $(P)$ bodies (also called GW bodies). According to current understandings, the AGOassociated microRNA recognizes its target mRNA by base-pairing to its 3'UTR. The Argonaute then interacts with a P-body protein, GW182 and is delivered to the processing bodies. The target mRNA is then either decapped and degraded, or just stored in a translationally static state. The mechanisms of which process to adopt however, differs in cases of individual microRNA-mRNA pairs and seems to result from the mRNA context ${ }^{10-14}$. The translationally-stalled mRNA, could be reshuffled into the active polysomes in special cases of stress or external stimuli ${ }^{9,13}$. 


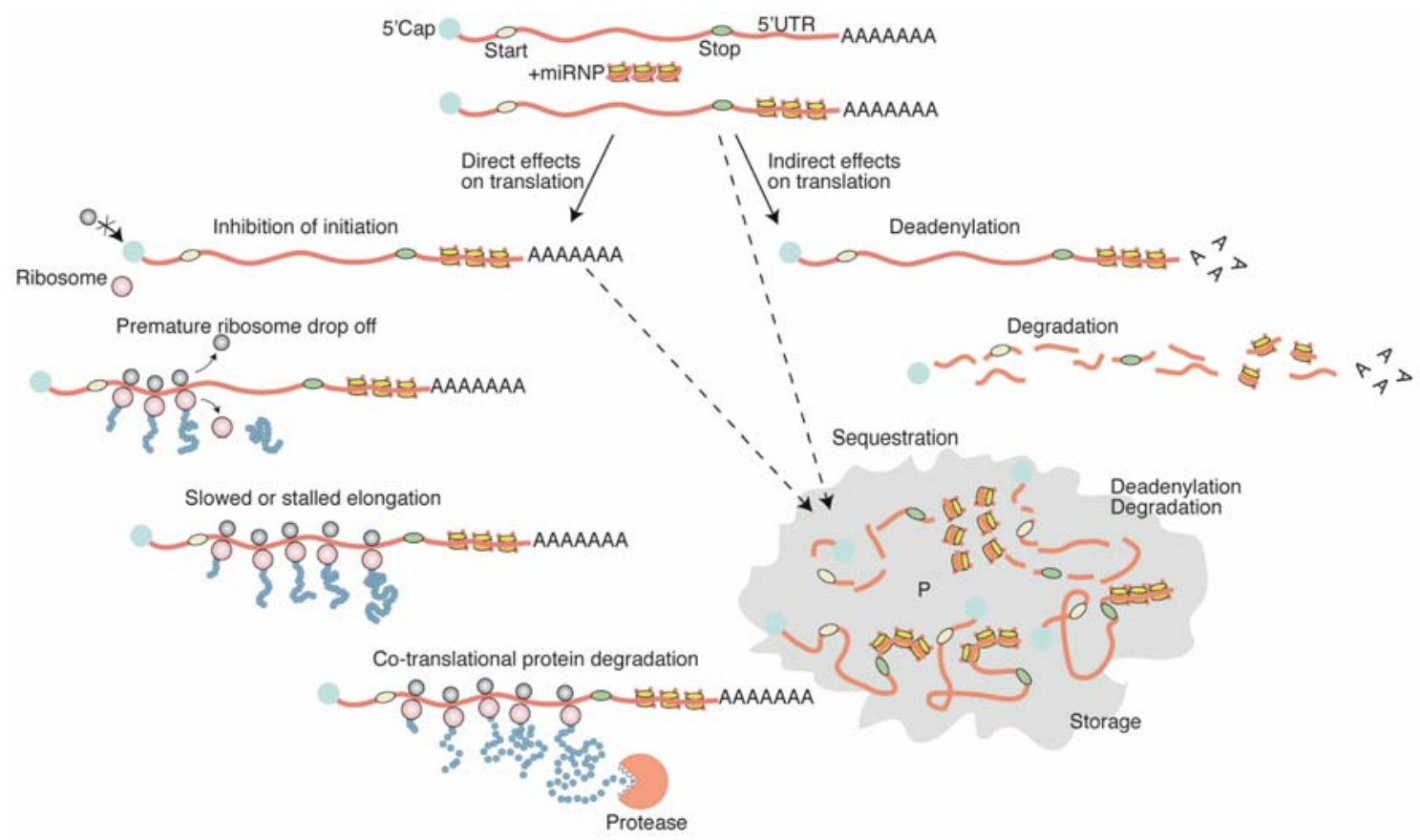

Fig. 2 Different mechanisms of microRNA-mediated gene silencing (produced after ${ }^{10}$ )

Although most of the microRNAs recognize their targets through an imperfect pairing, there are also cases of microRNAs which are perfectly complementary to their target sequences and hence form the A-form RNA double helix which would mark the miRmRNA duplex for the siRNA pathway and would eventually result in the degradation of the target mRNA by the endonucleolytic ability of the siRISC and the cleavage of the mRNA in the central part of the duplex (positions10 and 11) ${ }^{9}$. Such special cases however, are not abundant.

\section{Nomenclature}

The microRNA registry database (http://microrna.sanger.ac.uk/sequences), rules over the newly characterized microRNAs before being accepted, by assigning nomenclature guidelines. The guidelines are basically designed in such a way that would ease some basic information withdrawals by just comparing the microRNA names. 
The microRNA precursor hairpin that is predicted by the RNAfold Vienna program ${ }^{15}$ and the mature microRNA are named as 'miR' (e.g. miR-196) and 'miR' (e.g. miR196), respectively. MicroRNAs with identical sequences which are identified in different species (Orthologous microRNAs) are given the same number and the name of the species can precede the microRNA name (e.g. hsa-miR-196 or gga-miR-196). Identical sequences of mature microRNAs from a certain species, but with different genomic loci are regarded as paralogous, and are differentiated with numbers (e.g. gga-miR-196-1 on chromosome 27 and gga-miR-196-2 on chromosome 2). Paralogous microRNAs which have a difference of one or two bases, are named with alphabets (e.g. mmu-miR196a and mmu-miR-196b) ${ }^{16-18}$.

\section{The role of microRNAs during animal development}

The first evidence for microRNAs having a significant role during development comes from studies which involve the depletion of embryos from their whole microRNA supplies, basically by deletion of the pre-microRNA processing enzyme, 'Dicer'. Dicer knockout mice showed a lethal phenotype at very early stages of development, before gastrulation ${ }^{19}$. The Dicer null embryos were reported to be devoid of stem cells and hence, explains the inability to pass through gastrulation ${ }^{19}$. The loss of stem cells in Dicer null embryos, which was determined by the loss of the stem cell maintenance marker, Oct4, seemed to be however an indirect outcome of Dicer mutation, since, in another study, the Dicer knockout ES cells were generated and showed a normal level of Oct4 expression, despite of their defects in differentiation potentials ${ }^{20}$. Deletion of the zebrafish Dicer homologue also resulted in an early arrest of embryonic development, though the embryos survived longer than mice dicer knockouts, as a result of maternal contribution ${ }^{21,22}$. Apart from data derived from whole microRNA pool depletions, there is extensive evidence that single microRNAs are involved in several developmental pathways from heart and muscle development ${ }^{23-26}$ to hematopoiesis ${ }^{27}$, stem cell maintenance ${ }^{28}$, cell cycle regulation ${ }^{29}$, neurogenesis ${ }^{30,31}$ and differentiation of internal organs ${ }^{32,33}$ by regulating the key transcription factors involved in each process (for a summary see also ${ }^{34}$. 


\section{MicroRNAs and the Hox gene regulation}

\section{The non-coding transcription in the Hox cluster}

The homeobox genes of the Hox family are involved in the antero-posterior patterning of the embryos both in early embryonic stages and also later during organogenesis ${ }^{35,36}$. In higher vertebrates, the 39 Hox genes map to four distinct clusters, named as HoxA to D, with paralogous genes sitting at comparable loci, from 3' to 5' (Fig.3). Genes of each paralogue group follow a collinear expression pattern with the 3 ' genes expressed earlier and more anterior, whereas the 5' genes are expressed later and more posterior. A concept that is often referred to as temporal and spatial colinearity ${ }^{35,36}$.

The presence of conserved non-coding sequences in Hox clusters, suggests the noncoding transcripts as direct or indirect regulators of Hox genes, acting either in cis on adjacent hox genes or in trans, affecting the Hox genes of the other clusters. The transcription of opposite strand non-coding intergenic regions, for example, is necessary for collinear activation of genes of HoxA cluster ${ }^{37}$. Although the exact regulatory mechanisms of collinear Hox gene expression remain to be understood, it is clear that a cellular epigenetic memory involving chromatin modifications is necessary to assign the active and silent Hox genomic loci ${ }^{38}$. The non-coding transcription is partly involved in functional assignment of active and silent Hox chromatin domains by affecting the chromatin rearrangements ${ }^{38-40}$.

Two microRNA families, miR-10 and miR-196 are mapped to vertebrate Hox clusters, which show a high degree of conservation among different vertebrates (Fig.3) ${ }^{41,42}$. Differential distribution of Hox transcripts and proteins, during embryonic patterning provides evidence of microRNA-mediated regulation, which still needs to be characterized ${ }^{35}$. 


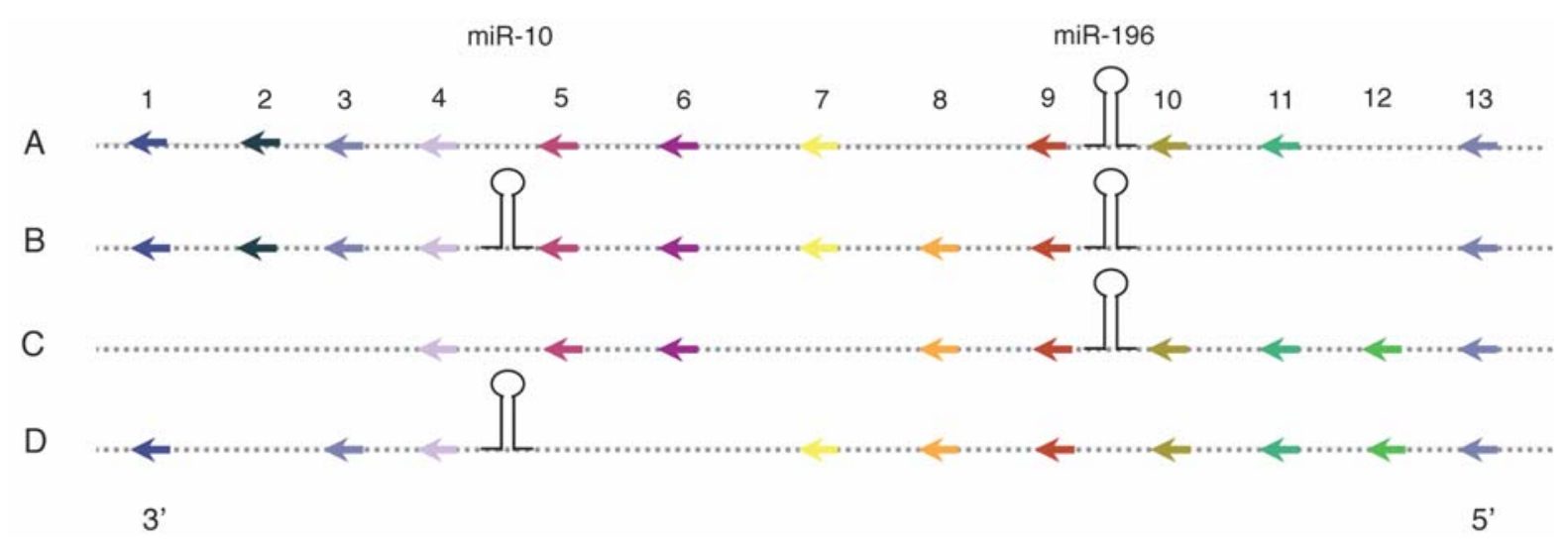

Fig.3 The structure of the Hox cluster as shown in human, mouse and chicken; Hox genes cluster into 13 paralogous groups with a termporal and spatial collinear expression. The miR-196 and miR-10 families of microRNAs are located within the Hox clusters.

\section{The miR-196 family}

MiR-196 was among the many microRNAs, which were originally cloned and identified from mouse tissues. In these primary studies, miR-196 was reported to be present in the ovaries of 18.5 weeks old adult mice and the human osteoblast sarcoma cell line, Saos- ${ }^{43}$. In mouse, the miR-196 family of microRNAs consists of 3 paralogues, named as mmu-miR-196-a-1, mmu-miR-196-a-2 and mmu-miR-196-b and located in the Hox$B, C$ and A clusters, respectively (Fig.3) ${ }^{44}$. Further RNA profiling of mouse tissues has shown a high enrichment of miR-196-a-1 and miR-196-b in the kidney and reproductive system of adult mice ${ }^{45}$. The chick homologues of miR-196 are named as miR196-1, miR-196-2 and miR-196-3, with gga-miR-196-1 being a true homologue of mmumiR196-a-1, having exactly the same sequence and the same location on the avian HOX-B cluster.

The expression pattern of miR-196 in the whole embryo was originally described to follow a Hox-like pattern, with an expression domain in the posterior trunk of stage 10.0 dpc mouse embryos transgenic for a LacZ miR-196 reporter sensor, which would be missing $\beta$-galactosidase activity in the domains where miR-196 was present ${ }^{46}$. Further development of detection techniques made it possible to detect the expression of the murine miR-196 with whole mount in situ hybridization using modified locked nucleid 
acid (LNA) oligonucleootides which had a much higher hybridization affinity to small RNAs, than the normally used RNA probes. According to these data, miR-196 is expressed in the posterior region of $9.5 \mathrm{dpc}$ mouse embryos ${ }^{47}$. Considering the high conservation of microRNAs among different species, it is of a great interest to see if conserved microRNAs would follow conserved expression patterns which would in turn be indicative of conserved functional aspects. It is evident that a number of microRNAs do show comparable expression, when analyzed in different species. In chick embryos, the expression of a number of microRNAs is nicely analyzed ${ }^{48}$. The expression pattern of the avian miR-196 during the early stages of chick development however, is missing from the expression atlas, eventually ending in a single expression pattern of $\mathrm{HH} 20+$ embryos, with a homogenous expression all over the embryo ${ }^{49,50}$.

Very little is known about the biology of miR-196, and its significance during embryonic and adult development. Among the list of mRNAs which are nominated as miR-196 targets, three of the Hox transcripts, Hoxa7, Hoxb8 and Hoxc8 were validated using luciferase reporters bearing the 3'UTR of the respective Hox mRNAs, which were repressed upon co-transfection with miR-196 into HeLa cells ${ }^{44}$. The mouse Hoxb8 mRNA, exhibits an exceptional perfect complementarity to miR-196-a-1 which would, according to the current understandings, drive the microRNA effect through the siRNA pathway and finally result in the degradation of the target mRNA ${ }^{9}$. Consequently, the targeted and hence degraded products of mouse Hoxb8 were also detected in mouse total RNA, using a modified 5'RACE assay ${ }^{44}$. In a further study, miR-196 was fished out of a small-RNA microarray analysis on mouse fore- and hindlimbs, as a microRNA preferentially expressed in the mouse hindlimbs ${ }^{51}$. Different behavior of fore and hindlimbs in turning on the HOXB8 expression upon exposure to retinoic acid (RA) is a known characteristic of the limb mesenchyme, and it is already shown that after RA treatment, HOXB8 is ectopically induced in fore but not hindlimbs ${ }^{52}$. The viral overexpression of miR-196 in chick embryos, however, impaired the RA-induced ectopic expression of HOXB8 in the forelimbs ${ }^{51}$ suggesting a negative regulatory role for miR196 in this context. 


\section{Introduction to the development of motor neurons}

Motor neurons rise from a progenitor domain in the ventral neural tube and further differentiate into defined subsets with specific axonal projection patterns along the antero-posterior axis.

\section{Establishment of motor neuron progenitor domains}

In the early neural tube, a gradient of Sonic hedgehog (Shh), secreted from the notochord and the floor plate, induces a group of precursor cells of the ventral neural tube, to follow motor neuron fates. The undifferentiated neuroepithelial cells, respond to different gradients of Shh, by switching two classes of homeodomain (HD) transcription factors. The class I HD transcription factors, including Pax6, Irx3, Dbx2, Dbx1 and Pax7 are differentially repressed by defined concentrations of Shh, and therefore, are more abundant in dorsal domains. For the class II transcription factors, including the Nkx2.2 and Nkx6.1 however, Shh acts as an activator, therefore resulting in the higher expression of these genes in more ventral domains ${ }^{1,53-55}$. The concentration-dependant response of the homeobox genes to Shh, and the reciprocal repression between some of the members, finally results in a unique combination of homeodomain transcription factors along the dorso-ventral axis, which further assigns the different progenitor domains of the ventral neural tube (Fig.4-a).

The motor neuron progenitor domain is defined by a combinatorial expression of Nkx6.1 and Pax6, with Nkx2.2 and Irx-3 limiting the ventral and dorsal boundaries, respectively (Fig.4-a) ${ }^{1,53-55}$. Within the established motor neuron progenitor domain, the Nkx6.1 expression in the early precursors, leads to the induction of a basic Helix-loop-helix (bHLH) transcription factor, Olig-2. Olig-2 is a pan motor neuron transcription factor, which coordinates the establishment of motor neuron identities with the general process of neurogenesis, involving the generation of post-mitotic neurons ${ }^{1,54-56}$.

\section{Generic motor neuron identities}

Based on studies in chick embryos, the expression of Olig-2 in motor neuron precursor cells, results in the induction of MNR2, a member of the Mnx family of homeodomain proteins (Fig.4-b). MNR2 specifies the motor neurons and, when misexpressed, can result in the generation of ectopic motor neurons and a concomitant repression of 
interneuronal fates ${ }^{57,58}$. The MNR2 protein is expressed in the last cell cycle of the progenitor cells, slightly before the cell cycle exit. Its expression further persists in certain subsets of differentiated motor neurons, whereas, completely excluded from other types, indicating a secondary role of the protein in more advanced levels of motor neuron differentiation ${ }^{57}$. Olig-2-induced expression of MNR2, which imposes specific motor neuron identities on the precursor cells, is accompanied with the expression of pan-neuronal genes such as ngn2, which mediate neurogenic pathways, resulting finally in the generation of post-mitotic motor neurons (referred to as motor neurons from here on) ${ }^{56}$. The newly born motor neurons, express specific subset of genes, which mainly encode members of the LIM homeodomain transcription factor family. The first activated LIM homeobox genes in early born motor neurons are Lim-3 and Islet-1 (Isl-1). The Lim3 protein is expressed shortly after the expression of MNR2 in the motor neuron precursors, but the expression persists after the cell cycle exit in certain motor neuron subpopulations. The Isl-1 expression however, is just detected in the newly generated motor neurons, shortly after the cell cycle exit. Upon further differentiation, different subsets of cells express a unique combination of LIM homeodomain proteins and form the motor neuron subtypes ${ }^{1,53-55}$.

a)

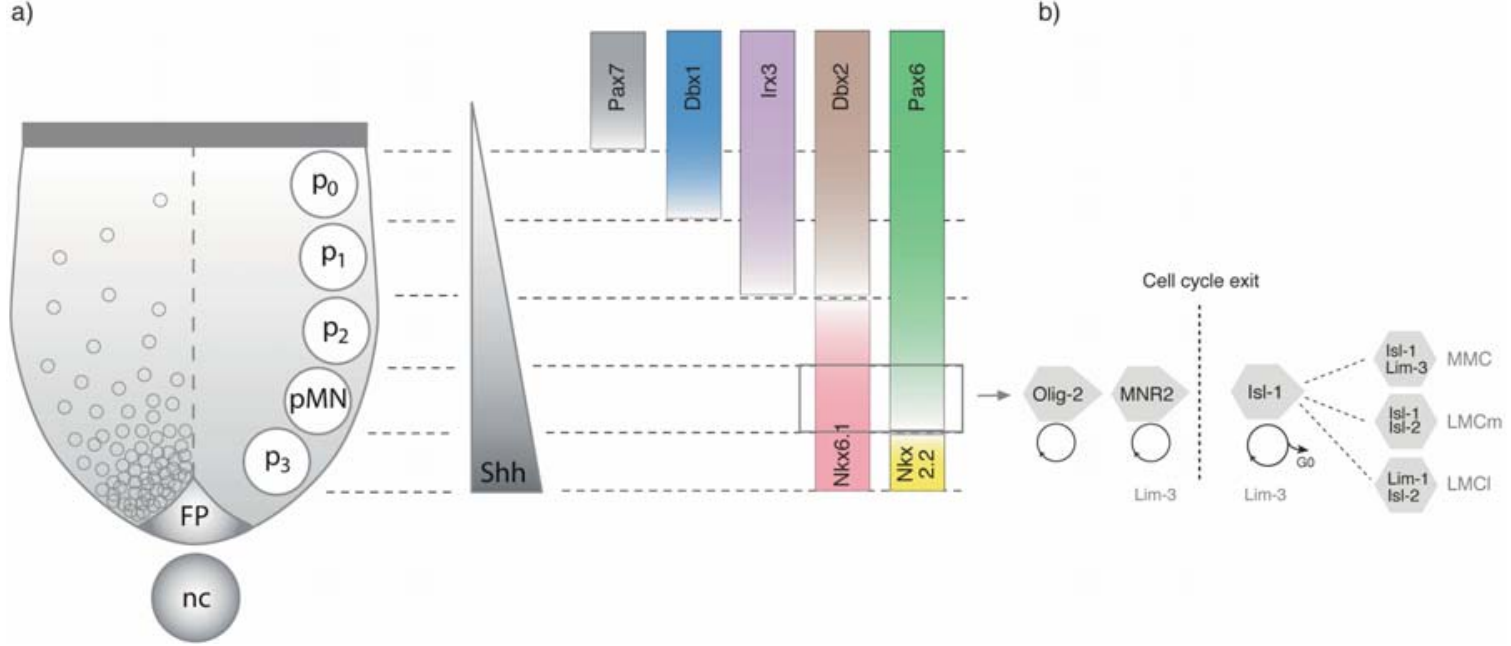

Fig.4 Sonic hedgehog-induced progenitor domains in the ventral neural tube and the formation of motor neurons; a) A combinatorial expression of homeobox genes, assign different neural progenitor domains. Motor neurons originate from the pMN domain. b) Cascade of motor neuron differentiation, with a focus on limb level motor neurons (Shh: Sonic hedgehog, FP: Floorplate, nc: notochord). (Redrawn after ${ }^{1}$ ). 


\section{Columnar identity of the motor neurons}

After exiting from the cell cycle, motor neurons generate axonal projections towards certain muscles. Motor neurons, can differentiate into different columnar subsets, according to their medio-lateral and antero-posterior location. Each of these columnar subsets, is distinguished by a unique combination of LIM-homeobox transcription factors as well as peculiar axonal projections (Fig.5). Along the medio-lateral axis of the neural tube, motor neurons follow an inside-out pattern of differentiation, with the innermost cells, always differentiating first. Motor columns are first distinguished as medial (MMC : Medial motor column) and lateral (LMC: Lateral motor column), according to their medio-lateral location. The medial motor column runs all way from the brachial to the lumbosacral level, being more extended at the thoracic level. The cells residing in the medial motor column, send axons to axial as well as body wall muscles ${ }^{1,53-55,59}$. An additional column of preganglionic autonomic motor neurons, the Column of Terni (CT), is present at thoracic level, located dorso-medial to the MMCs. At brachial and lumbosacral levels (fore and hind-limb levels), the medial motor column is reduced to a narrow column of cells residing close to the midline and projecting axons to axial muscles, whereas the rest of the motor neurons get organized into lateral motor columns (LMC), sending axonal projections to the limb muscles ${ }^{1,53-56}$. The lateral motor columns further divide into medial and lateral subcolumns, assuming axonal projections towards the ventral and dorsal limb muscles, respectively. Concomitant with distinct axonal projection patterns, motor columns express unique combinations of LIM homeodomain proteins. The MMC columns express Isl-1, Is|-2 and Lim-3. The Lim-3 expression is strictly excluded from the CT and LMC columns. The CT column, as well as the medial LMC column, are therefore expressing a combination of |s|-1 and |s|-2, whereas, the lateral LMC expresses Isl-2 and Lim1 1,53-56. Like Lim3, the MNR2 expression persists in postmitotic cells which reside in MMC columns, while missing from CT and LMC columns ${ }^{57}$. 
Fig.5 Motor neurons cluster into different motor columns along the antero-posterior axis. Each column expresses a unique combination of LIM homeodomain proteins (A: Anterior; $P$ : Posterior; CT: Column of Terni; MMC: Medial motor column; LMC: Lateral motor column (m: medial, l: lateral)).

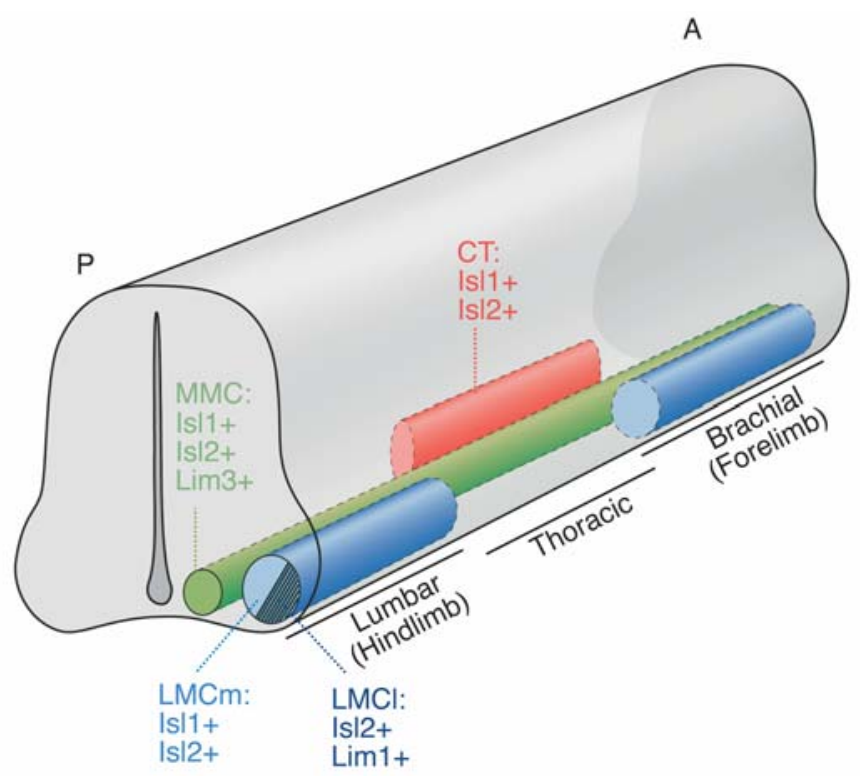

\section{Hox genes and motor neuron development}

Hox genes show a dynamic expression in different stages of motor neuron development along both the dorso-ventral and the antero-posterior axis of the neural tube ${ }^{60,61}$. Brachial LMC motor neurons of stage 29-31 chick embryos express a set of $11 \mathrm{Hox}$ genes, including HOXA3, A4, A5, A6, A7 and HOXB7, B8 as well as HOXC4, C5, C6 and C8. The lumbosacral LMC motor neurons however express a different subset of Hox genes, including the HOXA9, A10, A11, and HOXC10 and $\mathrm{C} 11$, as well as HOXD8, D9, D10 and HOXD11 ${ }^{61}$. The expression of single Hox genes also shows a large degree of dynamics at different embryonic stages with their expression level following a rostral to caudal gradient, concomitant with the temporal differentiation pattern of the motor neurons, in which more rostral cells are always more advanced in differentiation ${ }^{60}$.

Hox genes can assign columnar identities to motor neurons along the antero-posterior axis of the neural tube. According to studies in chick embryos, the restricted expression of HOXC6 to brachial and HOXC9 to thoracic motor neurons is in direct relationship to the columnar identities of motor neurons in corresponding axial levels, since misexpression of either of these genes in motor neurons of the other axial level, results in a shift in columnar identities from thoracic to brachial columns and vice versa ${ }^{62}$. Moreover, ectopic expression of lumbar HOXD10 at thoracic neural tube can cause a reciprocal switch of motor neuron identities ${ }^{63}$. Loss of lumbar Hoxc10 and Hoxd10 
genes on the other hand, results in severe hindlimb locomotor defects in mice which include the disruption of caudal-most lateral LMCs and the adoption of thoracic fates in motor neurons of rostral lumbar segments ${ }^{64}$. Moreover, mice lacking Hoxc8, show as increased apoptosis and deficient motor neuron development in the brachial neural tube 65 . Hox genes can however, also have negative effects on motor neuron development. Misexpression of HOXD10, for example, in the thoracic neural tube, results in a significant decrease in the number of postmitotic motor neurons ${ }^{63}$.

Motor neurons of a single columnar identity, further differentiate into motor pools which cluster together as group of cells and send axons to a specific muscle. Motor pools of different identities have differential Hox expression patterns, which is a determinant of their axon projecting properties ${ }^{61,66}$.

Taken together, Hox genes, define a further step of motor neuron maturation, after the original dorso-vetral patterning events.

\section{Aims and scopes of this study}

This study has tried to define a functional context for the regulatory role of microRNAs in the Hox gene-related temporal and spatial patterning.

The study starts with expression analysis of the prospective genes, which is further narrowed to a certain stage, in which a mutually exclusive expression domain along the antero-posterior axis is retained. HOXB8 is further validated as a true miR-196 target, following gain and loss of function studies. The role of miR-196 and HOXB8 is further focused on lumbar motor neuron development, leading to the conclusion that the miR196 functions in HOXB8-dependant maturation of lumbar motor neurons. 


\section{RESULTS}

\section{HOXB8 and miR-196 are expressed in a mutually exclusive pattern along the antero-posterior axis}

During chick embryonic development, HOXB8 shows a highly dynamic expression pattern. In early stages (before stage $\mathrm{HH} 14$ ), the expression has an anterior boundary at somites 6-7 in the neuroectoderm and somites 15-16 in the mesoderm, covering the whole length of the embryo till the most posterior regions (data not shown).

a)

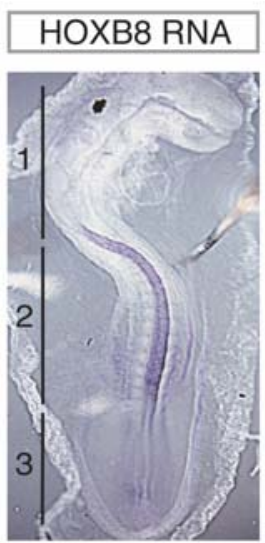

C)

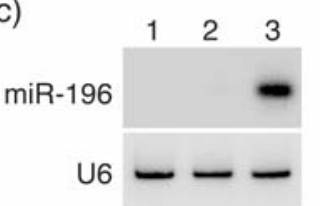

b)

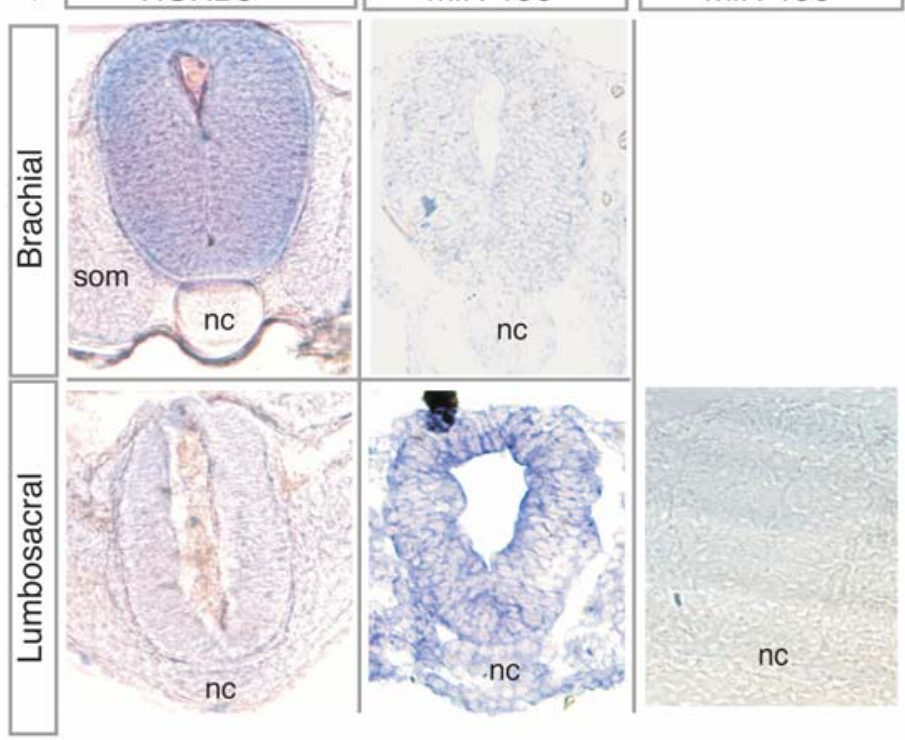

Fig.6 Expression patterns of HOXB8 and miR-196 along the antero-posterior axis of stage HH16 chick embryos; a) HOXB8 RNA in HH16 whole mount in situ hybridization. b) Sections of HOXB8 whole mount in situ hybridization, showing the HOXB8 transcripts in the brachial versus the lumbar neural tube. The miR196 expression follows a complementary pattern. miR-196 mutant LNA probe (miR-196*) results in no signal in HH16 lumbar neural tube. c) Expression of miR-196 in total RNA extracted from 3 different axial levels of $\mathrm{HH} 16$ chick embryos shown in (a). (nc: notochord, som: somite)

At stage $\mathrm{HH} 15$ and $\mathrm{HH} 16$, the HOXB8 expression keeps the early anterior boundary at somites 6-7, but is diminished from the regions posterior to somites 22-23 (Fig.6-a). In later stages (after stage $\mathrm{HH}_{22}$ ), most of the mesodermal expression is abolished and 
the HOXB8 transcript and protein are both detected in the neural tube, encompassing the fore and hindlimb levels (data not shown).

In sections through whole mount in situ hybridizations with HOXB8 probes on $\mathrm{HH} 16$ embryos, the HOXB8 signal was homogenously distributed along the dorso-ventral axis of the brachial neural tube, whereas the expression was completely abolished from the lumbar level (Fig.6-b). In situ hybridization of HH16 cryosections, with miR-196 antisense LNA probe, showed a complementary expression to HOXB8 being present in the lumbar neural tube and absent from the brachial (Fig.6-b). An LNA probe with 3 mutations in the center of the original miR-196 probe (miR-196*- see methods) did not result in any significant signal in the $\mathrm{HH} 16$ lumbar neural tube (Fig.6-b). Further analysis of miR-196 expression in total RNA of 3 different axial levels of HH16 chick embryos, confirmed the exclusive expression of miR-196 in embryonic levels caudal to somites 22-23 (Fig.6-C). Based on these observations, at HH16, the miR-196 is expressed in an axial level, where the HOXB8 expression is abolished.

In order to further confirm the lumbar level neural tube as the expression domain of miR-196, a GFP-sensor reporter was designed in which a GFP cassette is followed by a double concatamer of perfect miR-196 complementary sites (see methods and Fig.7$a, b)$. The presence of microRNA complementary sites in a sensor reporter causes the microRNA-mediated degradation of the reporter transcripts when the sensor is exposed to the microRNA. To test the miR-196 responsive GFP sensor, primary culture of chick embryonic fibroblasts was used (see methods) which express a basal level of miR-196 (Fig.7-a). After 48 hours co-transfection of GFP/GFP-sensor together with dsRED as a transfection control into CEF cells, the GFP signal from the GFP-sensor was to a large extend abolished, whereas most of the cells in the GFP control transfection were expressing GFP together with dsRED (Fig.7-b). The suppression of the GFP-sensor signal was further confirmed by western blot analysis, using the total protein of GFP/GFP-sensor- transfected CEF cells which showed the loss of GFP signal in cells transfected with GFP-sensor whereas the co-transfected dsRED was expressed at a comparable level (Fig.7-c). 
a)

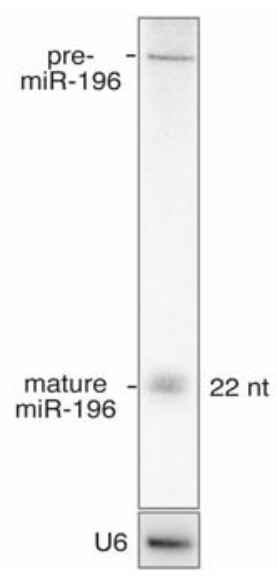

b) GFP-sensor

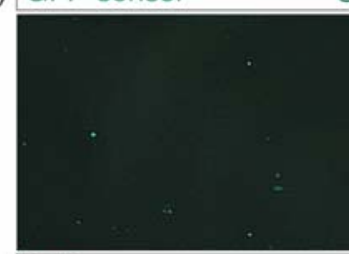

GFP

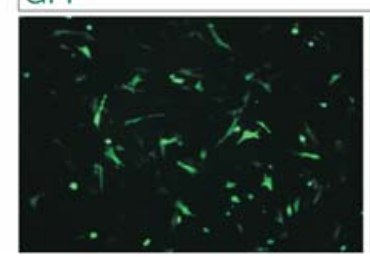

GFP-sensor dsRED merge

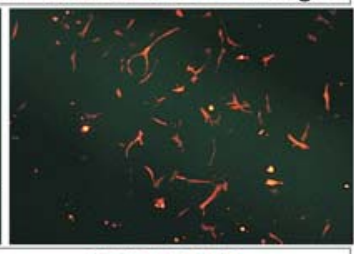

GFP dsRED merge

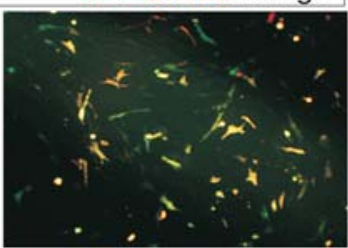

c)

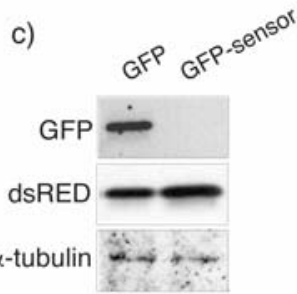

Fig.7 Test of miR-196 reporter sensor in CEF cells; a) Endogenous expression of miR-196 in CEFs. b) Cotransfection of GFP/GFP-sensor with dsRED into CEFs (for vector structures refer to Fig.8-a). c) Western blot analysis of the GFP protein from GFP/GFP-sensor - transfected CEFs. dsRED was co-transfected as a control.

The same GFP-sensor reporter system was used for mapping the expression domains of miR-196 in chick neural tube. The plasmids (Fig.8-a) were co-electroporated into the $\mathrm{HH} 16$ chick neural tube (for electroporation details see methods). The GFP vector was co-expressed with the tracer dsRED, wherever the neural tube was electroporated (Fig.8-C). The GFP-sensor also showed a co-expression with the dsRED tracer, except for the domains in which its expression was diminished in response to endogenous miR196. The red but not green domains in GFP-sensor electroporated neural tube were therefore defined as regions of miR-196 expression. These experiments demonstrate indirectly that miR-196 is present in the lumbar neural tube, confirming the posterior expression domain shown by in situ hybridization and total RNA analysis.

Taken together, these data suggest that the miR-196 and HOXB8 are expressed in a mutually exclusive expression pattern along the antero-posterior axis of stage $\mathrm{HH} 16$ chick embryos. 
a) Structure of the vectors
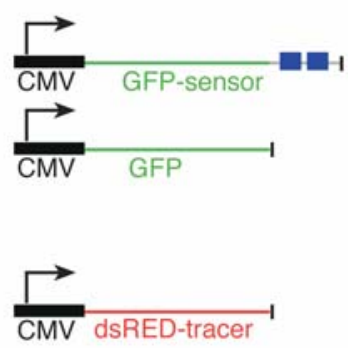

b) Principle of sensor-reporters

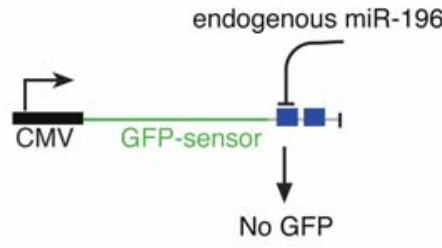

c)

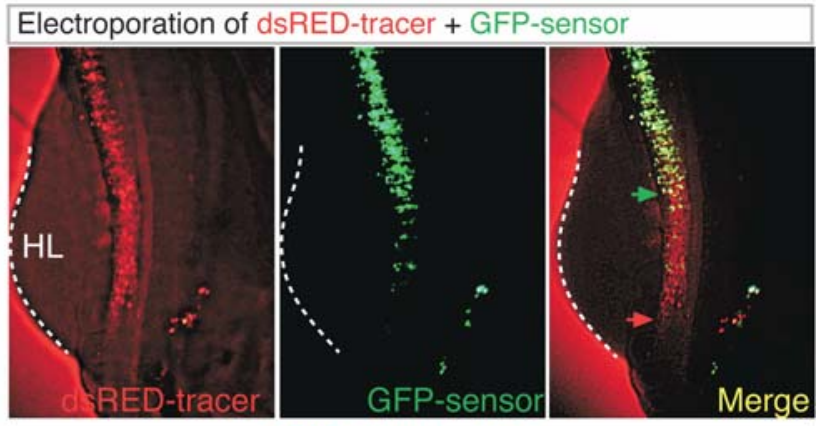

Electroporation of dsRED-tracer + GFP

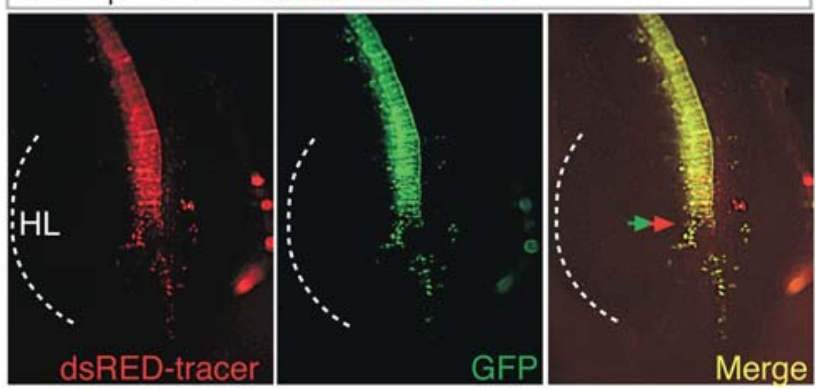

Fig.8 miR-196 expression domain shown by sensor reporter analysis; a) Structure of the vectors electroporated into $\mathrm{HH} 16$ chick neural tube (The blue box indicates the perfect complementary sequence to miR-196). b) The functional principle of sensor reporters. c) Co-localization of GFP and dsRED in electroporated regions of the neural tube. GFP-sensor signal is missing from the miR-196 expressing domains (HL: Hindlimb).

\section{miR-196 represses the HOXB8 translation by targeting its 3'UTR}

\section{miR-196 expression vectors}

The mutually exclusive expression domains of miR-196 and HOXB8 along the anteroposterior axis, suggests miR-196 as a putative regulator of HOXB8. In order to further check this hypothesis, there was a need to design expression vectors for the chick miR196. The expression vectors were based on a hairpin backbone, from which the mature miR-196 was processed as a 22 nucleotide small RNA. Two alternative approaches were taken to design the hairpin backbone. For the dsRED-miR-196 vector, an approximately 500 base pairs of the chicken genomic DNA flanking the miR-196 sequence was used as the hairpin sequence. For the dsRED-miR-196-30 vector however, the miR-30 backbone was used, with miR-196 substituting the original mature 
miR-30 sequence. In both of the cases, the hairpin was inserted into a bicistronic vector coding for dsRED and the microRNA (Fig.9-a / see methods).

Transfection of both vectors into HEK-293T cells, and the analysis of the total RNA, showed a higher expression of the mature miR-196 from dsRED-miR-196 (Fig.9-b). In a more functional approach, the miR-196 expression vectors were co-transfected into HEK-293T cells together with a luciferase reporter with a double concatamer of complementary sites to the miR-196 (see methods). DsRED-miR-196 resulted in a higher repression of the luciferase activity in comparison to dsRED-miR-196-30 and the vector alone (Fig.9-c). Putting these data together, the dsRED-miR-196 vector was chosen for the expression of miR-196. To further check if the expression vector resulted in ectopic miR-196 expression in chick neural tube, dsRED-miR-196 was electroporated into $\mathrm{HH} 16$ chick neural tube and after 48 hours, the neural tube was dissected into left (electroporated) and right pieces and the total RNA was analyzed. The electroporation of dsRED-miR-196 into chick neural tube resulted in the production of miR-196 in the left (electroporated) side of the neural tube, in comparison to the right side, which just showed a basal endogenous expression (Fig.9-d).

a)

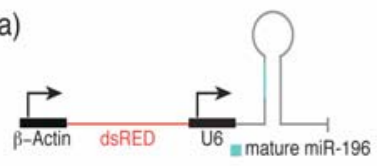

b)

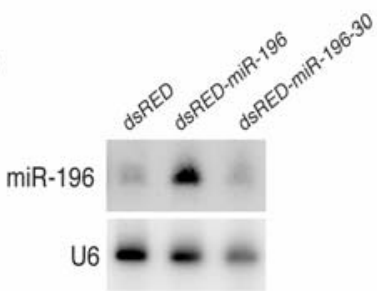

c)

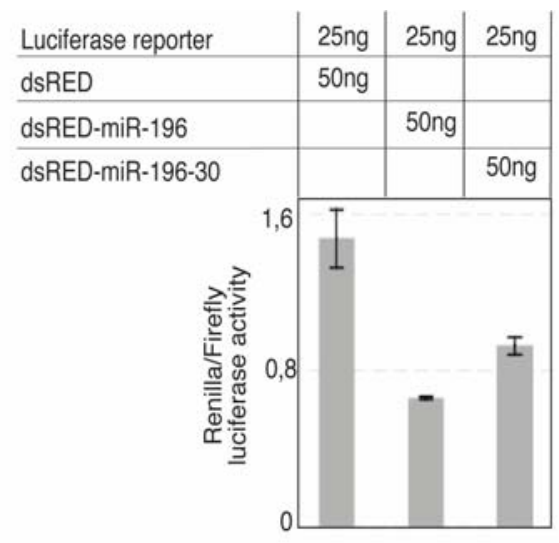

d)

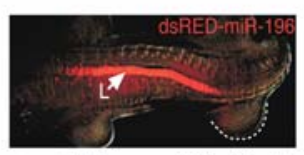

neural tube : left / right

miR-196

U6

Fig.9 miR-196 expression vectors; a) Structure of the vector backbone used for the generation of miR-196 expression vectors b) Higher production of mature miR-196 from dsRED-miR-196 in HEK-293T cells. c) Repression of the reporter luciferase activity upon co-transfection with the two miR-196 expression vectors into HEK-293T cells. d) Production of the mature miR-196 upon electroporation of dsRED-miR-196 into chick neural tube. The overexpressed miR-196 is detected in the electroporated (left) side of the $\mathrm{HH} 22$ neural tube, whereas the right side shows a basal endogenous expression. (L: left) 


\section{MiR-196 suppresses the endogenous HOXB8 protein}

In order to see if miR-196 can repress the endogenous HOXB8, dsRED-miR-196 was electroporated into $\mathrm{HH} 16$ chick neural tube and the HOXB8 protein was analyzed after 48 hours with immunostaining on $\mathrm{HH} 22$ brachial neural tube. Ectopic expression of miR-196 in chick neural tube, resulted in a significant decrease of $40 \%$ in total HOXB8 positive cells ( $p$-value: 0,0014) (Fig.10-a,c ; for details of quantitation see methods). The electroporated cells showed little or no overlap with the HOXB8 signal in dsRED-miR196 electroporated embryos, compared to control embryos electroporated with dsRED empty vector (Fig.10-b). To further confirm that miR-196 represses the endogenous HOXB8, the primary culture of chick embryonic fibroblasts was used that express HOXB8 at a basal level. Transfection of dsRED-miR-196 into CEF cells resulted in a significant decrease in the HOXB8 protein levels, compared to the level expressed in dsRED-transfected CEFs (Fig.10-d).

a)

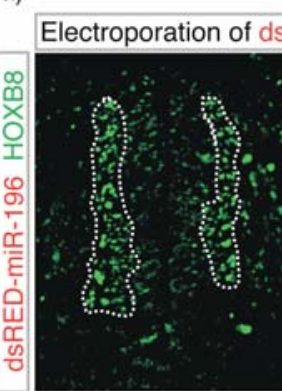

Electroporation of dsRED

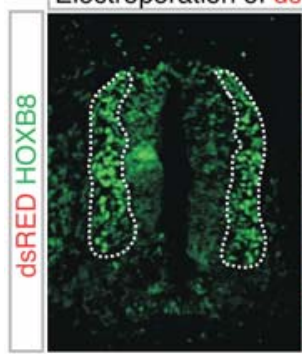

b)
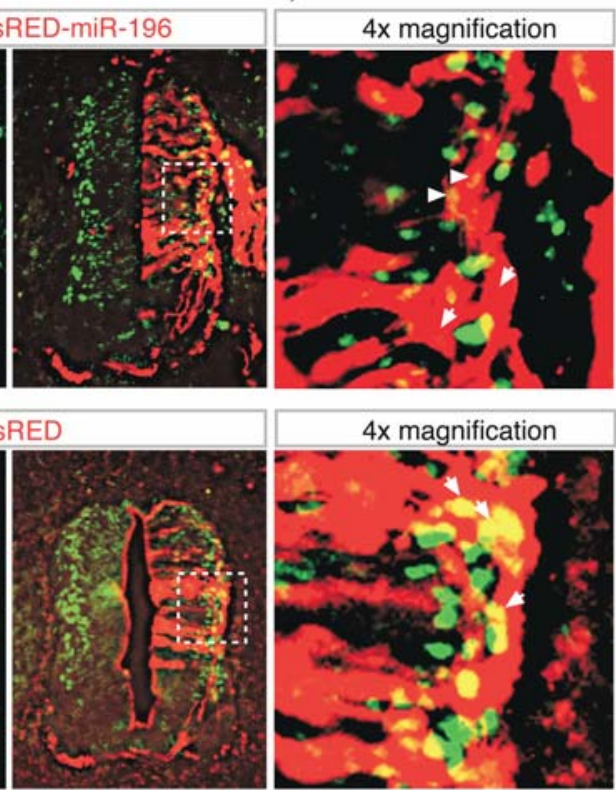

4x magnification

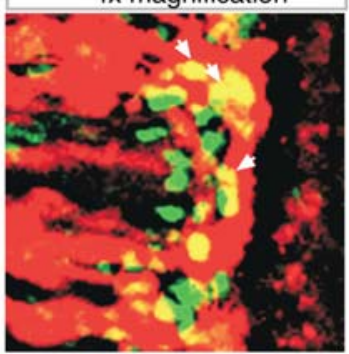

c) dsRED dsRED-miR-196

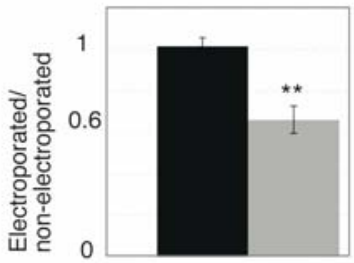

d) Transfection of dsRED/dsRED-miR-196 into CEF cells

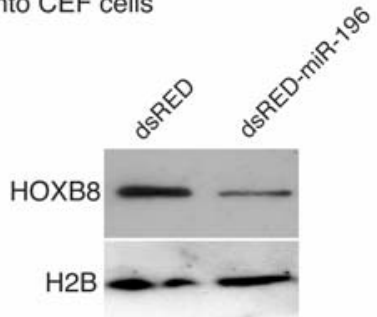

Fig.10 Effects of ectopic miR-196 on the endogenous HOXB8 protein ( $n=3 / 3$ ); a) Electroporation of dsREDmiR-196 into chick neural tube results in a decrease in HOXB8 positive cells compared to dsREDelectroporated embryos (compare the circled domains). b) DsRED-miR-196 - transfected cells show little or no overlap with the HOXB8 signal, compared to the control embryos. Arrows in dsRED-miR-196 electroporation point to red cells, which have received the miR-196 and are negative for HOXB8. Arrowheads point to miR-196 positive cells, which have a faint HOXB8 staining (note the faint yellow). Arrows in dsRED electroporation show electroporated cells, co-expressing HOXB8 (note the yellow fluorescence). c) Quantitation of HOXB8 positive cells in dsRED-miR-196 - electroporated embryos, compared to control embryos electroporated with dsRED. d) The repressive effect of ectopic miR-196 on the endogenous HOXB8 protein in CEF cells. 
miR-196 inhibitor, relieves the HOXB8 repression in CEF cells

If miR-196 can downregulate the HOXB8 protein, the translational repression of HOXB8 should be partly rescued by miR-196 knockdown. In order to test this hypothesis, the primary chick embryonic fibroblasts with a basal expression level of miR-196 and HOXB8 were used. Transfection of 2'-O-methylated oligonucleotides antisense to miR196 (miR-196 inhibitor-see methods) into CEF cells, resulted in the knockdown of the endogenous miR-196, and concomitantly, an increase in the HOXB8 protein level (Fig.6). Quantiation of the western signal, normalized to the H2B signal, showed an approximate 1.7 fold increase in the endogenous HOXB8 protein level, upon transfection with miR-196 inhibitor, compared to the level of HOXB8 protein in cells transfected with the cognate negative control oligonucleotide (Fig.6). It is therefore confirmed that miR-196 can repress the HOXB8 protein and that this repressive effect is specific.

Fig.11 MiR-196 inhibitor relieves the HOXB8 repression; Inhibition of miR-196 results in a concomitant increase of HOXB8 protein in CEF cells. Quantitation of the HOXB8 protein intensity normalized to $\mathrm{H} 2 \mathrm{~B}$ showed a 1.7 fold increase in miR-196 inhibitor-transfected CEFs compared to the control.

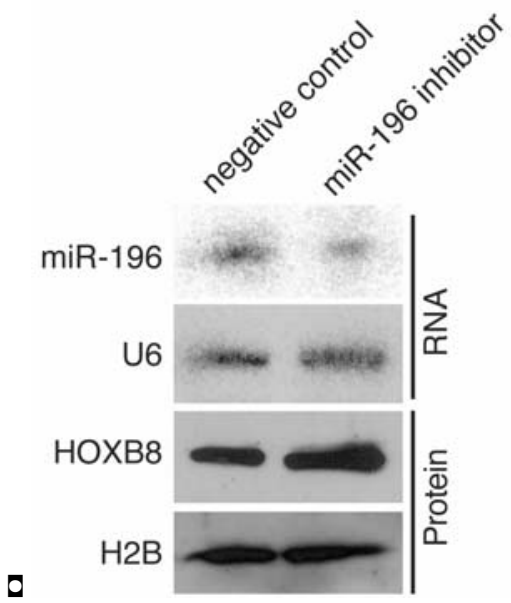

miR-196 targets the gga-HOXB8 3'-UTR

MicroRNAs usually result in the translational repression of target mRNAs upon targeting sequences in the 3' untranslated region (3'UTR)s. In order to test if miR-196 can also target the chick HOXB8 3'UTR, a GFP reporter was designed, having the native ggaHOXB8 3'UTR downstream of a GFP cassette (Fig.12-a). Co-transfection of GFP/GFP3'UTR together with dsRED into CEF cells which express a basal level of miR-196, 
resulted in a significant suppression of the GFP protein in GFP-3'UTR- transfected CEFs, compared to GFP-transfected control cells. The co-transfected dsRED vector was however, expressed at a comparable level in both of the cases (Fig.12- b). These data suggest that the repressive effect of miR-196 on the HOXB8 translation is mediated via an interaction with the 3'UTR of the gga-HOXB8 mRNA.

a) Vector structures

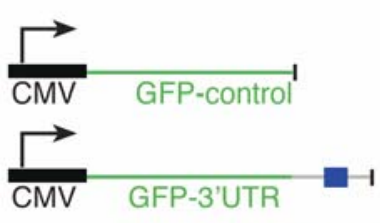

gga-HOXB8-3'UTR b) Co-transfection of dsRED + GFP/GFP-3'UTR into CEF cells

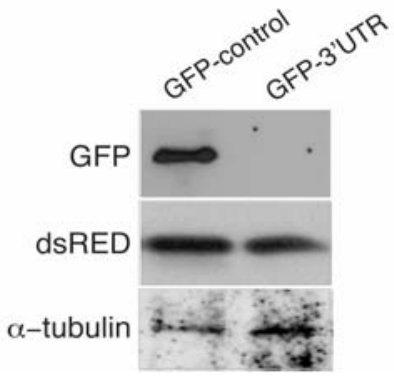

Fig.12 miR-196 targets the gga-HOXB8 3'UTR; a) Structure of the GFP-3'UTR vector in which the original HOXB8 3'UTR is cloned downstream of a GFP cassette (The blue box indicates the miR196-bound motif) b) Decrease of the GFP signal in GFP-3'UTR -transfected CEFs compared to GFP-transfected control. The co-transfected dsRED is expressed at a comparable level.

The interplay of HOXB8 and miR-196 is shortly before motor neuron generation in the lumbar neural tube

In order to further define the biological context of the miR-196 -mediated HOXB8 regulation, the pattern of motor neuron generation in $\mathrm{HH} 16$ chick neural tube was studied. In $\mathrm{HH} 16$ brachial neural tube, motor neuron precursors, defined by the expression of Olig-2 were already formed, covering the whole medio-lateral width of the tube (Fig.13-a). Olig-2, was however still absent from the HH16 lumbar neural tube (Fig.8-a). At lumbar levels, the expression of Olig-2 started at $\mathrm{HH} 18$, with the same pattern as the expression in $\mathrm{HH} 16$ brachial neural tube (Fig.13-b). 


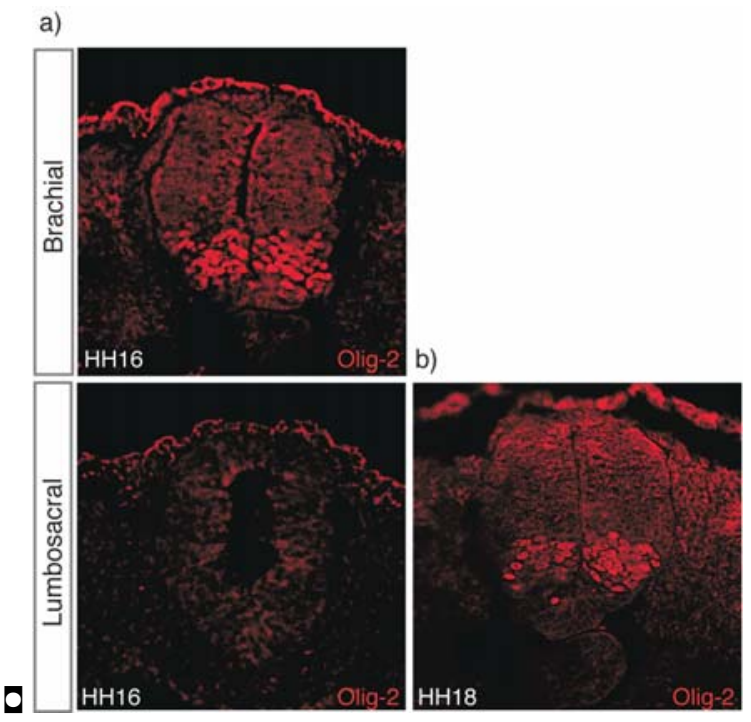

Fig.13 Generation of motor neuron precursors in the chick neural tube; a) At HH16 Olig-2-positive motor neurons precursors are formed already in the brachial neural tube, whereas, they are still absent from the lumbar level. b) The Olig-2-positive precursor motor neurons appear in lumbar neural tube, only around 10 hours later at $\mathrm{HH} 18$

The observation that miR-196-mediated absence of HOXB8 from the HH16 lumbar neural tube occurs shortly before motor neuron generation, lead to the hypothesis that HOXB8-free conditions is necessary for the correct generation of motor neurons. Following this idea, a series of experiments was designed including HOXB8 misexpression and miR-196 knockdown, as well as, overexpression and misexpression of miR-196 in the lumbar and brachial neural tube, respectively. Misexpression of hoxb8 in the lumbar neural tube results in delayed motor
neuron development

\section{gga-HOXB8 expression vector}

For ectopic expression of HOXB8, an expression vector based on the PCAGGS backbone was constructed (see methods). Transfection of the HOXB8 expression vector into HEK-293T cells, and the analysis of the total protein from the un-transfected and HOXB8-transfected cells, resulted in the detection of a single band around 45KD which is the predicted size of the chick HOXB8 protein and corresponds to the endogenous HOXB8 protein detected in the $\mathrm{HH} 22$ chick embryonic total protein (Fig.14). 
Fig.14 Tests of gga-HOXB8 expression vector; Transfection of the HOXB8 expression vector into HEK293T cells resulted in the ectopic expression of the 45KD gga-HOXB8 protein which matches in size to the endogenous HOXB8 detected in $\mathrm{HH} 22$ total protein extract. (UT: Untransfected, M: marker)

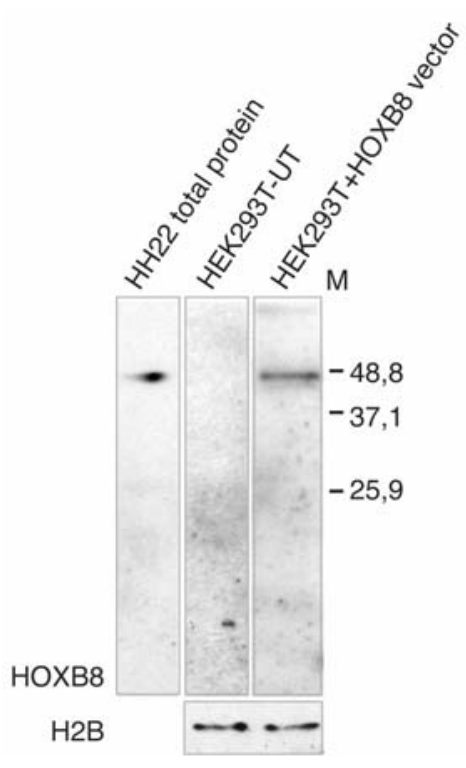

HOXB8 misexpression in the lumbar neural tube, results in an increase in motor neuron precursors at the expense of post-mitotic and differentiated motor neurons

In order to see the effect of misexpressed HOXB8 on the pattern of motor neuron generation, the HH16 lumbar neural tube was co-electroporated with a CMV-EGFP vector and the HOXB8 expression vector (Fig.14), and the motor neuron markers where checked after 48 hours. To circumvent effects resulting from over-loaded electroporated cells, the HOXB8 expression vector was electroporated at a limit of $700 \mathrm{ng}-1 \mu \mathrm{g} / \mu \mathrm{l}$ to meet the endogenous protein levels. The misexpression of HOXB8 in the lumbar neural tube, resulted in $80 \%$ increase of Olig-2-positive precursor motor neurons ( $p$ value $=0,0088)($ Fig.15-a,c). Concomitantly, a $40 \%$ ( $p$-value $=0,0014)$ decrease of Is $\mid 1 / 2$ positive postmitotic motor neurons and, a 40\%(p-value $=0,0054)$ and $60 \%(p-$ value $=0,0054)$ decrease of IsI-2 and Lim1 positive differentiated motor neurons was observed (Fig.15-a,c). 
a)
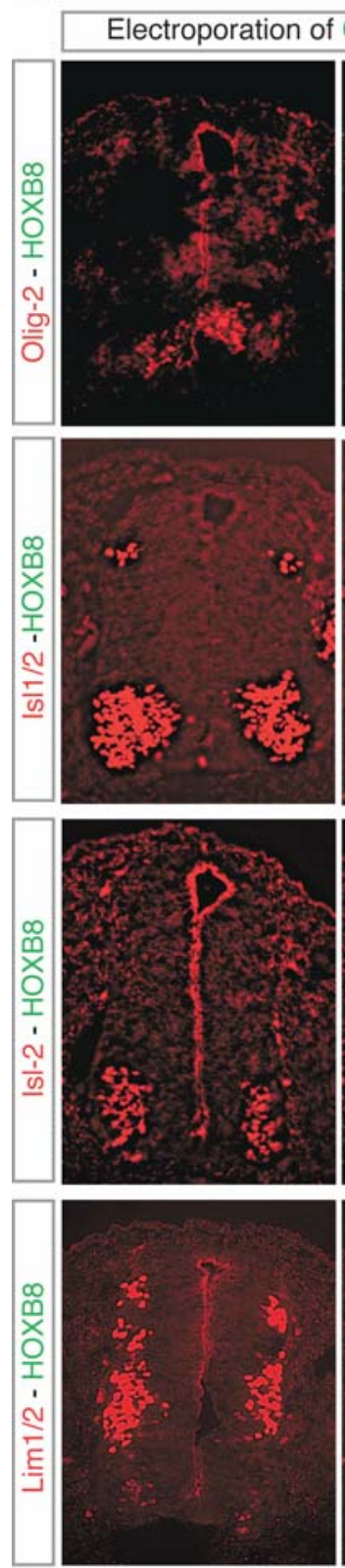

b)
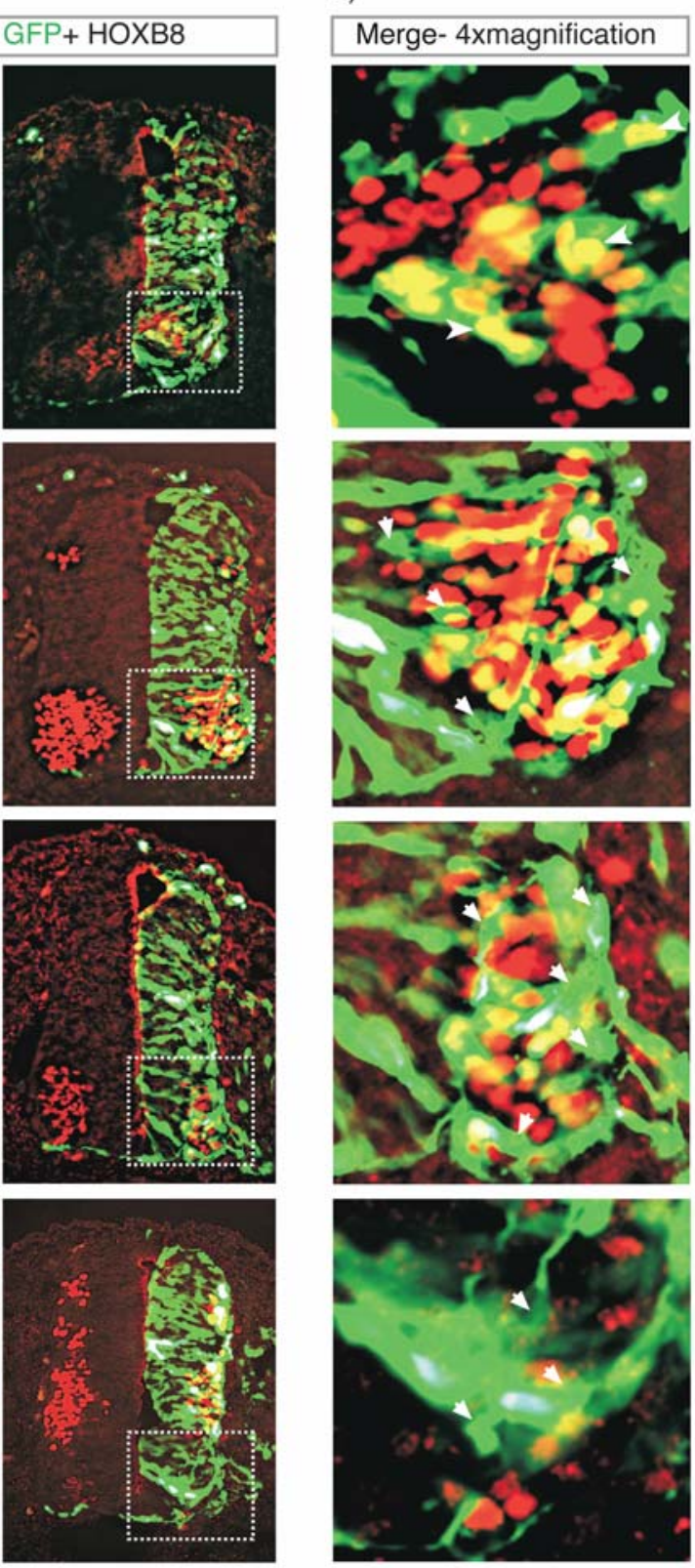
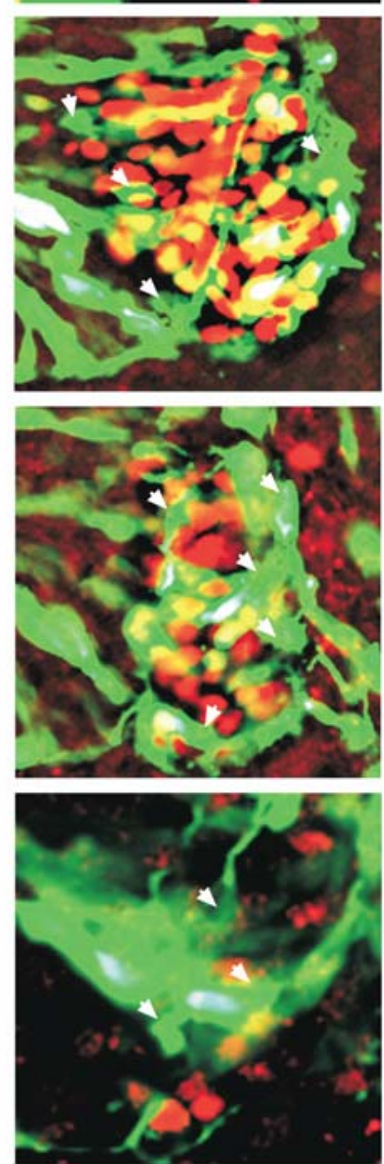

c)
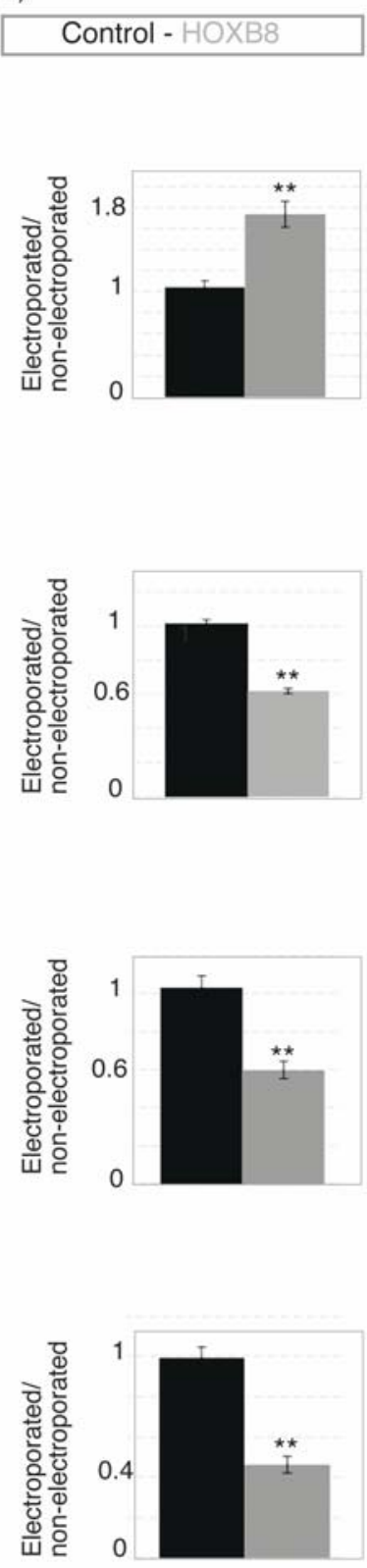

Fig.15 HOXB8 misexpression delays the differentiation of lumbar motor neurons $(n=6 / 6) ; \quad$ a) HOXB8 misexpression results in an increase in the Olig-2 positive cells, and a concomitant decrease in Isl1/2, Isl-2 and Lim1 positive cells. b) Arrowheads show electroporated cells, which are co-expressiing Olig-2 (yellow). Arrows point to electroporated cells (green), which fail to express mature motor neuron markers. c) Quantitation of the total number of cells positive for each marker, compared to the control embryos electroporated with GFP (For quantitation details see methods). 
A number of HOXB8 misexpressing cells (green) were co-expressing the motor neuron precursor marker, Olig-2 (Fig.15-b). In the case of postmitotic (IsI1/2 positive) and differentiated (IsI-2 and Lim1 positive) motor neurons, there were a number of HOXB8 misexpressing cells (green) which were not co-stained for Isl1/2, Isl-2 and Lim1 (Fig.15b), suggesting that they were incapable of differentiating to mature motor neurons. There were, however, cells that despite receiving the HOXB8, expressed the mature motor neuron marker (yellow cells) indicating that they were able to mature. The number of motor neuron markers, did not show any significant change in control embryos electroporated with GFP.

These results suggest that the misexpression of HOXB8 in the stage $\mathrm{HH} 16$ lumbar neural tube, results in a delay in motor neuron maturation, by increasing the motor neuron precursors, in the expense of postmitotic and differentiated motor neurons.

The generation of axonal projections is impaired in HOXB8 misexpressing lumbar motor neurons

The lumbar LMC can be visualized by retrograde labeling of axonal projections through the application of dextran (red) to nerve endings in the hindlimb muscles. In order to check the structure of LMCs, embryos electroporated at stage $\mathrm{HH} 16$ with a GFP vector alone, or co-electroporated with the GFP and the HOXB8 vector, were sacrificed and Dextran-labeled on E5.

In control embryos the left (internal control) and the right (electroporated) LMCs reached similar levels at the border between the thoracic and the lumbar region. Practically all GFP expressing cells in the LMC could be retrogradely labeled, resulting in a yellow fluorescence (Fig.16-C). In embryos which were electroporated with the HOXB8 vector the left and the right (electroporated) LMCs reached either similar levels at the border between the thoracic and the lumbar region ( $n=6 / 9$; Fig.16-b), or were shifted posteriorly ( $n=3 / 9$; Fig.16-a). In these LMCs many cells which received HOXB8/GFP could not be labeled with Dextran, resulting in green fluorescence (Fig.16-a,b).

Together, these observations indicate that the ectopic presence of HOXB8 inhibits the maturation of precursors into lumbar motor neurons with axonal projections to the periphery. 
D

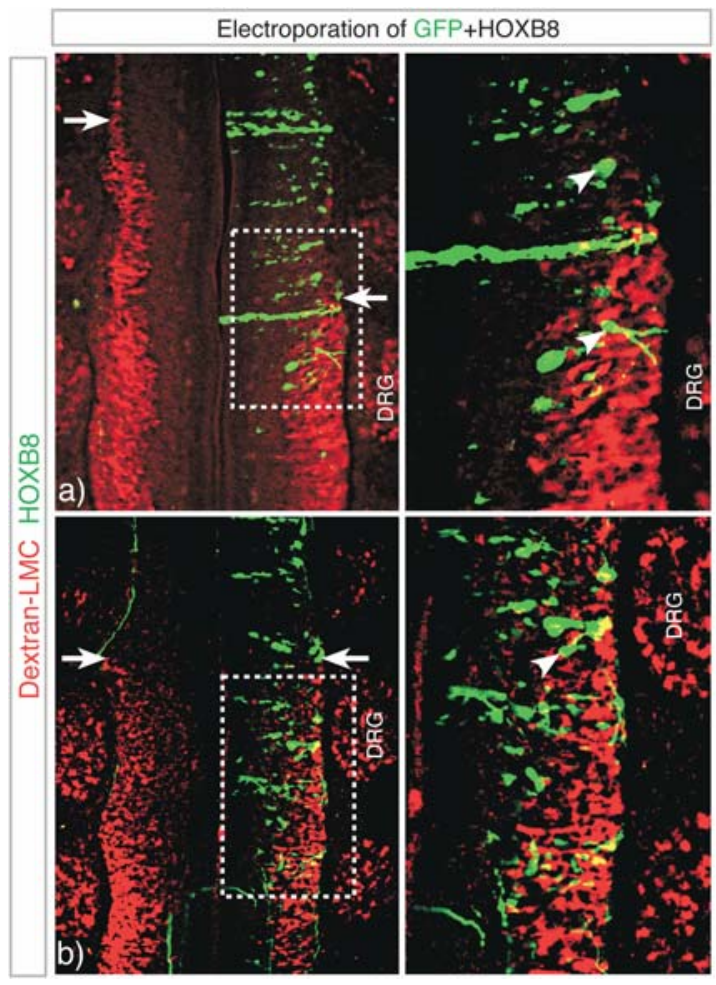

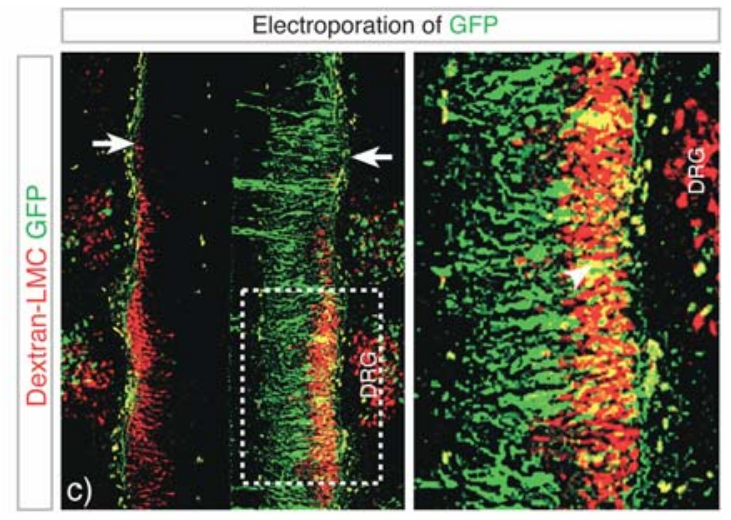

Fig.16 Axonal projections from lumbar LMCs Upon HOXB8/GFP electroporation; a) Posterior shift of the right LMC after HOXB8 misexpression (arrows). Arrowhead points to a HOXB8 expressing green cells, which could not be retrogradely labeled. Note the absence of double (yellow) fluorescence. b) No posterior shift of the right LMC after HOXB8 misexpression. Arrowhead points to a HOXB8 expressing, green cell, which could not be retrogradely labeled. Note the absence of double (yellow) fluorescence. c) Normal development of LMCs in control embryos. Note that most electroporated cells could be retrogradely labeled, and therefore appear yellow (arrowhead). (DRG: Dorsal root ganglion)

\section{Knockdown of miR-196 results in delayed motor neuron development similar to HOXB8 misexpression}

miR-196-depleted lumbar neural tube shows a delayed motor neuron differentiation pattern, with more precursor cells at the expense of post-mitotic motor neurons

In order to see if inhibition of miR-196 in the lumbar neural tube can partly mimic the effect of HOXB8 misexpression (Fig.15), the HH16 neural tube was electroporated with miR-196 inhibitor and CMV-EGFP and the differentiation pattern of motor neurons was analyzed after 48 hours. Like HOXB8 misexpression, inhibition of miR-196 in lumbar motor neurons, resulted in a significant $60 \%$ ( $p$-value $=0,0074)$ increase in the number of Olig-2 positive precursor motor neurons, with a concomitant $20 \%$ ( $p$-value $=0,001)$ decrease in the number of IsI1/2 positive postmitotic motor neurons (Fig.17- a,c). 
In most of the analyzed embryos ( $n=4 / 6)$, no significant change of differentiation markers was observed, whereas, in some cases $(n=2 / 6)$ (data not shown), a consequential decrease in the number of IsI-2 and Lim1 positive differentiated motor neurons was present. As a control, a cognate RNA oligo, based on a microRNA sequence from $C$. elegans with no homologue in vertebrates (see methods), was coelectroporated with CMV-EGFP into $\mathrm{HH} 16$ neural tube. No significant change in the motor neuron markers was observed in negative control embryos (data integrated into the quantitation plots, Fig.17-c). The cells receiving the miR-196 inhibitor, were coexpressing the motor neuron precursor marker, Olig-2 (Fig.17-b). Concomitantly, a number of miR-196 depleted cells (green), failed to co-express the mature motor neuron markers, Isl1/2, IsI-2 and Lim1 (Fig.17-b).

Taken together, like the HOXB8 misexpression, the depletion of miR-196 resulted in a delay in the lumbar motor neuron maturation by increasing the number of motor neuron precursors in the expense of postmitotic motor neurons. The effect was however, milder, and did not fully phenocopy the HOXB8 misexpression at the level of differentiated motor neurons. 
a)

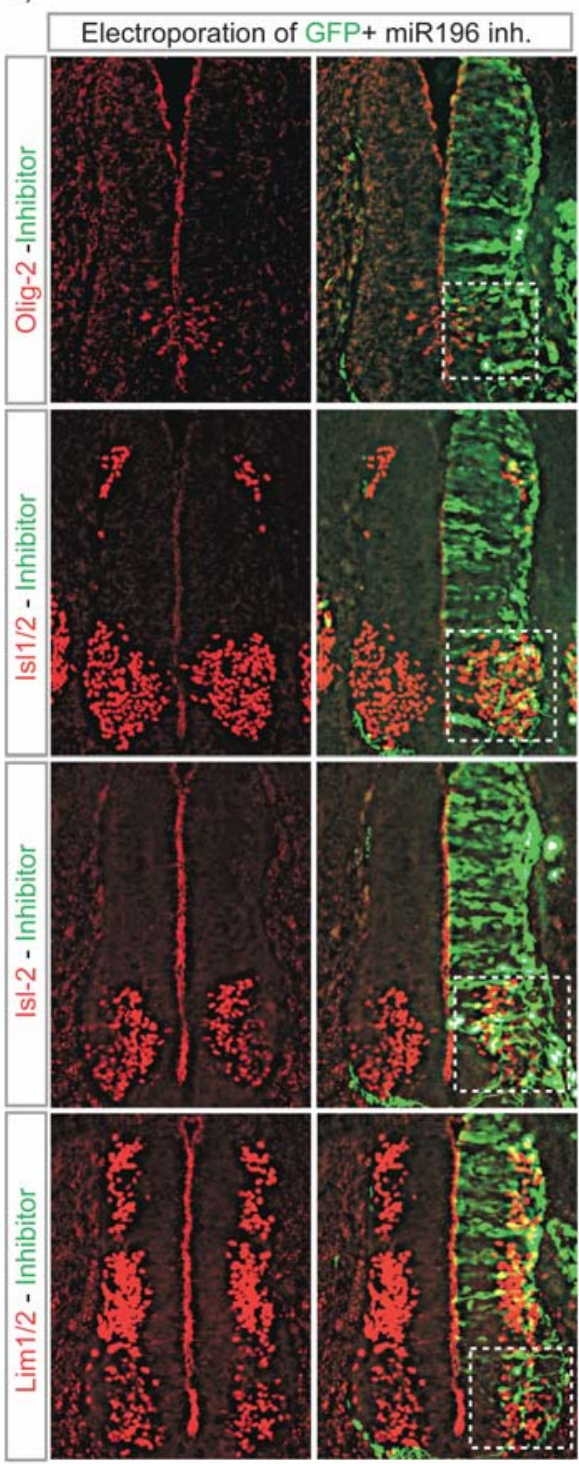

b)
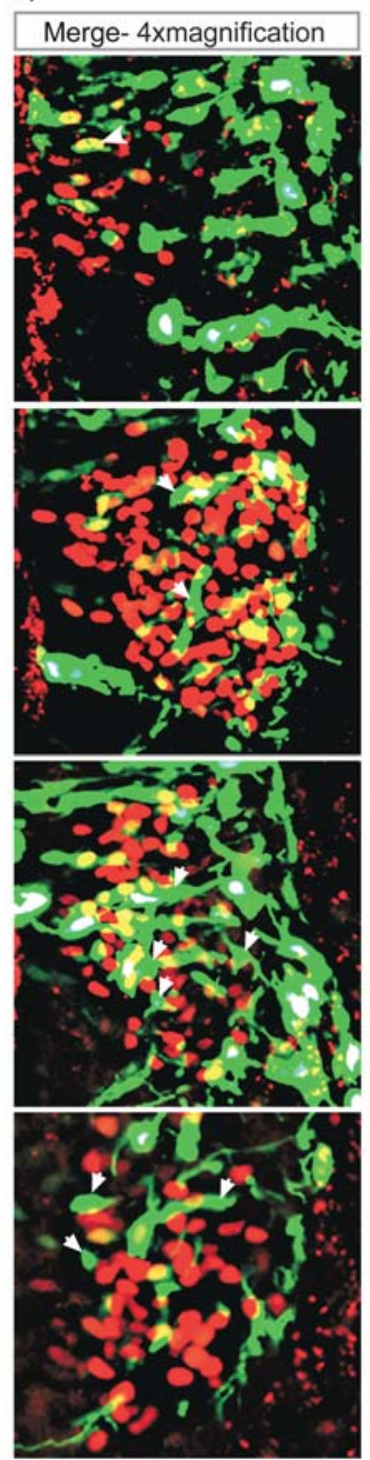

c) Control - Inhibitor
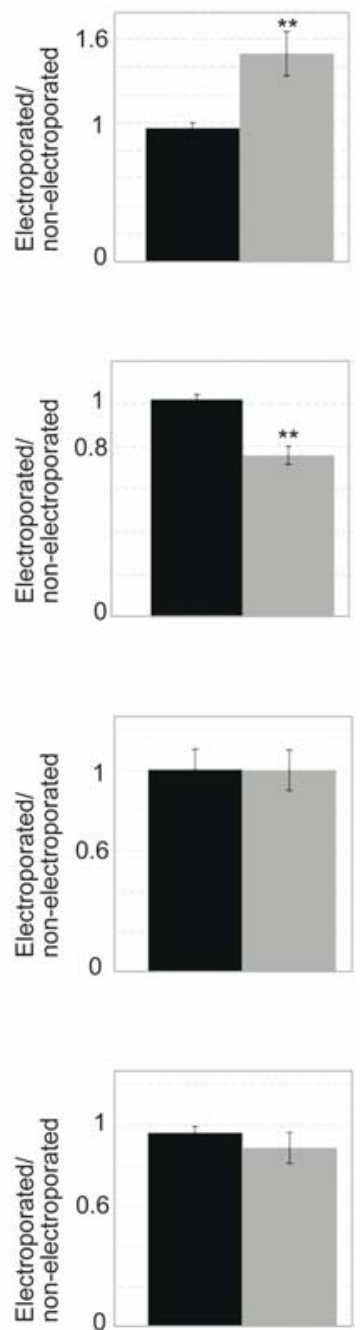

Fig.17 miR-196 depletion delays lumbar motor neuron maturation; a) miR-196 depletion resulted in an increase in Olig-2, and a concomitant decrease in IsI1/2 positive cells. In the majority of the cases, the number of IsI-2 and Lim1 positive cells remained unchanged. b) Arrowhead points to a yellow cell, which has received the miR-196 inhibitor and is co-expressing Olig-2. Arrows point to green cells that have received the miR-196 inhibitor, and fail to express postmitotic and mature motor neuron markers. c) Quantitation of the number of cells positive for each marker, compared to control embryos electroporated with the cognate oligo (The effect on Olig-2 and IsI1/2 expression was observed in all the analyzed embryos $(n=6 / 6)$. The Isl-2 and Lim1/2 markers however, showed a decrease in 2/6, and no change in 4/6 embryos analyzed). 
MiR-196-depleted lumbar LMC neurons show little defects in the development of axonal projections

In order to trace the delayed development of miR-196-depleted motor neurons, at the level of axonal projections, the lumbar LMC motor columns, electroporated with miR196 inhibitor and the control oligo, were labeled with Dextran (red). In both the control and miR-196 inhibitor electroporated embryos, the right (electroporated) and left (internal control) LMCs were at a similar level (Fig.18 a,b). The cells, which had received the miR-196 inhibitor (green) however, were not labeled with Dextran, suggesting that they were unable to generate axonal projections (Fig.18- a).

Fig.18 Axonal projections from lumbar LMCs upon miR-196 knockdown ( $n=5 / 5)$; a) MiR196 inhibition, does not shift the LMC levels (Arrows point to the anterior boundary of lumbar LMC). Arrowhead points to a green cell, which has received the miR-196 inhibitor and is not labeled with Dextran. b) Normal development of lumbar LMCs, in control embryos electroporated with the cognate oligo (DRG: Dorsal root ganglion).

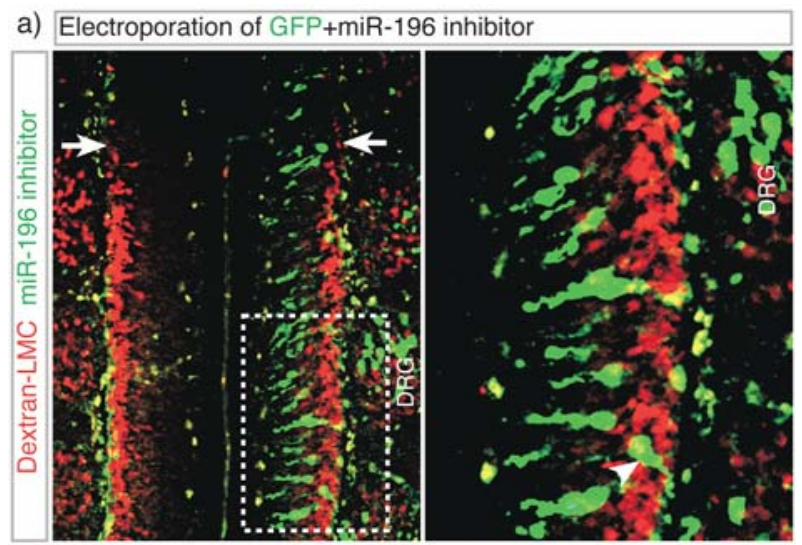

b) Electroporation of GFP+ negative control

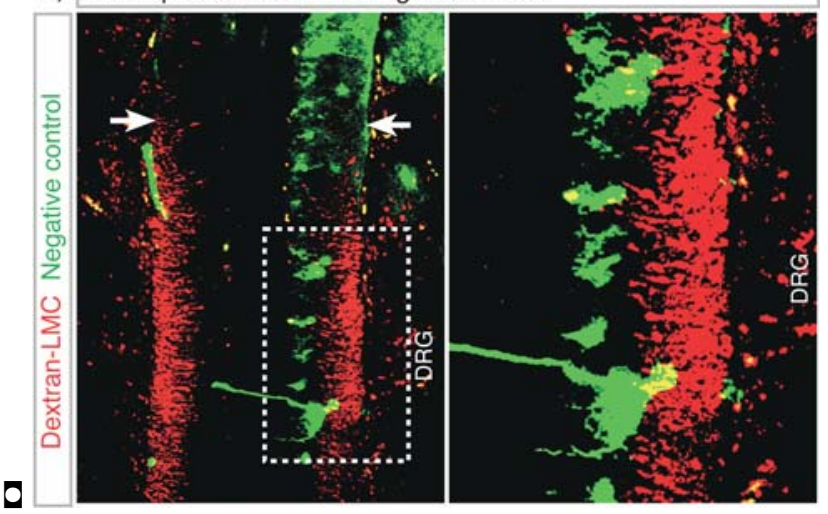




\section{Change of miR-196 expression dosage or domain, does not result in any defects in motor neuron development}

miR-196 overexpression in the lumbar neural tube, results in no significant change in motor neuron differentiation

In order to see if an increased amount of miR-196 would affect the development of lumbar motor neurons, the dsRED-miR-196 vector was electroporated into $\mathrm{HH} 16$ neural tube and the differentiation of the motor neurons was analyzed after 48 hours. The increased amount of miR-196 in lumbar neural tube did not have any significant effect on the differentiation of motor neurons as evidenced from the number of Olig-2, IsI1/2, Isl-2 and Lim1 positive cells, compared to control dsRED-electroporated embryos (Fig.19).

miR-196 misexpression in the brachial neural tube, results in no significant change in motor neuron differentiation

In order to see if a rostral shift in the expression domain of miR-196 could affect the development of motor neurons, the dsRED-miR-196 vector was electroporated into $\mathrm{HH} 16$ brachial neural tube, and the differentiation of motor neurons was analyzed after 48 hours. Misexpression of miR-196 in brachial motor neurons, did not have any significant effect on the number of Olig-2, Isl1/2, Isl-2 and Lim1 positive cells (Fig.20). In a similar approach, the misexpression of miR-196 in the thoracic neural tube resulted in no significant effect on motor neuron differentiation (data not shown). 
a)

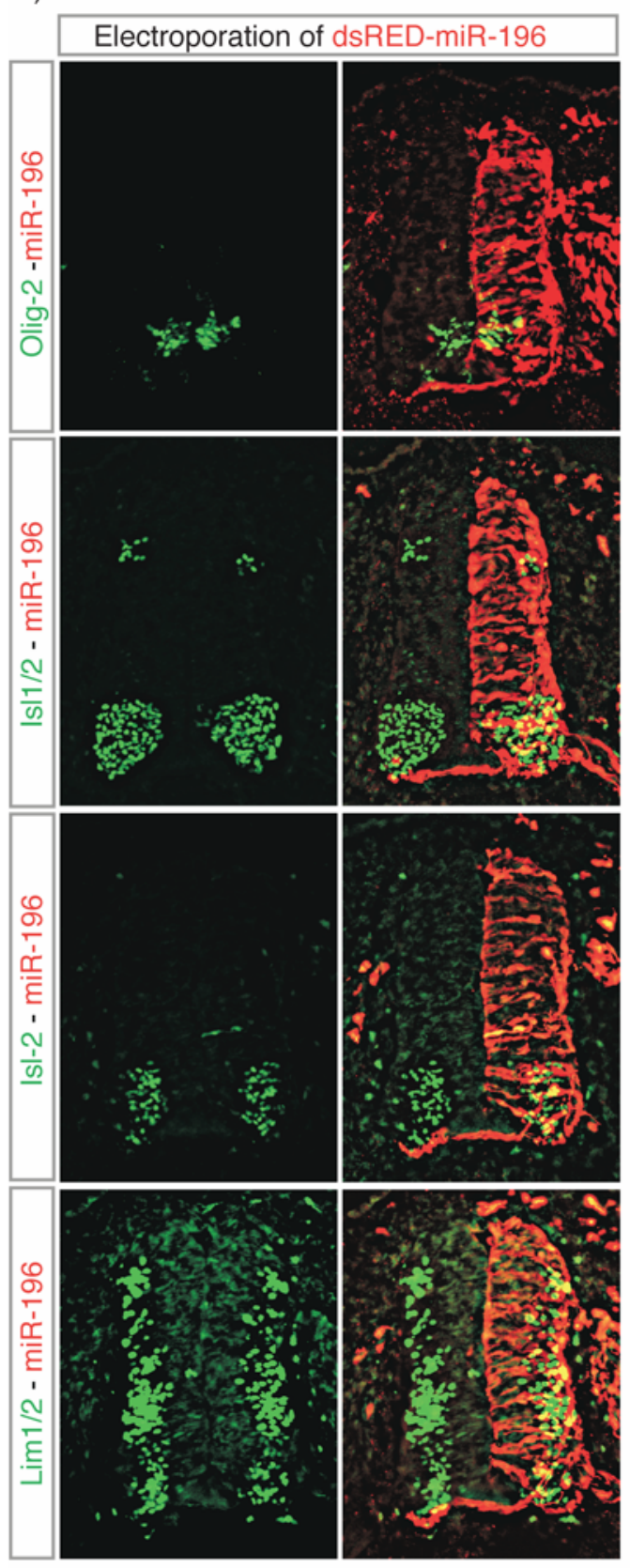

b)

Control - miR-196
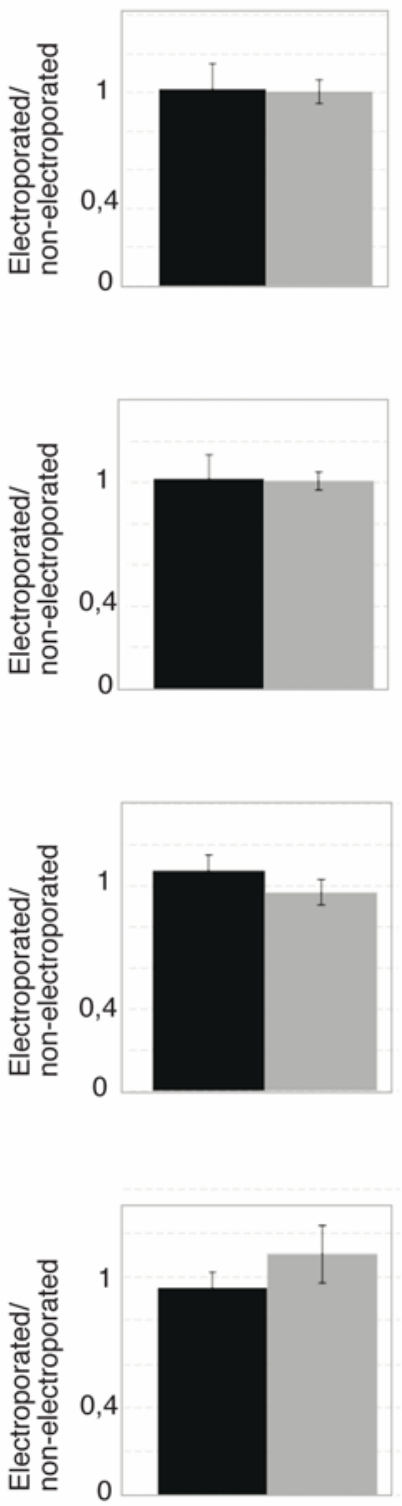

Fig.19 miR-196 overexpression in the lumbar neural tube ( $n=6 / 6)$; a) Increased level of miR-196 does not change the number of Olig-2, Is|1/2, Isl-2 and Lim1 positive cells. b) Quantitation of the cell numbers positive for each marker, compared to control embryos electroporated with dsRED. 
a)

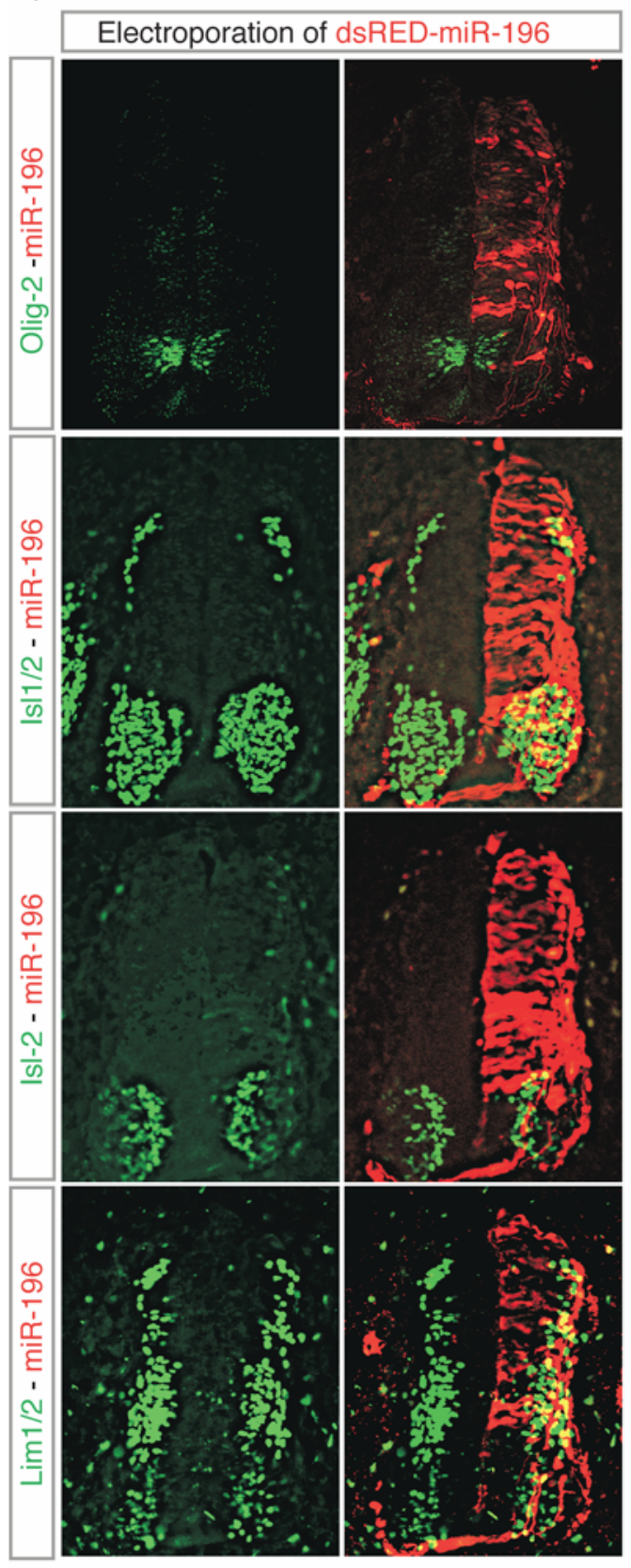

b)

Control - miR-196
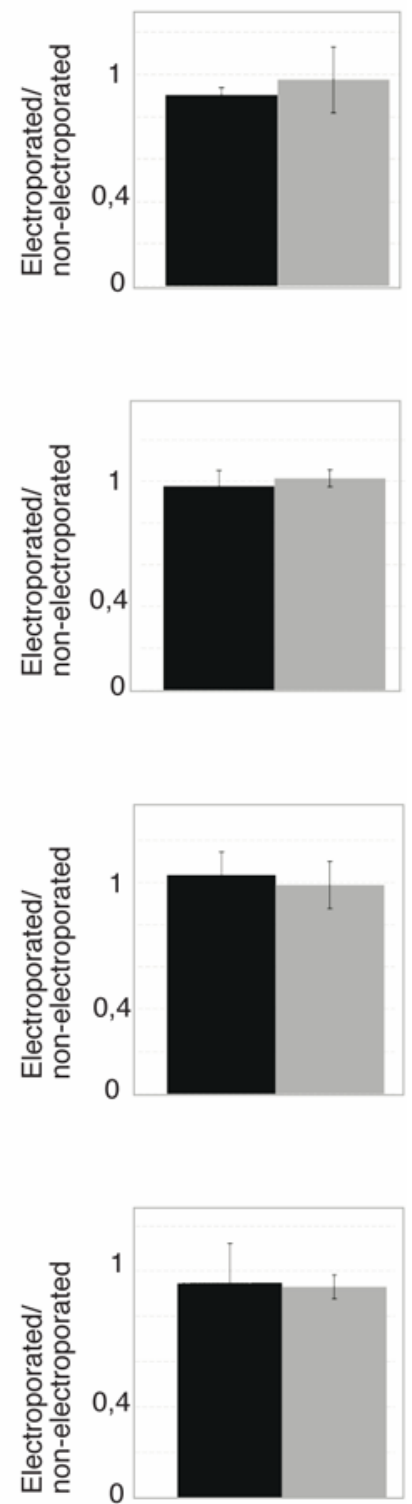

Fig.20 miR-196 misexpression in the brachial neural tube ( $n=6 / 6)$; a) Misexpression of miR-196 does not change the number of Olig-2, Is|1/2, Isl-2 and Lim1 positive cells. b) Quantitation of the cell numbers positive for each marker, compared to control embryos electroporated with dsRED. 
Ectopic miR-196 does neither affect the antero-posterior positioning of the lumbar $L M C s$, nor the ability of these cells in developing axonal projections

In order to see if an increased level of miR-196 expression and/or the anterior shift of its expression domain could alter the development of lumbar LMCs, the dsRED-miR-196 vector was electroporated into $\mathrm{HH} 16$ neural tube and lumbar LMCs were labeled with Dextran (green) on E5. In embryos electroporated with dsRED-miR-196, there was no shift in the right (electroporated) compared to the left (internal control) LMCs (Fig.21-a). The cells which received miR-196 (red) were also labeled with Dextran leading to a yellow fluorescence (Fig.21-b- Arrowhead).

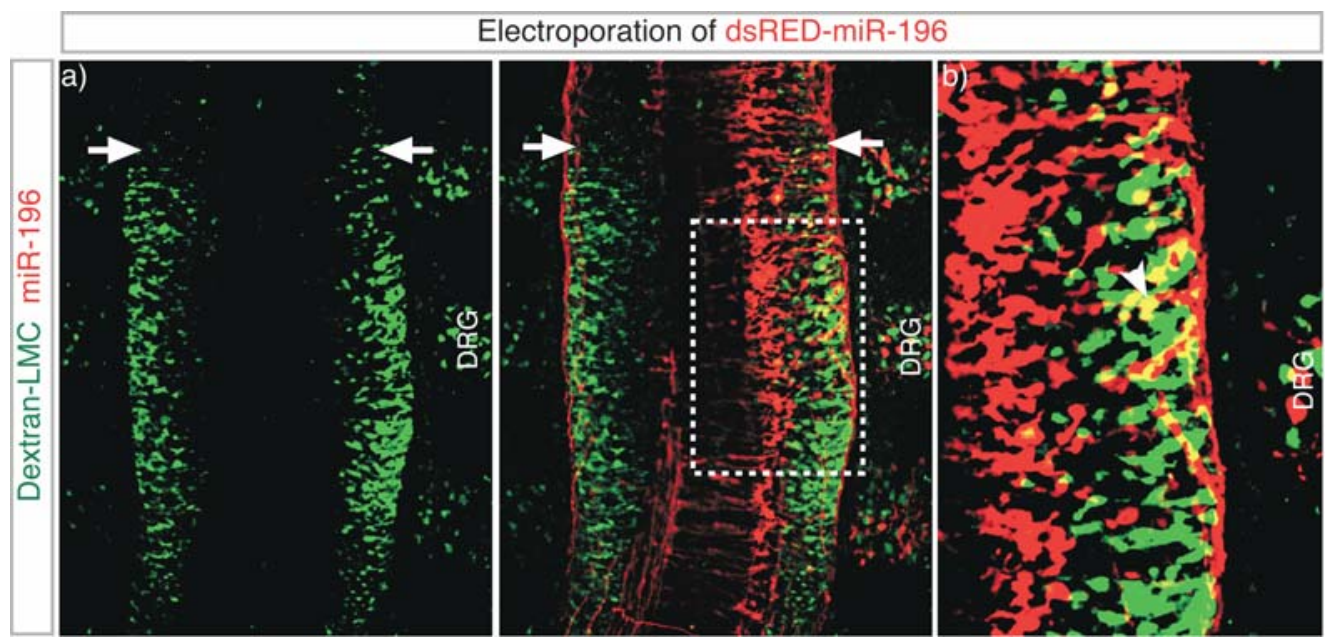

Fig.21 The antero-posterior patterning of the lumbar LMC upon expression of miR-196 $(n=6 / 6)$; a) The rostro-caudal position of the lumbar LMC, shows no change in the electroporated versus the contra-lateral side of the neural tube (arrows show the rostral boundary of the lumbar LMC). b) Most of the cells that have received miR-196 are labeled. Arrow points to a cell in which the dsRED and dextran signals co-localize- Note the yellow double flourescence (DRG: Dorsal root ganglion)

Taken together, the change in the amount of miR-196 or its expression domain, does not affect the motor neuron development and the ability of lumbar motor neurons in generating axonal projections. 
The developmental delay in HOXB8 misexpressing motor neurons does not result from altered progenitor domains

In order to see if the effect of HOXB8 in delaying lumbar motor neuron development, results from an alteration in the early progenitor domains, HOXB8 and GFP vectors were co-electroporated into $\mathrm{HH} 16$ neural tube, and the formation of lumbar progenitor domains was analyzed after 48 hours.

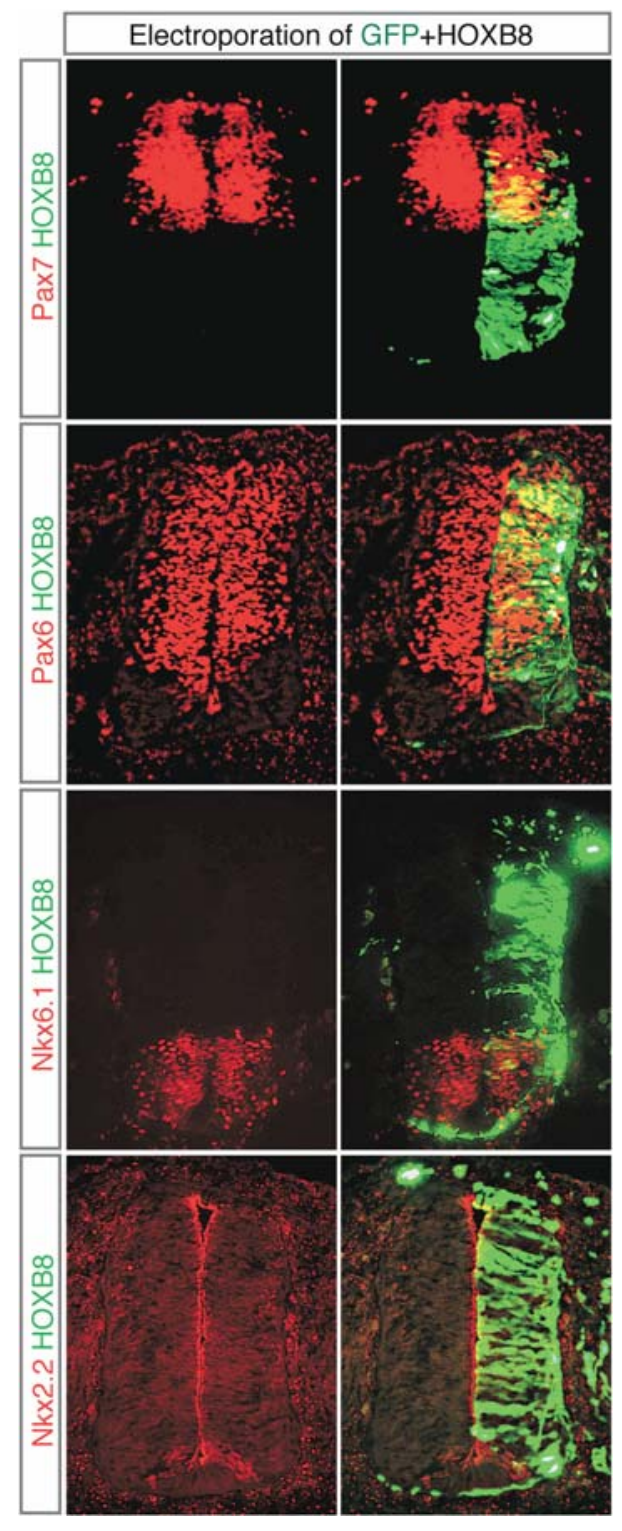

Fig.22 The formation of lumbar motor neuron progenitor domains upon HOXB8 misexpression; HOXB8 misexpression does not change the expression of homeobox transcription factors which pattern the progenitor domains along the dorsoventral neural tube. The expression pattern of the homeobox transcription factors that establish the motor neuron progenitor domain (Nkx6.1 and Pax6), is as well not altered upon HOXB8 misexpression. 
HOXB8 misexpression in the lumbar neural tube did not alter the dorso-ventral expression domains of the P3-specific Nkx2.2, and the dorsal interneuron marker Pax7 (Fig.22). The dorso-ventral expression boundaries of Nkx6.1 and Pax6 also remained intact, suggesting that the repressive effect of HOXB8 does not result from an altered motor neuron progenitor domain. It is therefore more probable that HOXB8 affects the differentiation of lumbar motor neurons, at a stage later than the establishment of motor neuron progenitor domain. In accordance with these observations, the analysis of few HOXB8-electroporated embryos ( $n=2 / 2$-data not shown) at $\mathrm{HH} 18,24$ after electroporation, showed no significant change in the number of Olig-2 positive cells, indicating that the correctly generated Olig-2 expressing cells, later on fail to mature normally.

The developmental delay in HOXB8 misexpressing motor neurons results from a failure in expressing pan motor neuron factors and a defect in the cell cycle exit

HOXB8 misexpression negatively affects the expression of the pan motor neuron factor MNR2

The MNR2 protein is expressed downstream of Olig-2, in the last cell cycle of the motor neuron precursors, as well as the transition to the postmitotic stage. In order to see if the negative effect of HOXB8 expression on the development of postmitotic motor neurons is partly due to a change in MNR2 expression, the expression of MNR2 was analyzed in HOXB8-electroporated lumbar neural tubes. Misexpression of HOXB8 in lumbar neural tube, resulted in an approximate $40 \%(p$-value $=0,015)$ decrease in the number of MNR2 positive cells, compared to control embryos electroporated with GFP (Fig.23-a,c). A number of cells which had received the ectopic HOXB8 (green), failed to co-express the MNR2 protein (Fig.23-b). There were however cells, which showed a yellow fluorescence, indicating that they were able to express MNR2, despite having HOXB8.

Shortly after MNR2 expression, the motor neuron progenitors start expressing a LIM homeodomain transcription factor, Lim3. After exiting the cell cycle however, the expression of Lim3 gets restricted to certain subpopulations of motor neurons, particularly the cells residing in the medial motor column (MMC). In order to see if the 
negative effect of HOXB8 misexpression on the number of MNR2 positive cells is exerted specifically in the period of MNR2 expression (last cell cycle and the transition to exit), or is rather a general effect on the hierarchy of motor neuron differentiation, the expression of Lim3 was analyzed in HOXB8-electroporated lumbar neural tube. The misexpression of HOXB8 resulted in no significant change in the total number of Lim3 expressing cells compared to control GFP-electroporated embryos (Fig.23-a,c).

Based on these findings, the misexpression of HOXB8 in the lumbar neural tube, results in a decrease in the committed motor neuron marker, MNR2.

a)

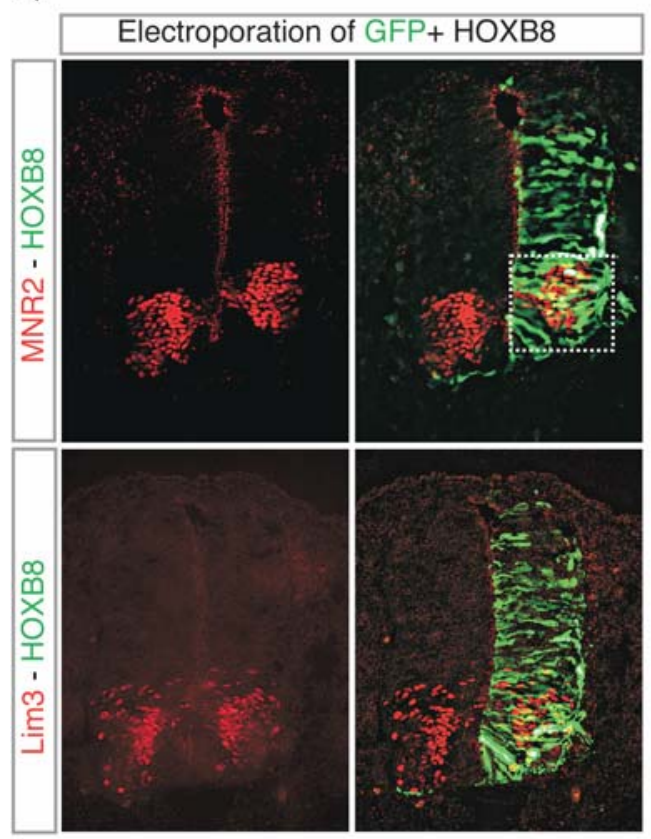

b)

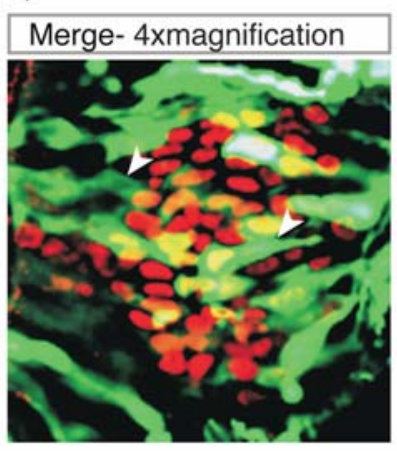

c)
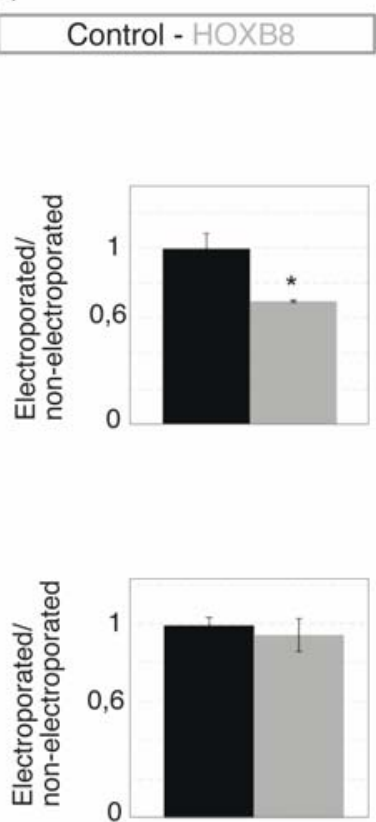

Fig. 23 Expression of MNR2 and Lim3 in HOXB8-electroporated lumbar neural tube ( $n=5 / 5)$; a) HOXB8 misexpression decreases the number of MNR2 positive cells, but does not affect the Lim3 positive cells b) Arrowhead points to a cell which has received the HOXB8 (green) and fails to express MNR2. c) Quantitaion of the number of MNR2 and Lim3 positive cells compared to control embryos electroporated with GFP. 
HOXB8 misexpression results in an increase in BrdU-positive cycling cells in the lumbar neural tube

In order to see if the HOXB8 misexpression affects the cell cycle exit of the motor neurons, the expression of phosphorylated histone $\mathrm{H} 3(\mathrm{H} 3 \mathrm{P})$ as a marker of cells in mitosis and the incorporation of BrdU as a marker of cycling cells was analyzed in HOXB8-electroporated lumbar neural tube. The H3P marker was detected in the ventricular zone of the neural tube, in both HOXB8-electroporated and control embryos, with no ectopic H3P positive cell in HOXB8 misexpressing motor columns (Fig.19). The number of $\mathrm{H} 3 \mathrm{P}$ positive cells did as well show no significant change between the HOXB8-electroporated and control embryos indicating that the general mitotic activity is not affected by HOXB8 misexpression.

In order to check the status of the cycling cells, the HH16 HOXB8-electroporated embryos were incubated for 48 hours and at $\mathrm{HH} 22$, after a $30 \mathrm{~min}$ pulse of $\mathrm{BrdU}$, the labeled cells were analyzed. Upon HOXB8 misexpression, the total number of BrdU positive cells increased by approximately $20 \%$ (p-value=0,021) (Fig.24 - a,c). Within the motor neuron progenitor domain, the cells that had received the ectopic HOXB8 (green), were often positive for BrdU resulting in yellow fluorescence. The control embryos electroporated with GFP did not show any significant change in the number of BrdU positive cells (data integrated into quantitaion plots- Fig.24-c). 
a)

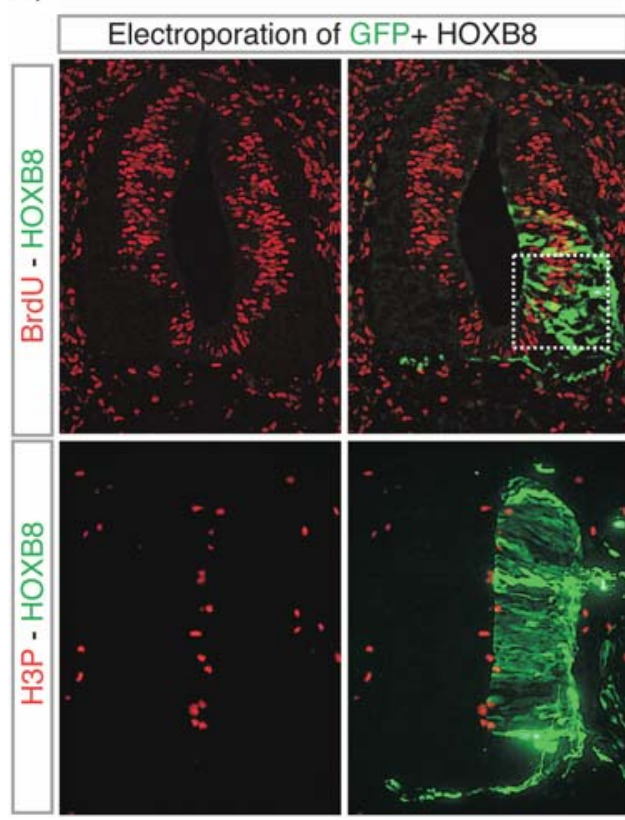

b)

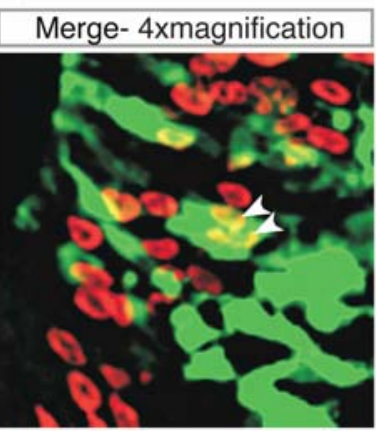

c) Control - HOXB8

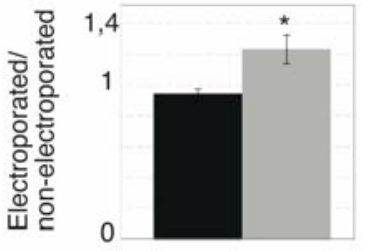

Fig.24 Proliferation status of HOXB8- electroporated lumbar neural tube $(n=5 / 5)$; a) HOXB8 misexpression increases the number of BrdU positive cycling cells, whereas the number of H3P positive mitotic cells remains unchanged. There is also no ectopic H3P positive mitotic cell in the motor column b) Arrowhead points to cells which have received HOXB8 and are BrdU positive. Note the yellow fluorescence resulting from co-localization of HOXB8 (green) and BrdU (red). c) Quantitation of the number of BrdU positive cells in HOXB8-electroporated lumbar neural tube, compared to GFP-electroporated control embryos.

Taken together, these data suggest that the maintained HOXB8 expression in the lumbar neural tube decreases the expression of motor neuron commitment factors and concomitantly, affects the cell cycle exit and subsequent maturation of progenitor cells to mature motor neurons. 


\section{DISCUSSION}

\section{Mutually exclusive expression domains of miR-196 and HOXB8 along the antero- posterior axis}

The presence of microRNA target sites in the 3'UTR of mammalian mRNAs, causes an evolutionary constraint, defined as the avoidance mechanism through which the microRNA and its putative targets adopt exclusive expression domains ${ }^{67}$. The expression pattern of miR-196 was first analyzed in mice using transgenic lines with a LacZ-sensor fused to miR-196 complementary target sites ${ }^{46}$. In this study, the lacZnegative regions were defined as the miR-196 expression domains, located in the posterior trunk of $10.0 \mathrm{dpc}$ mouse embryos. In a further study, using whole mount in situ hybridization with LNA probes, the expression domain of miR-196 was confirmed as the posterior domains of $9.5 \mathrm{dpc}$ mouse embryos, but since the study was embedded in a whole screen for microRNA expression analysis, a higher resolution of expression pattern and a more detailed analysis was to be done ${ }^{47}$. The expression pattern of miR196 was described to follow a similar pattern like HOXB8 ${ }^{46}$, indicating that both genes might be under comparable transcriptional regulations. The present study demonstrates that in stage $\mathrm{HH} 16$ chick embryos (26-28 somites), the expression domain of miR-196 adopts a pattern complementary to HOXB8, encompassing the lumbar level of the embryos, where the HOXB8 expression is abolished. A similar expression pattern was observed in mouse embryos of comparable stage (9.5dpc- data not shown). Such mutually exclusive expression domains could be an indication of a microRNA-mediated regulation. So far, the only evidence for mutually exclusive expression of miR-196 and HOXB8 comes from embryonic limb buds, where the presence of miR-196 in the hindlimbs, avoids the ectopic induction of HOXB8 expression when the hindlimbs are treated with retinoic acid ${ }^{51}$.

MicroRNA-responsive sensors provide a nice tool for mapping functional expression domains of microRNAs. Using this principle in designing a microRNA responsive LacZ sensor, miR-196 expression was mapped to the posterior trunk of mouse $10.0 \mathrm{dpc}$ embryos ${ }^{46}$. The interpretation of negative LacZ stainings, however, is only limited and indirect. In this study, a double fluorescence sensor/tracer vector system is used, which was electroporated into $\mathrm{HH} 16$ chick neural tube and defined the lumbar neural tube as the functional domain of miR-196 expression. Taken together, miR-196 is present at the right time in the right cells to regulate HOXB8 translation in the lumbar neural tube. 


\section{Repressive effect of miR-196 on HOXB8 translation by targeting the 3'UTR of its mRNA}

Although the sequence of miR-196 is highly conserved among different species, including mouse and chick, the 3'UTR sequences of HOXB8 ortologues, show variations (data not shown). The sequence of miR-196 is complementary to a motif in the mouse HOXB8 3'UTR, which finally results in miR-196 - mediated degradation of mouse Hoxb8 transcripts ${ }^{44,51}$. miR-196 has only a partially complementary target site in the gga-HOXB8-3'UTR. It is therefore expected that the main suppression occurs at the translation level, and the mRNA decay be a secondary consequence of translational suppression. In chick embryos overexpressing miR-196, the total HOXB8 transcript level decreases, but the expression in the neuroectoderm remains to an extent ${ }^{51}$. According to this study, ectopic miR-196 decreases the level of endogenous HOXB8 protein, in $\mathrm{HH} 22$, chick brachial neural tube and in primary cultures of chick embryonic fibroblasts. In dicer knockout mice, which lack the whole microRNA pool, the Hoxb8 expression does not show a significant change, or upregulation ${ }^{51}$. It was therefore concluded that Hoxb8 is mainly regulated at the transcriptional level, whereas, a posttrascriptional microRNA-mediated regulation is taken as a safe guard mechanism to attain sharp expression boundaries. In this study, the inhibition of miR-196 in CEF cells, which express a basal level of both HOXB8 and miR-196, interferes with the balance and results in partial relieve of the miR-196 -regulated HOXB8 dosage. Additionally, the GFP reporter with the gga-HOXB8-3'UTR is repressed when transfected into CEF cells. A parallel analysis at the RNA level, however, does not show any significant effect on the GFP-3'UTR transcript (data not shown), confirming the fact that the main level of miR-196 -mediated HOXB8 suppression in avian cells, is translational. Taken together, it is suggested that despite of the conserved role of miR-196 in regulating the HOXB8 translation ${ }^{44}$, the level of regulation may differ among species.

\section{Delayed lumbar motor neuron development upon HOXB8 misexpression and miR- 196 knockdown}

Studies in chick, have defined the HH15-16 as a critical period of motor neuron development in the lumbar neural tube ${ }^{68}$. It is accepted that by this stage, the molecular cues, which further guide the lumbar motor neurons through differentiation and axon projection pathways, are already formed. After stage $\mathrm{HH} 16$, an inversion in the neural 
tube, results in an inverted pattern of differentiation along the antero-posterior axis. In this study, the complementary expression pattern of HOXB8 and miR-196 at stage $\mathrm{HH} 16$, coincides with the $\mathrm{HH} 16$ lumbar motor neuron specification, being slightly before the emergence of Olig-2 positive motor neuron precursor cells. Misexpression of HOXB8 as well as knockdown of miR-196 at this stage resulted in an increase in the Olig-2 positive precursors and a concomitant decrease in IsI1/2 positive post mitotic motor neurons in the lumbar neural tube. Several Hox genes are involved in the anteroposterior patterning of the motor neuron columns ${ }^{62,64,69}$ as well as in further differentiation of motor neurons into motor pools ${ }^{61,64,66}$. Besides their role in anteroposterior patterning, however, Hox genes are as well involved in temporal development of neuronal populations. Mice lacking Hoxc8, showed an increased apoptosis and deficient motor neuron development in the brachial neural tube ${ }^{65}$. Loss of Hoxa10 and Hoxd10, also resulted in a defect in motor neuron development, and a decrease in post mitotic motor neurons ${ }^{70}$. The increase of Olig-2 positive precursor cells at the expense of postmitotic motor neurons in HOXB8 misexpressing lumbar neural tube, implicates a negative role for this 5' Hox gene on the motor neuron development. An effect, which was also observed when the expression domain of Hoxd10 was, shifted rostrally to thoracic neural tube, and consequently, not only the axial patterning of the neural tube was altered, but also the number of postmitotic motor neurons decreased ${ }^{63}$. The fact that the miR-196 knockdown, phenocopies the effect of HOXB8 misexpression to some degrees, emphasizes that miR-196 is just part of the whole regulatory machinery which keeps the lumbar neural tube devoid of HOXB8 protein. Co-transfcetion of miR-196 together with luciferase reporters with several Hox 3'UTRs, suggests Hoxb8 as well as Hoxc8 and Hoxa7 as putative targets of miR-196 ${ }^{44}$. Based on expression patterns, HOXB8 is the only member of the putative miR-196 Hox gene targets that show the complementary expression pattern in $\mathrm{HH} 16$ and $\mathrm{HH} 17$ chick embryos. At this stage, HOXA7 is expressed mostly in the tail bud neural tube and the somitic mesoderm (Geisha data base) and HOXC8 does not show any discrete neural tube expression (Geisha data base), although later on it is expressed in brachial/thoracic neural tube ${ }^{62}$. 
The negative effect of HOXB8 on the expression of motor neuron fate determinants and cell cycle exit in lumbar neural tube

The motor neuron progenitor domain is initially established in the ventral neural tube, by the Shh -induced expression of unique combinations from homeodomain transcription factors ${ }^{1,53-56,59}$. The expression of Nkx6.1 together with Pax6, defines the early motor neuron progenitor domain along the dorso-ventral axis of the neural tube. The cells residing in the early formed progenitor domain get further instructions to express motor neuron fate determinants, including Olig-2 and subsequently the MNR2 proteins ${ }^{54,57,58}$. In this study, the misexpression of HOXB8 in the lumbar neural tube, did not result in a change in the dorsoventral patterning of the neural progenitor domains as observed from the expression domains of Nkx2.2 and Pax7, ventral and dorsal homeobox transcription factors, respectively. The expression of Pax6 and Nkx6.1 did as well show no significant change in either the dorso-ventral expression pattern or in the number of cells expressing either of the markers (data not shown). It is therefore concluded that the effect of HOXB8 on the number of Olig-2 positive cells is rather in the transition state of these cells to more differentiated cells, than in the original generation of Olig-2 positive cells.

The expression of the basic Helix-loop-helix factor (bHLH), Olig-2, further induces the expression of a motor neuron fate determinant factor MNR2 which instructs the motor neuron-specific features to the precursor cells ${ }^{1,54-56}$. The MNR2 protein is expressed in the last cell cycle of somatic motor neurons and also in the transition to the cell cycle exit ${ }^{58}$. Ectopic expression of MNR2, can induce motor neurons in the expense of interneurons in dorsal neural tube suggesting it as a sufficient factor in motor neuron fate determination leading to the cell cycle exit and expression of LIM homeodomain proteins, including IsI-1 and Lim3. Misexpression of HOXB8 in the HH16 lumbar neural tube resulted in a decrease in the number of MNR2 positive cells, compared to control GFP-electroporated embryos. It is therefore suggested that the negative effect of HOXB8 on temporal development of the motor neurons is exerted in the transition state from Olig-2 positive cycling precursor motor neurons to MNR2 positive precursor cells which are instructed to exit the cell cycle, eventually resulting in a decrease in postmitotic and differentiated motor neuron markers. Lim3 is expressed in the motor neuron progenitors, shortly after MNR2 and persists later on in postmitotic motor neurons residing in the MMC ${ }^{58}$. Although MNR2 is supposed to function upstream of Lim3 in the induction of ectopic motor neurons, the Lim3 protein is also expressed in the 
MNR2-negative V2 interneurons ${ }^{57,58,71}$ suggesting that alternative MNR2-independent mechanisms may be involved in the regulation of Lim3 expression. In this study, despite the negative effect of HOXB8 on MNR2 expression in the lumbar neural tube, the number of Lim3 positive cells did not show any significant difference compared to control embryos. The fact that Lim3 is expressed both by precursor cells and postmitotic motor neurons, makes it a 'buffer marker' for which the Lim3-positive, cycling cells may increase in the expense of Lim3-positive postmitotic (MMC) cells, without resulting in any change in the total number of Lim3 positive cells.

The motor neuron precursors should be instructed to exit the cell cycle, in order to express IsI-1 and other markers of postmitotic motor neurons ${ }^{1,54-56,58}$. This process involves a number of regulatory factors, including the expression of the MNR2 protein in the last cell cycle of the motor neuron precursor cells ${ }^{58}$. In this study, the decrease in the MNR2 positive cells in HOXB8-electroporated lumbar neural tube, coincided with the accumulation of BrdU positive cells in the HOXB8 misexpressing motor neuron precursor domain, despite no change in the number of H3P positive mitotic cells in the ventricular zone of the lumbar neural tube. Based on the observations therefore, it is suggested that the delaying effect of HOXB8 on the development of lumbar motor neurons, results from a defect in the cell cycle exit and concomitant failure in the expression of motor neuron fate determinants, such as MNR2. Whether the later phenomenon is a consequence of the failure in cell cycle exit and vice versa, or they are affected via separate mechanisms, still needs to be determined. The processes of precursor cell specification, cell cycle exit and the later migration of motor neuron cell bodies to proper columnar locations, are known to be highly synchronized ${ }^{1,53,55,72}$, however, there is evidence that persistent motor neuron cycling, does not impair the expression of postmitotic motor neuron markers ${ }^{73}$ suggesting that the two processes may be under independent regulatory mechanisms.

The fact that HOXB8 misexpression results in the delayed motor neuron development in the lumbar neural tube, can be either a direct effect of the HOXB8 protein itself, since there is evidence that Hoxb8 gain of function can lead to an increase in the basic proliferative capacity of hematopoietic progenitors ${ }^{74}$, as well as mouse fibroblasts ${ }^{75}$. The effect of the misexpressed HOXB8 can also be exerted indirectly through a more 5'Hox gene, which could therefore explain the overlapping domains of HOXB8 expression and the markers of postmitotic motor neurons in the brachial neural tube. In this hypothesis, the expectation would be that the persistent HOXB8 expression, 
represses the expression (and/or) the proper function of a more caudal Hox gene, which is in turn required for the lumbar motor neuron development. Such a reciprocally repressive circuit is present between HOXC6 and HOXC9 in the brachial/thoracic neural tube ${ }^{62}$. Among the 5' Hox candidates, loss of Hoxa10 and d10 in mice, leads among other defects to a decrease in the postmitotic lumbar motor neurons ${ }^{70}$, which could suggest them as putative Hox genes, inhibited by HOXB8.

The presence of the miR-196 gene in the Hox cluster suggests that it should follow the rules of the cluster and therefore that the expression starts only after the preceding more 3' gene, HOXB8, is already expressed. The regulatory effect of miR-196 on HOXB8 can also be a depiction of posterior prevelance which is a concept pretty well known in Hox gene studies. So far, the main focus of Hox-related effects, has involved the anterior boundary of Hox gene expression domains. This study suggests however, that a posterior, microRNA- regulated boundary may as well be critical in the Hox gene mediated cellular identities. 


\section{MATERIALS \& METHODS}

\section{RNA analysis}

\section{Whole mount in situ hybridization for chick embryos ${ }^{76}$}

Chick embryos were dissected in cold PBS, fixed overnight in 4\%PFA in PBS and then dehydrated through successive stages of methanol and finally, stored at $-20^{\circ} \mathrm{C}$ in pure methanol till the time of hybridization.

\section{Day1. hybridization}

* all the steps are performed on ice, unless otherwise indicated

- Rehdydrate the embryos by passing them through successive stages of methanol in PBT $(0.1 \%$ tween20 in PBS) as follows:

- $75 \% \mathrm{MeOH} / \mathrm{PBT}, 5 \mathrm{~min}$

- $\quad 50 \% \mathrm{MeOH} / \mathrm{PBT}, 5 \mathrm{~min}$

- $\quad 25 \% \mathrm{MeOH} / \mathrm{PBT}, 5 \mathrm{~min}$

- Wash in PBT, 2x 5 min each

- Bleach the embryos in 6\%H2O2/PBT for $1 \mathrm{~h}$

- Wash 3x PBT, 5min each

- Permeabilize with $10 \mu \mathrm{g} / \mathrm{ml}$ Proteinase K/PBT at RT for an appropriate time according to embryonic stages

$\begin{array}{ll}\text { Stage }(\mathbf{H H})^{*} & \text { Minutes Prot K } \\ \text { Up to } 5 & 0 \\ 6-7 & 0-1 \\ 8-10 & 1 \\ 11-13 & 2-3 \\ 14-18 & 5-10 \\ \text { Older than } 20 & 10-15\end{array}$

* staging is based on the Hamburger and Hamilton system ${ }^{77}$

- Inactivate the proteinase $\mathrm{K}$ by $2 \mathrm{mg} / \mathrm{ml}$ Glycin $/ \mathrm{PBT}, 5 \mathrm{~min}$

- Wash 2x PBT, 5 min each

- Refix the embryos in $0.2 \%$ Glutaraldehyde/ $4 \%$ PFA in PBS for 20 min

- Wash 2x PBT, 5min each 
- Prehybridize the embryos in prehybmix $(50 \%$ Formamide, 5xSSC pH4.5, $1 \% \mathrm{SDS}, 50 \mu \mathrm{g} / \mathrm{ml}$ yeast tRNA, $50 \mu \mathrm{g} / \mathrm{ml}$ heparin) for $1 \mathrm{~h} @ 70^{\circ} \mathrm{C}$

- Synthesize the probe:

\begin{tabular}{ll} 
Template DNA & $4 \mu \mathrm{l}$ (around 200ng) \\
Polymerase & $1 \mu \mathrm{l}$ \\
DIG-UTP mix & $2 \mu \mathrm{l}$ \\
Transcription buffer & $2 \mu \mathrm{l}$ (from 10x) \\
RNAse inhibitor & $1 \mu \mathrm{l}$ \\
Nuclease-free water & Up to $20 \mu \mathrm{l}$ \\
\hline Total & $20 \mu \mathrm{l}^{*}$
\end{tabular}

* the reaction is incubated at $37^{\circ} \mathrm{C}$ for T7 and T3 polymerases (at $40^{\circ} \mathrm{C}$ for SP6), for 2 hours and the probe is then diluted by adding 30 $\mu$ l water, purified with a G-50 micro column (GE Healthcare) and run and checked on a normal agarose gel. The antisense DIG-labeled probe in finally diluted 1:100 in the hybridization mix and added to the embryos

Transcript

gga-hoxb8
Template Linearization enzyme

EcoRV
Antisense producing polymerase

SP6

- Hybridize the embryos with the appropriate probe, overnight at the same temperature as the prehybridization step.

\section{Day2. Antibody incubation}

- Wash the overnight hybridized embryos in wash solution I (50\% Formamide, $5 \mathrm{x}$ SSC $\mathrm{pH} 4.5,1 \%$ SDS) at the same temperature as the hybridization temperature, $2 \times 30$ min each

- Wash the embryos in solutionlll (50\% Formamide, 2x SSC pH4.5) plus $0.1 \%$ tween-20,30min at the hybridization temperature

- Wash in MABT (10mM Maleic acid, 150mM NaCl, 0.1\% Tween-20), 2x 5min each at RT 
- Incubate in $2 \%$ blocking reagent (10\% stock from $10 \mathrm{gr}$ blocking powder (Roche) in $M A B$ ) in MABT, 30 min at $R T$

- Block the embryos in blocking solution (20\%FCS, $2 \%$ blocking reagent in MABT), 90 min at RT

- Incubate the embryos with the anti-DIG Alkaline phosphatase-conjugated antibody (Roche) in a dilution of 1:2000 in blocking solution, overnight at $4^{\circ} \mathrm{C}$

Day3. Washing

- Wash the embryos with MABT, $3 \times 5$ min each at RT

- Wash with MABT, 4x 1 hour each at RT

- Wash in MABT, overnight at $4^{\circ} \mathrm{C}$ (for probes which produce a high background the washing can continue for two days, with frequent changes of the buffer, and in small $2 \mathrm{ml}$ screw-capped glass bottles)

Day4. Staining

- Equilibrate the embryos in the staining buffer- NTMT (100mM Tris/HCl pH 9.5, $50 \mathrm{mM} \mathrm{MgCl} 2,100 \mathrm{mM} \mathrm{NaCl}, 0.1 \%$ Tween-20), 3x 10 min each at RT

- Stain the embryos with a 1:50 dilution of NBT/BCIP stock (Roche) in the staining solution for an appropriate time from $2 \mathrm{~h}$ to overnight. The staining is best done at room temperature, in cases of overnight staining however, the embryos should be kept at $4^{\circ} \mathrm{C}$ in the staining solution.

- Stop the staining reaction in PBT overnight at $4^{\circ} \mathrm{C}$

- Put the embryos in $80 \%$ glycerol in PBS (successive stages from $20 \%-50 \%$ $80 \%$ ) for further analysis and photography. 


\section{In situ hybridization on cryosections using LNA antisense probes ${ }^{78}$}

The slides were dried at room temperature for at least 30 minutes while delineating each section by a liquid-repellant line (ImmEdge pen, Vectorlaboratories). The protocol thereafter was as follows:

- $\quad$ Refix the slides in 4\%PFA/PBS for 10 min at RT

- Wash the slides in PBS, 2x3min each

- Acetylate the tissue in the acetylation solution ( $20 \mathrm{mM}$ Triethanolamine, $525 \mu \mathrm{l}$ concentrated $\mathrm{HCl}$ in $200 \mathrm{ml}$ total volume with DEPC water, plus freshly added acetic anhydrate $(750 \mu \mathrm{l}$ per $200 \mathrm{ml}$ total volume)), $10 \mathrm{~min}$ at RT

- Wash in PBS, $5 \mathrm{~min}$

- Treat the slides with ProteinaseK $(5 \mu \mathrm{g} / \mathrm{ml}$ final concentration in PBS), $5 \mathrm{~min}$ at RT (The PK treatment time needs to be optimized according to the density of the tissue and the age of the embryos)

- Wash in PBS, 3x5min each

- Prehybridize* the slides in the prehybridization solution $(50 \%$ Formamide, $5 x$ SSC, 5x Denhardt's solution, $200 \mu \mathrm{g} / \mathrm{ml}$ yeast RNA, $500 \mu \mathrm{g} / \mathrm{ml}$ Salmon sperm DNA, 0.4g Roche Blocking reagent in DEPC-water), for $4 \mathrm{~h}$ at the hybridization temperature (20-22 degrees below the Tm of the LNA probe) - for miR-196 antisense LNA probe, the temperature was kept at $50^{\circ} \mathrm{C}$

* For both prehybridization and hybridization a humidified chamber was prepared, by rinsing 3mm Watmann papers in 5xSSC and 50\% Formamide

Label the LNA probe (predesigned LNA probes, Exiqon) with the DIG- oligonucleotide 3 '-end labeling kit (Roche) as follows:

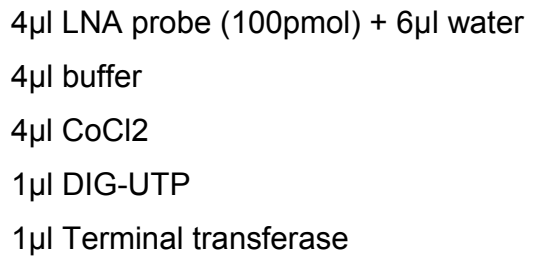

\footnotetext{
* The reaction was incubated at $37^{\circ} \mathrm{C}$ for $1 \mathrm{~h}$, stopped by adding $5 \mu \mathrm{l} 0.1 \mathrm{M}$ EDTA, and the labeled probe was purified on a G-25 micro column (GE Healthcare). The labeled probe is stable at $-20^{\circ} \mathrm{C}$.
} 
The sequences of the miR-196 and the mutated miR-196 (miR-196*) LNA probes are as follows:

$\begin{array}{lll}\text { Probe name } & \text { Type } & \text { Sequence (5'-3') } \\ \text { miR-196 } & \text { LNA (Exiqon) } & \text { CCAACAACATGAAACTACCTA } \\ \text { MiR-196* } & \text { LNA (Exiqon) } & \text { CCAACAAGATCEAICTACCTA }\end{array}$

- Hybridize the slides in denaturing hybridization solution $(50 \%$ Formamide, $5 x$ SSC, $5 x$ Denhardt's solution, $200 \mu \mathrm{g} / \mathrm{ml}$ yeast RNA, $500 \mu \mathrm{g} / \mathrm{ml}$ Salmon sperm DNA, 0.4g Roche Blocking reagent, 0.25\% CHAPS, 0.1\% Tween-20 in DEPCwater) plus 1:500 diluted end-labeled LNA probe, overnight at $50^{\circ} \mathrm{C}$

- Soak the slides in prewarmed $60^{\circ} \mathrm{C} 5 x S S C, 10 \mathrm{~min}$

- $\quad$ wash the slides in $0.2 \times S S C, 1 \mathrm{~h}$ at $60^{\circ} \mathrm{C}$

- Incubate the slides in $\mathrm{B} 1$ solution (0.1M Tris pH 7.5, 0.15M NaCl), 10 min at RT

- Block the slides in the blocking solution (10\% FCS in B1 plus 0.5\% Tween-20), $1 \mathrm{~h}$ at RT

- Incubate the slides in Alkaline phosphatase-conjugated Anti-DIG antibody (Roche) diluted in blocking solution (1:2000), at $4^{\circ} \mathrm{C}$ overnight

- Wash the slides in B1 solution, 3x5min each, at RT

- Equilibrate the slides in $\mathrm{B} 3$ solution $(0.1 \mathrm{M}$ Tris pH 9.5, $0.1 \mathrm{M} \mathrm{NaCl}, 50 \mathrm{mM}$ $\mathrm{MgCl} 2), 10 \mathrm{~min}$ at $\mathrm{RT}$

- Stain the slides in the staining solution (1:50 NBT/BCIP stock solution(Roche) in B3, plus $2 \mathrm{mM}$ levamisole and $0.05 \%$ Tween-20) in the dark for 1-4 days

- After the color reaction is complete, the slides can be mounted in Moviol or any other mounting medium and kept at $4^{\circ} \mathrm{C}$ till the time of analysis

\section{Total RNA extraction from tissue culture cells}

Cells were trypsinized and washed once with autoclaved RNAse-free PBS. The cell pellet was resuspended and homogenized in an appropriate amount of TRIZOL reagent

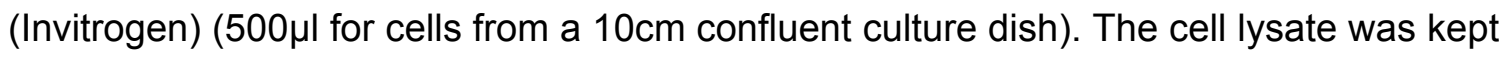
at room temperature for $5 \mathrm{~min}$. $100 \mu \mathrm{l}$ of chloroform was added and mixed completely and let at room temperature for another $2 \mathrm{~min}$ to help the phases separate. The mixture 
was centrifuged at $10,000 \mathrm{rpm}$ for $15 \mathrm{~min}$ at $4^{\circ} \mathrm{C}$ and the upper layer was transferred to a new tube for RNA precipitation. High purity ethanol (ACS grade, Merck) was added as 3 times the volume and let overnight at $-20^{\circ} \mathrm{C}$ for precipitation. The total RNA was precipitated at $10,000 \mathrm{rpm}, 4^{\circ} \mathrm{C}$ for $15 \mathrm{~min}$, washed once with $1 \mathrm{ml} 70 \%$ Ethanol and the pellet was dissolved in RNAse free water and kept at $-80^{\circ} \mathrm{C}$ till the time of use.

\section{Total RNA extraction from embryos}

Chick embryos were dissected in cold RNAse-free PBS, the whole embryos or dissected pieces were transferred to $500 \mu \mathrm{I}$ TRIZOL and homogenized. From this step on the RNA extraction was followed as tissue culture cells.

\section{Northern blot analysis for small RNA visualization ${ }^{79}$}

Separation of RNA fragments on a denaturing gel

RNA samples were separated on a $12 \%$ acrylamide-urea gel using the Sequagel reagents (National diagnostics):

- $18 \mathrm{ml}$ concentrate

- $9 \mathrm{ml}$ diluent

- $3 \mathrm{ml}$ buffer

- $\quad 100 \mu \mathrm{l} 10 \%$ APS

- $30 \mu \mathrm{l}$ TEMED

The following steps were followed for the separation of RNA fragments on the acrylamide-urea gel:

- Let the gel polymerase for at least $30 \mathrm{~min}$ at RT

- Assemble the vertical gel apparatus, using a $0.5 \%$ TBE solution as the running buffer

- Make 20- $30 \mu \mathrm{g}$ of RNA samples. Add a proper amount of Ambion RNA loading buffer (add at least in a 1:1 ratio for each $\mu$ l of RNA sample). Heat the samples 
in a $80^{\circ} \mathrm{C}$ heat block for $10 \mathrm{~min}$ and load slowly on the gel so that the solution sinks in the wells

- Run the gel at a constant voltage of $200 \mathrm{~V}$ for $1 \mathrm{~h}$ and change to $500 \mathrm{~V}$ for an additional run till the bromophenol blue and xylene cyanol bands are almost at the middle of the gel

- Stain the gel by sinking it in an Ethidium bromide solution in 0.5\% TBE for 10 min and destain for $5 \mathrm{~min}$ in water or $0.5 \%$ TBE and visualize under UV. The tRNA and 5SrRNA bands (78 and 120nt in length, respectively) are used as a rough control for equal loading and also as a check for RNA integrity

\section{Blotting and hybridization}

The RNA samples were transferred to a nitrocellulose membrane and hybridized to appropriate probes following the sequence below:

- Cut two times three Wattmann papers in a size little bit bigger than the gel, rinse them in $0.5 \%$ TBE, stack three of them on the bottom plate (positive pole) of the semidry blotting apparatus (Blue flash-L, Serva). Cut a similar size of the blotting membrane (Hybond $\mathrm{N}+$, Amersham), rinse in 0.5x TBE and place on the stack of Wattmann papers avoiding air bubbles. Place the gel on the blotting membrane, in the right orientation and stack the additional three watmann papers on top of the sandwich and close the lid of the apparatus. The blotting occurs from top to the bottom, transferring the same pattern of RNAs in the gel to the membrane below it.

- Connect the apparatus to a constant current of $3.3 \mathrm{~mA} / \mathrm{cm}^{2}$ for $35 \mathrm{~min}$. If the calculated current is too high (more than $400 \mathrm{~mA}$ ), the blotting time could in turn be extended to avoid the excess warming up of the blotting block. After the blotting time is over, the gel is kept for further staining to see the transfer efficiency, and the membrane is further processed to get ready for the hybridization.

- Put the membrane on a tissue paper to let it dry a bit, crosslink on a UV cross linker (Fluolink, Bachofer) at $0.7 \mathrm{~J} / \mathrm{cm}^{2}$. Bake the membrane for a minimum of 30 min in a $80^{\circ} \mathrm{C}$ incubator. At this step, the membrane could be wrapped in a 
Saran and kept at $4^{\circ} \mathrm{C}$ for a later hybridization or alternatively, hybridized directly.

- Prehybridize the membrane for at least $2 \mathrm{~h}$ in prehybridization solution (5x SSC, 20mM Na2HPO4 pH 7.2, 7\%SDS, 2x Denhardt's solution (2\% polyvinyl pyrolidone, $2 \%$ BSA, $2 \%$ Ficoll400)) plus freshly added $1 \mathrm{mg}$ of sheared salmon sperm DNA (100 $\mu \mathrm{l}$ from $10 \mathrm{mg} / \mathrm{ml}$ stock (Stratagene)). Preheat the salmon DNA for $5 \mathrm{~min}$ at $95^{\circ} \mathrm{C}$ before adding to the prehybridization mix.

- Label the DNA or LNA probe following the instructions below:

20-25 pmol of oligo $(0.2 \mu \mathrm{l}$ from $100 \mathrm{pmol} / \mu \mathrm{l}$ DNA oligos, or $1 \mu \mathrm{l}$ from $25 \mathrm{pmol} / \mu \mathrm{l} L N A)$

$2 \mu \mathrm{l}$ 10x T4 Polynucleotide kinase (PNK) buffer (Roche)

$2.5 \mu \mathrm{l}{ }^{32} \mathrm{P} \gamma$-ATP (Amersham)

RNAse- free water up to $20 \mu \mathrm{l}$

- Incubate the labeling mixture for $1 \mathrm{~h}$ at $37^{\circ} \mathrm{C}$. Add $30 \mu \mathrm{l}$ of RNAse free water, purify on G25 columns (GE healthcare), and add to a new prehybridization solution prepared as mentioned before.

- Hybridize overnight at $50^{\circ} \mathrm{C}$. The probe details were as follows:

$\begin{array}{lll}\text { Probe name } & \text { Type } & \text { Sequence (5'-3') } \\ \text { miR-196 } & \text { LNA (Exiqon) } & \text { CCAACAACATGAAACTACCTA } \\ \text { U6 } & \text { DNA (IBA) } & \text { GGCCATGCTAAATCTTCTCTGTA }\end{array}$

- Discard the hybridization solution, wash the membrane with the non-stringent wash solution (3xSSC, 25mM NaH2PO4 pH 7.5, 5\% SDS, 10x Denhardt's solution) for $2 \times 10$ min each

- Wash again for $2 \times 30$ min at the hybridization temperature

- Wash $5 \mathrm{~min}$ in the stringent wash solution (1xSSC, $1 \%$ SDS), wrap in saran and expose it to a film or a phospho-imaging plate 
Stripping a northern blot:

- Wash the blot for $30 \mathrm{~min}$ in $1 \% \mathrm{SDS}$, at $85^{\circ} \mathrm{C}$. Check the striping by exposing to an imaging plate

\section{Protein analysis}

\section{Total Protein extraction from cells}

To extract the total protein from cells, the cells were trypsinized, and washed with PBS and the cell pellet was then lysed in the lysis buffer $(50 \mathrm{mM}$ Tris- $\mathrm{HCl} \mathrm{pH} 8.0,150 \mathrm{mM}$ $\mathrm{NaCl}, 1 \% \mathrm{NP}-40){ }^{80}$ by pipetting and keeping on ice for $10 \mathrm{~min}$. The lysed cells were centrifuged for $15 \mathrm{~min}$ at $4^{\circ} \mathrm{C}, 13000 \mathrm{rpm}$ and the supernatant was used as the protein source for further analysis.

\section{Total Protein extraction from embryos}

The embryos were prepped and washed in cold PBS. The lysis was done in the lysis buffer (50mM Tris-HCl pH 7.5, 150mM NaCl, 1mM EDTA, 1mM EGTA, 10\%Glycerol, $1 \%$ Triton-X-100) plus freshly added $1 \mathrm{mM} \mathrm{MgCl} 2$ and proteinase inhibitors. The embryos were homogenized by pipetting in the cold lysis solution and the embryonic total protein was kept at $-80^{\circ} \mathrm{C}$.

\section{SDS-PAGE separation of protein samples}

The protein samples were run on a $10 \%$ SDS-PAGE gel consisting of stacking and resolving layers as follows:

For $3 \mathrm{ml} 5 \%$ stacking gel:

- $\quad 0.83 \mathrm{ml}$ from 4xStacking buffer pH 6.8 (0.5M Tris, 0.4\% SDS, pH 6.8)

- $\quad 0.553 \mathrm{ml}$ from 30\%Acrylamide/bisacrylamide solution (Rotiphorese Gel 30, Roth) 
- $\quad 1.95 \mathrm{ml}$, distilled water

- $\quad 16.6 \mu \mathrm{l} 10 \%$ APS

- $8.3 \mu \mathrm{I}$ TEMED

For $10 \mathrm{ml} 10 \%$ resolving gel:

- $\quad 2.5 \mathrm{ml}$ from resolving buffer $\mathrm{pH} 8.8$ (1.5M Tris, 0.4\% SDS, $\mathrm{pH} 8.8$ )

- $\quad 3.3 \mathrm{ml}$ from $30 \%$ Acrylamide/bisacrylamide solution

- $\quad 4.1 \mathrm{ml}$, distilled water

- $\quad 33 \mu \mathrm{l} 10 \%$ APS

- $\quad 33 \mu \mathrm{I}$ TEMED

Protein samples were denatured in the loading buffer $(62.5 \mathrm{mM}$ Tris, $2 \%$ SDS, $10 \%$ glycerin, $0.001 \%$ bromophenol blue) incubating for $5 \mathrm{~min}$ at $95^{\circ} \mathrm{C}$ before loading on the gel. The gel was run at a constant current of 10-20 mA in the electrophoresis buffer (25mM Tris , 192mM Glycine, $0.1 \%$ SDS) till the bromophenol blue of the loading buffer ran out.

\section{Western blot analysis}

The SDS-PAGE gel was transferred on a nitrocellulose membrane sandwiched between two watmann papers and using a wet transfer system (BioRad). The transfer was done overnight in the transfer buffer $(3.9 \mathrm{mM}$ Glycerine, $48 \mathrm{mM}$ Tris, $0.037 \%$ SDS, $20 \%$ $\mathrm{MeOH})$, at a constant voltage of $30 \mathrm{~V}$. The steps after the overnight blotting were as follows:

- Disassemble the blotting sandwich and rinse the membrane in buffer $A$ (10mM Tris- $\mathrm{HCl}, 0.9 \% \mathrm{NaCl}, 0.1 \%$ Tween-20)

- Stain the membrane in PonceauS (2gr Ponceau S, 30gr trichloroacetic acid, $30 \mathrm{gr}$ Sulfosalicylic acid) for a maximum of $3 \mathrm{~min}$, destain in buffer $A$ till the protein bands become visible in the lanes and make a picture

- Destain completely in buffer A

- Block the membrane with appropriate concentration of milk powder in buffer A (from $1-4 \%$ ) for $1 \mathrm{~h}$ at RT 
- Incubate with the $1^{\text {st }}$ antibody diluted in the blocking solution for $2 \mathrm{~h}$ at RT or overnight at $4^{\circ} \mathrm{C}$

- Wash in buffer A, 10 min on a rocker

- Wash in buffer $\mathrm{B}(0.9 \% \mathrm{NaCl}, 0.5 \%$ Triton-X-100, $0.2 \% \mathrm{SDS}), 2 \times 10 \mathrm{~min}$

- Wash in buffer $A, 10$ min

- Incubate with the secondary antibody (antimouse or antirabbit- HRP conjugated) in the blocking solution for $1 \mathrm{~h}$ at RT

- Wash in buffer A, 10min at RT

- Wash in buffer B, 2x 10 min at RT

- Wash in buffer A, 10min at RT

- Develop the luminescent signal by covering the membrane with a 1:1 mixture of chemiluminesence substrate (Super signal west pico, Pierce) and exposing to $x$ ray films for an appropriate time

The antibodies used and their concentrations were as follows:

$\begin{array}{llll}\text { Antibody } & \text { Host species } & \text { Dilution } & \text { Blocking solution } \\ \alpha \text {-GFP(Roche) } & \text { mouse } & 1: 1000 & 4 \% \text { milk powder in buffer A } \\ \alpha \text {-H2B (Upstate) } & \text { rabbit } & 1: 2000 & 4 \% \text { milk powder in buffer A } \\ \alpha \text {-hoxb8 (Abnova) } & \text { mouse } & 1: 1000 & 1 \% \text { milk powder in buffer A } \\ \alpha \text {-alpha tubulin (Sigma) } & \text { mouse } & 1: 4000 & 4 \% \text { milk powder in buffer A }\end{array}$

\section{Histological techniques}

\section{Vibratome sectioning of whole embryos}

Chick embryos were sectioned after whole mount in situ hybridization in order to have a better resolution of the signal. After the staining, the embryos were kept in PBS till the time of embedding. The Gelatin/Albumin embedding matrix was prepared as follows:

- Heat 2.2gr Gelatin in 450ml PBS

- Add 135gr Bovine albumin (Sigma)

- Stir till the solution is clear 


\section{- Add 90gr Saccharose}

- Keep at $-20^{\circ} \mathrm{C}$ till the time of use

At the time of embedding, the Gelatin/Albumin embedding matrix was defrozen, and $2 \mathrm{ml}$ of it was poured into two separate small containers. $140 \mu$ l Glutaraldehyde was added to the first portion of gelatin, stirred, and the embryo was placed in it in the desired orientation. The second portion of the gelatin was added on top of the already hardening medium after the addition of glutaraldehyde and left till the whole block hardened. The whole procedure was done in a chamber made of L-shaped metal bars with a cleaned glass placed at the bottom. The metal bars were removed after the block was hard enough. The Gelatin/Albumin embedded blocks can be stored for a maximum of 2 days wrapped in saran, in a closed humid falcon tube.

At the time of vibratome sectioning, the block was glued on the sectioning plate of the vibratome (Leica), in the desired orientation and cut as $10-20 \mu \mathrm{m}$ sections. The sections were collected on slides and mounted in Moviol. Mounted slides could be directly used for imaging.

\section{Embedding the embryos for cryosectioning}

Chick embryos were dissected in cold PBS and fixed for $2 \mathrm{~h}$ in $4 \% \mathrm{PFA} / \mathrm{PBS}$ at $4^{\circ} \mathrm{C}$. The steps after the fixation were as follows:

- Wash the embryos $3 \times 5 \mathrm{~min}$, in PBS, on ice

- Incubate the embryos in $25 \%$ sucrose in PBS from 4 h to overnight on ice till the embryos sink in the solution (sucrose decreases the freeze fracturing of the embryos during cryoembedding. The overnight incubation in sucrore however, sometimes results in fragile tissues, therefore, it is recommended to keep the sucrose incubation time at a maximum of 6 hours).

- Embed the embryos in cryomatrix (Leica) in the desired orientation under a dissecting microscope. The matrix would freeze by putting on crushed dry ice.

- Keep the embedded embryos at $-20^{\circ} \mathrm{C}$ or cut directly afterwards.

The cryoblocks were cut at the desired tickness $(10 \mu \mathrm{M}$ for cross sections, $100 \mu \mathrm{M}$ for horizontal sections) (Leica cryostat) and the sections were kept at $-80^{\circ} \mathrm{C}$ or processed directly for immunostaining. 


\section{Immunohistochemistry}

\section{Immunostaining of the frozen sections}

The following steps were followed for immunostaining of the cryosections ${ }^{81}$ :

- Keep the slides at room temperature to dry. Make a border around each section with a fatty pen (vector laboratories). Let the line dry.

- Wash the slides in PBS, 3x5min at RT

- Incubate with the primary antibody in the blocking solution overnight at $4^{\circ} \mathrm{C}$

- Wash 3x 5min in PBS or the FCS blocking solution

- Incubate with the 1:1000 dilution of the secondary antibody (antimouse/antirabbit Alexaflour $488 / 595$ (Molecular probes)) in the FCS blocking solution for $1 \mathrm{~h}$ at RT.

- Wash 3x 5min with PBS or the FCS blocking solution.

- Mount the slides with the mounting medium (Vectashield, Vector laboratories) containing DAPI for counterstaining the nuclei

The antibodies used in the study and details of their application are as follows:

$\begin{array}{lll}\text { Antibody } & \begin{array}{l}\text { Host } \\ \text { species }\end{array} & \text { Dilution/Blocking solution } \\ \text { Isl1/2 (DSHB) } & \text { mouse } & 1: 100 / \text { FCS blocking (1\%FCS, 0.1\%Triton-X100 in PBS) } \\ \text { Lim1/2 (DSHB) } & \text { mouse } & 1: 10 / \text { FCS blocking (1\%FCS, 0.1\%Triton-X100 in PBS) } \\ \text { Isl2 (DSHB) } & \text { mouse } & 1: 100 / \text { FCS blocking (1\%FCS, 0.1\%Triton-X100 in PBS) } \\ \text { Hoxb8 (Abnova) } & \text { mouse } & 1: 100 / \text { Western blocking reagent (Roche) } \\ \text { Olig2 (Abcam) } & \text { rabbit } & 1: 500 / F C S \text { blocking (1\%FCS, 0.1\%Triton-X100 in PBS) } \\ \text { DsRED (Clontech) } & \text { rabbit } & 1: 100 / \text { FCS blocking (1\%FCS, 0.1\%Triton-X100 in PBS) } \\ \text { Phosphorylated histone H3 } & \text { mouse } & 1: 100 / \text { FCS blocking (1\%FCS, 0.1\%Triton-X100 in PBS) } \\ \text { (Cell signaling tech.) } & & \\ \text { Nkx2.2 (DSHB) } & \text { mouse } & 1: 100 / \text { FCS blocking (1\%FCS, 0.1\%Triton-X100 in PBS) } \\ \text { Pax6 (DSHB) } & \text { mouse } & 1: 100 / \text { FCS blocking (1\%FCS, 0.1\%Triton-X100 in PBS) } \\ \text { Nkx6.1 (DSHB) } & \text { mouse } & 1: 100 / \text { FCS blocking (1\%FCS, 0.1\%Triton-X100 in PBS } \\ \text { Pax7 (DSHB) } & \text { mouse } & 1: 100 / \text { FCS blocking (1\%FCS, 0.1\%Triton-X100 in PBS) }\end{array}$




$\begin{array}{lll}\text { Lim3 (DSHB) } & \text { mouse } & 1: 100 / \text { FCS blocking (1\%FCS, 0.1\%Triton-X100 in PBS) } \\ \text { MNR2 (DSHB) } & \text { mouse } & 1: 100 / \text { FCS blocking (1\%FCS, 0.1\%Triton-X100 in PBS) } \\ \text { GFP (Roche) } & \text { mouse } & 1: 500 / \text { FCS blocking (1\%FCS, 0.1\%Triton-X100 in PBS) } \\ \text { GFP*Alexaflour-488 (Invitrogen) } & \text { rabbit } & 1: 1000 / \text { FCS blocking (1\%FCS, 0.1\%Triton-X100 in PBS) }\end{array}$

\section{Luciferase reporter assay}

The luciferase reporter assay was performed using the Dual-luciferase reporter assay kit (Promega) with minor modifications to the manufacturers instructions. After transfection with appropriate reporter constructs, cells were washed with PBS and lysed

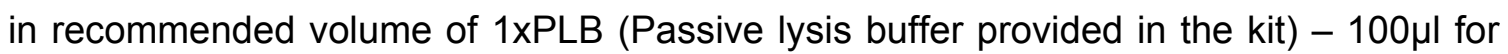
each well of a 24-well culture dish. For efficient lysis, the cells were incubated in the lysis buffer for $15 \mathrm{~min}$ at room temperature and an additional time of around $1 \mathrm{~h}$ (till they were frozen) at $-20^{\circ} \mathrm{C} .25 \mu \mathrm{l}$ of the cell lysate was then used for the reporter assay using $20 \mu l$ from each of LARII and Stop and Glo reagents.

For each reporter analysis, the Firefly and the Renilla luciferase activity was measured separately, and the relative luciferase activity was calculated as the ratio of Renilla/Firefly luciferase. Each of the measurements was performed as 3 replicates and the mean value was used for further analysis.

The luciferase signal was measured with the Victor TM Light 1420 Luminescence Counter (Perkin Elmer).

\section{Vector designs}

\section{MiR-196 expression vectors}

In order to express the microRNA miR-196, an expression vector was designed based on the backbone of a bicistronic RNAi expression vector including a reporter RFP gene after a $\beta$-actin promoter and a microRNA cassette transcribed from a chick U6 promoter 82 (Fig.25). The miR-196 microRNA was transcribed and processed through two alternative approaches. In one vector (dsRED-miR-196-500), a 675bp piece of the genomic DNA, surrounding the miR-196 predicted hairpin was amplified out of the chick 
genomic DNA, and further subcloned into the Mlul and Nhel sites of the vector. In the second approach (dsRED-miR196-30), the backbone of a pretty defined microRNA, miR-30, is used as a platform to produce the mature miR-196, by substituting the original mature miR-30 sequence with miR-196.

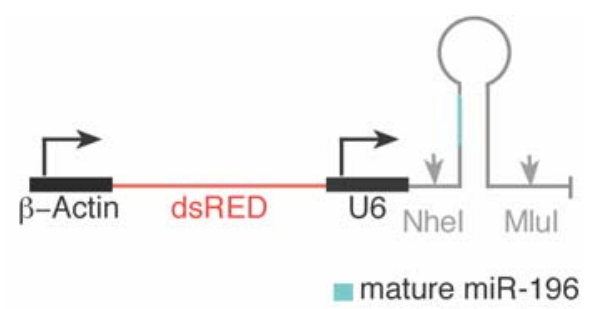

Fig.25 Structure of the bicistronic vector used for the expression of the miR-196

The primer sequences used for each of the alternative approaches are as follows:

\section{Vector Name}

DsRED-miR 196-500

DsRED-miR196-30

\section{Primer sequences (5'-3')}

F: CTAGCTAGCCCTCGATAATCGCTTGTTTCTC

R: CGACGCGTTACACGACGGAAAAAGAAAACC

F: GGCGGGGCTAGCTGGAGAAGATGCCTTCCGGAGAGGTGCTGCTGAGCG

R: GGGTGGACGCGTAAGAGGGGAAGAAAGCTTCTAACCCCGCTATTCACCA CCACTAGGCA

To produce the dsRED-miR196-500 vector, the PCR product of $675 \mathrm{bp}$, resulting from the amplification of the chick genomic DNA, was cut with the two restriction enzymes, Mlul and Nhel, and ligated to the vector (cut with the same enzymes) using T4 DNA ligase (Roche).

In order to produce the miR-30 backbone, containing the mature miR-196 sequence, a PCR was performed using the mentioned primers, together with the following sense and antisense oligos: 
Hairpin oligo1:

5' GAGAGGTGCTGCTGAGCGACCAACAACATGAAACTACCTATAGTGAAGCCACAGATGTA 3' Hairpin oligo2:

5'ATTCACCACCACTAGGCACCAACAACATGAAACTACCTATACATCTGTGGCTTCACT 3'

The PCR reaction was as follows:

\begin{tabular}{ll} 
MiR-30 Forward & $10 \mathrm{ng}-1 \mu \mathrm{l}$ \\
MiR-30 Reverse & $10 \mathrm{ng}-1 \mu \mathrm{l}$ \\
Hairpin oligo1 & $100 \mathrm{ng}-1 \mu \mathrm{l}$ \\
Hairpin oligo2 & $100 \mathrm{ng}-1 \mu \mathrm{l}$ \\
dNTPs (10x) & $5 \mu \mathrm{l}$ \\
Reaction buffer & $5 \mu \mathrm{l}$ \\
Pfu & $1 \mu \mathrm{l}$ \\
$\mathrm{H}_{2} \mathrm{O}$ & $35 \mu \mathrm{l}$ \\
\hline Total & $50 \mu \mathrm{l}^{*}$
\end{tabular}

* Reaction for $25-30$ cycles@ $@ 5^{\circ} \mathrm{C}$ annealing temperatur 
The PCR product is then cut and ligated to the vector as mentioned above.

\section{MiR-196 knockdown oligonucleotides}

Knockdown of miR-196 was performed using a 2'O-methylated antisense oligonucletides ${ }^{83}$ (miRIDIAN miR-196 inhibitor-Dharmacon) complementary to the mature miR-196. As a negative control, a cognate oligonucleotide was used which is based on the C.elegans miR-239b with no vertebrate homologue (miRIDIAN microRNA negative control\#2- Dharmacon). The oligos were dissolved as $200 \mathrm{pmol} / \mu \mathrm{l}$ stocks in $1 \mathrm{X}$ siRNA buffer (Dharmacon), incubated at $90^{\circ} \mathrm{C}$ for $3 \mathrm{~min}$ and $37^{\circ} \mathrm{C}$ for another 1 hour and kept as aliquots at $-20^{\circ} \mathrm{C}$.

\section{miR-196-targeted sensor constructs}

A microRNA sensor reporter is supposed to carry an extra sequence which is partially/completely complementary to the microRNA sequence. The presence of the sensor sequence in the transcribed reporter RNA, marks it as a target of the microRNA which in turn results in a post-transcriptional/translational repression of the reporter and hence loss of the reporter signal.

miR-196 GFP sensor

In order to produce a miR-196 GFP sensor, a double stranded oligo was designed to carry two successive perfect complementary sequences to miR-196. The annealing reaction was as follows:

$46 \mu \mathrm{l}$ 1x DNA annealing buffer

(30mM HEPES pH 7.4, 100mM Potassium Acetate, 2mM Magnesium Acetate)

$2 \mu \mathrm{l}$ sense oligo $(10 \mathrm{pmol} / \mu \mathrm{l})$

$2 \mu \mathrm{l}$ antisense oligo $(10 \mathrm{pmol} / \mu \mathrm{l})$

$50 \mu l$ total

heat the reaction for $3 \mathrm{~min} @ 90^{\circ} \mathrm{C}$ and anneal @ $37^{\circ} \mathrm{C}$ for 1 hour 
Oligos:

HindIII sense:

5' AGCTTCCAACAACATGAAACTACCTAGCCGTACCAACAACATGAAACTACCTAG 3'

BamHI antisense:

5' GATCCTAGGTAGTTTCATGTTGTTGGTACGGCTAGGTAGTTTCATGTTGTTGGA 3'

The annealed fragment can then be used in a 1:50 and 1:100 dilutions in a ligation reaction as follows:

200ng of the cut vector (EGFP-C1 (Clontech) digested with HindIII and BamHI)

$1 \mu \mathrm{l}$ of the $1: 50$ or $1: 100$ dilution of the oligos

$1 \mu$ ligation buffer (Roche)

$1 \mu \mathrm{l}$ T4 DNA ligase (Roche)

Add water to $10 \mu \mathrm{l}$

Incubate @ RT for 4h, transform the bacteria and check for the insert

miR-196 luciferase sensor

The luciferase sensor follows the same principle of the GFP sensor besides that its suppression is more quantitative and the presence of an internal control (another luciferase which does not respond to the microRNA), makes the outcome of this assay more trustable for comparative studies. The miR-196 sensor was constructed by adding the same oligos used for the GFP-sensor, downstream of a Renilla luciferase gene on the backbone of psiCheck double luciferase vector (Promega). The psiCheck vector consists of a bicistronic structure, in which the Renilla luciferase gene is driven by a T7 promoter and the Firefly luciferase (the internal control), by a TK promoter. The relative luciferase activity can therefore be calculated as the Renilla to Firefly luciferase ratio, which compensates for errors/deviations during transfection and handling. For the construction of the miR-196 luciferase sensor, the annealing and ligation was done as described for the GFP-sensor, using the following oligonucleotides:

Xhol sense:

5' TCGAGCCAACAACATGAAACTACCTAGCCGTACCAACAACATGAAACTACCTAGC 3'

Notl antisense:

5' GGCCGCTAGGTAGTTTCATGTTGTTGGTACGGCTAGGTAGTTTCATGTTGTTGGC 3' 


\section{GFP-gga HOXB8 3'UTR}

In order to verify the effect of miR-196 on the 3'UTR of gga-HOXB8, the 3'UTR of the mRNA (UTresourse accession number: CR318427) was cloned downstream of the GFP coding sequence, in the EGFP-C1 vector (Clontech). The annealing and ligation reactions were performed as described before using the following oligonucleotides:

Hindlll sense:

5'AGCTTAAAGGAGTTTTGAGGACTGAAAGGAGAGCGCTGCTGGGGTAGAGAGCCCCCCTCCCCCCTT TTTCTTTG 3'

BamHI antisense:

5'GATCCAAAGAAAAAGGGgGAGgGGgGCTCTCTACCCCAGCAGCGCTCTCCTTTCAGTCCTCAAAA CTCCTTTA 3'

\section{gga-HOXB8 expression vector}

The coding sequence of gga-HOXB8 was cloned after a chick $\beta$-actin rabbit $\beta$-tubulin hybrid promoter in the PCAGGS expression vector. The DNA was amplified out of the total chick embryonic RNA (HH14), by reverse transcription using the one step RT-PCR kit (Qiagen), following manufacturer's instructions. To amplify the cDNA the following primers were used:

\section{EcoRI forward:}

CCGGAATTCTCCTTTCAGTCCTCAAAACTCC

EcoRI reverse:

CCGGAATTCTTCCTCCTCCTCCGTACAAATA

The RT-PCR product was then purified by the PCR purification kit (Qiagen), cut with EcoRI and ligated to the cut vector. The correct orientation and sequence of the cloned piece was confirmed by sequencing. 


\section{Generation of the ISH probes}

Custom ISH probes were generated by amplifying a piece of the CDNA via RT-PCR on total embryonic RNA. The name of the probe, the primers used for the amplification reactions and the reference to the sequence is as follows:

$\begin{array}{lll}\text { Name } & \text { Primers (F/R) } & \text { Accession number } \\ \text { Gga-HOXB8 } & \text { F: 5' CTTCTATGGCTACGACCCTTTG 3' } & \text { NM_204911 } \\ & \text { R: 5' TTCTGGAACCAGATTTTGACCT 3' } & \end{array}$

The RT-PCR product was cut out of a $1 \%$ agarose gel, and purified by the gel extraction kit (Qiagen) following the manufacturer's instructions. The DNA fragment was then cloned into the TOPOII vector (Invitrogen), using the instructions of the TOPO cloning kit. The cloning reaction was incubated for $30 \mathrm{~min}$ at room temperature and $1 \mu \mathrm{l}$ was further transferred to bacteria for colony checks. The screening for the positive clones were done on Ampicillin plates covered with IPTG and X-gal. The white colonies were almost $100 \%$ positive. The orientation of the fragments was confirmed by sequencing and the TOPO-cloned CDNA was then linearized by a restriction enzyme, which cuts 5' to the fragment. The appropriate enzyme (T7 or SP6) was then used for generating antisense probes.

\section{In ovo electroporation}

In ovo electroporation was used to deliver plasmids/oligonucleotides of interest into the neural tube cells ${ }^{84}$. In this method, one side of the neural tube (adjacent to the positive electrode) receives the ectopic plasmid, whereas, the contra-lateral side always serves as a negative control (Fig.26). In this study, chicken embryos were electroporated at $\mathrm{HH} 14-16$, and analyzed 2 or 3 days after electroporation. The following steps were taken during the electroporation process:

Preparation

The eggs were taken out of the incubator. The egg shell was taped to avoid the dropping of the egg shell pieces on to the embryos. The embryos were exposed by 
opening a round whole in the eggshell above the embryo, after removing $2-3 \mathrm{ml}$ of the albumen by a syringe. To prevent the embryos from drying, 1XTyrode's buffer (10mM HEPES, $150 \mathrm{mM} \mathrm{NaCl}, 5 \mathrm{mM} \mathrm{KCl}, 1.4 \mathrm{mM} \mathrm{CaCl}, 1 \mathrm{mM} \mathrm{MgCl} 2,5.6 \mathrm{mM}$ Glucose, $0.1 \%$ $\mathrm{BSA}, \mathrm{pH7.4)}$ was added to the embryos. The Tyrode's buffer was diluted from a $10 \mathrm{X}$ stock, right before use and to avoid contaminations, penicillin and streptomycin was added in a 1:100 dilution from the Penicillin/Streptomycin stock solution (GIBCO). The removed $2-3 \mathrm{ml}$ albumen was at this stage added to the embryo to bring it to a better position for further manipulations. To increase the survival, several steps of the original electroporation methods were omitted. No black ink was added under the embryo for the contrast and the vitelline membrane was not torn. Instead, the contrast was obtained by having the embryos at a position where a light source from the left side could make it visible.

Injection of the DNA/RNA

A DNA concentration of $700 \mathrm{ng}-4 \mu \mathrm{g} / \mu \mathrm{l}$ in 1 XPBS was prepared. In order to visualize the DNA, $0.05 \mu \mathrm{l}$ of fast green (stock: $0,5 \mu \mathrm{g} / \mu \mathrm{l}$ ) was added to the DNA solution. The DNA solution was injected into the lumen of the neural tube using fine glass micropipettes (Clark Electromedical Instruments, $1 \mathrm{~mm}$ thick needles). The glass needles were pulled using a Sachas-Fleming micropipette puller. For the injection, a Pneumatic PicoPump was used, and the vitelline membrane and the neural tube were pierced by slightly pressing the needle at a level anterior to the forelimb and the DNA solution was injected into the lumen of the neural tube, till the very posterior end.

\section{Electroporation}

After the injection, $0.3 \mathrm{~mm}$ thick and $6 \mathrm{~mm}$ long L-shaped tungsten electrodes were placed parallel to the neural tube, encompassing the posterior end of the embryo, and avoiding the heart region. the distance of the electrodes was constantly kept at $4 \mathrm{~mm}$. The electrodes were pressed enough so that the electric field covers the ventral neural tube, which was the region of interest. 5 pulses, $50 \mathrm{msec}$ each with a $950 \mathrm{msec}$ interval, at 25 volts were applied to deliver the nucleic acids into the neuroepithelium. Electroporation was done using Electro Square Porator ECM830 (BTX). After the electroporation, drops of tyrode's buffer were added on top of the embryos, and the eggs were taped and incubated in the $38^{\circ} \mathrm{C}$ incubator for the desired period. 
Fig.26 In ovo electroporation in chick neural tube; The DNA/RNA is delivered unilaterally into the neural tube (note the right side of the neural tube which has received the GFP plasmid). The contralateral side serves as an internal control.

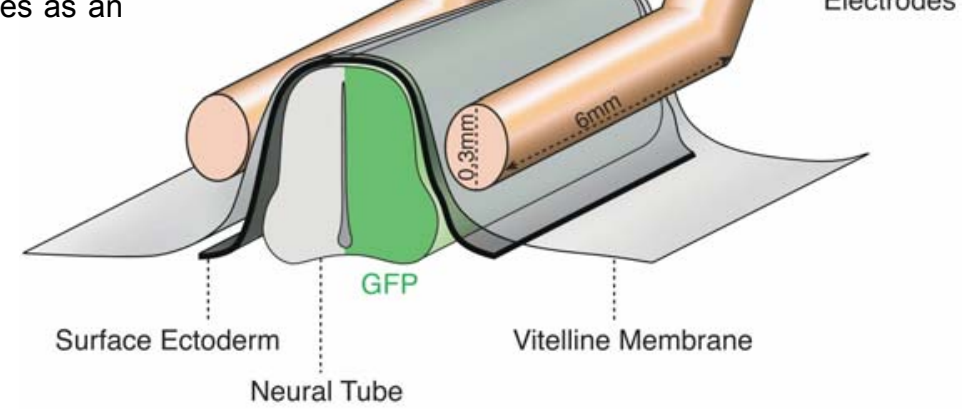

\section{Retrograde labeling of axonal tracts}

In order to visualize the LMC columns, hindlimb axonal ends were labeled with Dextran 85. The Dextran label was retrogradely transported along the axons, and finally detected in the cell bodies residing in the LMCs (Fig.27).

\section{Preparation}

Chick embryos (E5) were removed from the eggs, and further dissected in freshly made ACSF (139 mM NaCl, 3mM KCl, 17mM NaHCO $3,12 \mathrm{mM}$ Glucose, 3mM CaCl $2,1 \mathrm{mM}$ $\mathrm{MgCl}_{2}$ ). The ACSF was firstly prepared without $\mathrm{CaCl}_{2}$, which was added after $15 \mathrm{~min}$ of Carbogenation. The embryos were eviscerated and beheaded in ACSF prewarmed to $30^{\circ} \mathrm{C}$. At the time of labeling, embryos were pinned in the right position, with the dorsal side up in silicon plates. 


\section{Dextran labeling}

The retrograde labeling was performed, using $10 \%$ Alexa Flour488 or 594- conjugated dextran (Invitrogen) kept as alliquotes at $-20^{\circ} \mathrm{C}$. The Dextran dye was injected along the body wall into the base of the hindlimb. To increase the probability of all the nerves being hit by the injection, the limb was cut at its base and the injection side was corrected, reaching a homogenous, symmetric dye distribution at both limbs.

\section{Post-labeling incubation}

The embryos were kept for $5 \mathrm{~h}$ in constantly carbogenated ACSF buffer at $30^{\circ} \mathrm{C}$. During the incubation period, the buffer was replaced every 2 hours with fresh prewarmed ACSF buffer to avoid concentrations changes due to evaporation.

Fig.27 Schematic illustration of retrograde

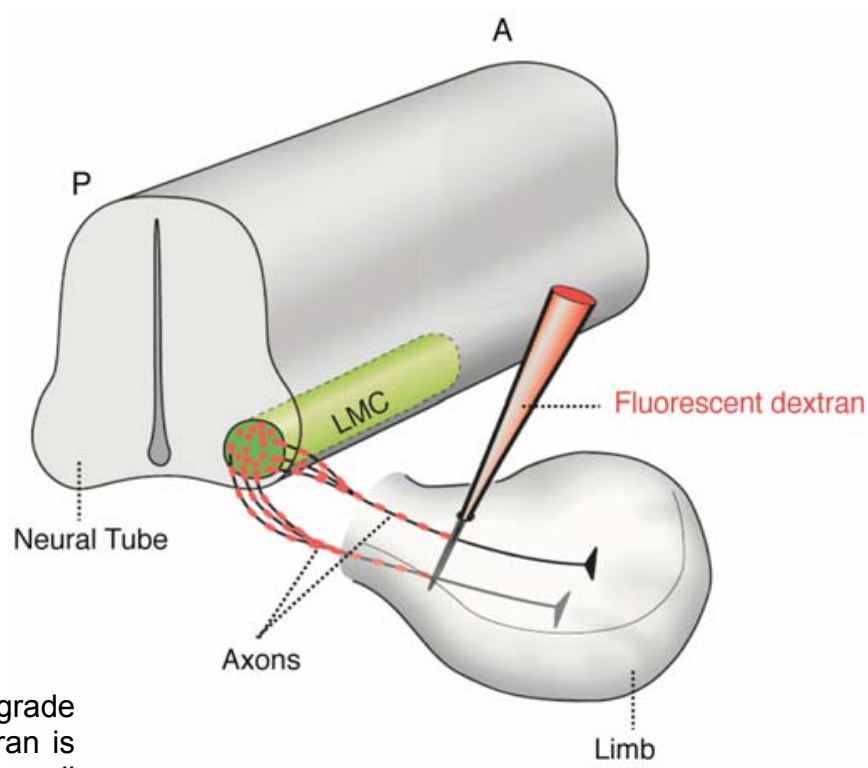
axonal labeling; The fluorescent dextran is transported along the axons to the cell bodies sitting in the LMC column 


\section{Fixation and embedding}

After the labeling incubation, the embryos were further dissected in fresh ACSF. At this stage, the neural tube was dissected out and laid flat in 4\%PFA/PBS to maintain a straight line. The tissues were then fixed for $2 \mathrm{~h}$ at $4^{\circ} \mathrm{C}$ and moved to PBS overnight. On the second day, the tissues were incubated for approximately $4-5$ hours in $25 \%$ Sucrose/PBS and horizontally embedded in the cryomatrix. The embedding should be done carefully so that the neural tube stays on a horizontal straight line, with the two lateral sides at the same height. In this way, the LMC columns could be retrieved at the same section.

\section{Sectioning/ Staining}

The neural tubes were sectioned as $100 \mu \mathrm{m}$ thick sections. The sections were dried and kept at -80 or processed directly to the staining step. The sections were immunostained stained with dsRED (rabbit) or GFP (mouse) antibodies, as described for the cryosections. The staining step increases the intensity of the electroporated fluorescence vector. During the two days immunostaining protocol, the background which rises from unspecific Dextran distribution in the tissue as well decreases, leading to a higher signal to noise ratio.

\section{BrdU labeling of chick embryos}

The BrdU labeling of chick embryos was performed when the embryos were still inside the eggshell ${ }^{86}$. In order to access the embryo, a small opening was made on top of the egg and around $50 \mu \mathrm{l}$ of the $100 \mu \mathrm{M}$ BrdU stock (1:100 diluted from freshly made $10 \mathrm{mM}$ BrdU (Sigma) in PBS) was added on top of the embryo. The egg was further incubated for 30min and the embryos were dissected in cold PBS and fixed for $2 \mathrm{~h}$ at $4^{\circ} \mathrm{C}$ in $4 \%$ PFA/PBS. The fixed embryos were then embedded in cryomatrix as explained before and cut as $10 \mu \mathrm{m}$ sections. 


\section{Immunostaining with anti-BrdU antibody}

Since the detection of $\mathrm{BrdU}$ incorporation into the replicating chromatin requires additional denaturarion of DNA, the immunostaining protocol contains certain steps besides the conventional protocols. The BrdU staining protocol can be combined with a normal immunostaining to generate double stained tissue sections. For double stainings, the following steps were taken:

- Dry the sections at room temperature, draw a liquid repellant line around each section and after drying wash in PBS, $3 \times 5$ min each

- Block the sections with 1\%FCS/PBS + $0.1 \%$ Triton-100 for 1 hour at RT

- Incubate with the appropriate concentration of the desired antibody (e.g. GFP: rabbit), in blocking solution, at $4^{\circ} \mathrm{C}$ overnight

- Wash with PBS, 3X 5min each

- Incubate with the secondary antibody (in case of GFP: anti rabbit Alexaflour 488) for 1 hour at RT

- Post fix the slides in $4 \% \mathrm{PFA} / \mathrm{PBS}$, for $15 \mathrm{~min}$ at $4^{\circ} \mathrm{C}$

*The BrdU immunostaining starts from this step on:

- Wash the slides with PBS, 3X 5min each

- Incubate in prewarmed $2 \mathrm{~N} \mathrm{HCl}$, for 30 min at $37^{\circ} \mathrm{C}$

- Neutralize the $\mathrm{HCl}$ by washing the slides with Borate buffer $(0,1 \mathrm{M} \mathrm{pH} 8.5), 2 \mathrm{X}$ 5 min each at RT

- Block the slides with 1\% BSA/PBS + 0.04\% Tween-20, for 1 hour at RT

- Incubate with mouse antiBrdU (Roche) antibody (1:50 in BSA blocking solution), overnight at $4^{\circ} \mathrm{C}$

- Wash with PBS, 3X 5min each

- Incubate with secondary anti mouse Alexaflour594 antibody (1:1000 in BSA blocking solution)

- Wash with PBS, 3X5min each

- Mount the slides in DAPI-containing vectashield mounting medium (vector laboratories) and proceed to imaging. 


\section{Cell culture experiments}

The tissue culture cells used for the experiments include previous chick embryonic fibroblasts (CEF), prepared from day E11.5 chicken embryos ${ }^{87}$ and human HEK-293T cells. The CEF cells were cultured in DMEM (Gibco) with $10 \%$ chick serum (CS) and 1\% Glutamine. HEK293T cells were cultured in DMEM medium, with 10\% Fetal calf serum (FCS) and $1 \%$ Glutamine. Both of the cell types were incubated in a $37^{\circ} \mathrm{C}$ incubator with $5 \% \mathrm{CO}_{2}$.

\section{Transfection methods}

CEF cells were transfected with Lipofectamine (Invitrogen), with the recommended amounts of the DNA. Co-transfections were performed using an equal amount of each DNA (the molecular weights were almost the same), meeting the total recommended amount of the DNA. To avoid toxicity effects on the cells, the transfection cocktails were replaced by fresh medium after 5 hours of incubation. For transfection of small RNA molecules, the lipofectamine protocol for the transfection of small RNAs was used.

HEK293T cells were transfected by FuGENE6 (Roche), following the recommended amounts of total DNA, always maintaining a 3:2 ratio of the FuGENE6 reagent to the DNA.

\section{Quantitative approaches}

\section{Quantitation of western blot signals}

The intensity of western blot signals was calculated using the ImageJ gel analysis software ${ }^{88}$ and following the application manual. The absolute intensity was calculated as the area value, multiplied by the percentage value. To normalize the intensity and generate the relative intensity, the absolute intensity was divided by the absolute intensity of each loading control. The fold increase was then calculated by comparing the normalized relative intensities. 


\section{Quantitation of cell numbers in immuno-stained embryos}

The relative number of cells positive for each marker was calculated as the ratio of positive cells on the electroporated /non-electroporated sides, averaged between 6 successive sections, and compared to the same value in control embryos. Standard deviation is calculated among ratios of successive sections.

The statistical significance of the effects was determined using the paired student T- test (Excel). P-values $<0,05$ were regarded as significant changes, depicted as $\left(^{*}\right)$ for $p$ value $<0,05$ and $\left({ }^{* *}\right)$ for $p$-value $<0,01$. 


\section{REFERENCES}

1. Jessell, T. M. Neuronal specification in the spinal cord: inductive signals and transcriptional codes. Nat Rev Genet 1, 20-9 (2000).

2. Lee, Y. et al. MicroRNA genes are transcribed by RNA polymerase II. Embo $\mathrm{J}$ 23, 4051-60 (2004).

3. Cai, X., Hagedorn, C. H. \& Cullen, B. R. Human microRNAs are processed from capped, polyadenylated transcripts that can also function as mRNAs. Rna 10, 1957-66 (2004).

4. Zeng, Y. Principles of micro-RNA production and maturation. Oncogene 25, 6156-62 (2006).

5. Kim, V. N. MicroRNA biogenesis: coordinated cropping and dicing. Nat Rev Mol Cell Biol 6, 376-85 (2005).

6. Han, J. et al. Molecular basis for the recognition of primary microRNAs by the Drosha-DGCR8 complex. Cell 125, 887-901 (2006).

7. Seitz, H. \& Zamore, P. D. Rethinking the microprocessor. Cell 125, 827-9 (2006).

8. Bartel, D. P. MicroRNAs: genomics, biogenesis, mechanism, and function. Cell 116, 281-97 (2004).

9. Pillai, R. S., Bhattacharyya, S. N. \& Filipowicz, W. Repression of protein synthesis by miRNAs: how many mechanisms? Trends Cell Biol 17, 118-26 (2007).

10. Nilsen, T. W. Mechanisms of microRNA-mediated gene regulation in animal cells. Trends Genet 23, 243-9 (2007).

11. $\mathrm{Wu}, \mathrm{L}$. \& Belasco, J. G. Let me count the ways: mechanisms of gene regulation by miRNAs and siRNAs. Mol Cell 29, 1-7 (2008).

12. Meister, G. miRNAs get an early start on translational silencing. Cell 131, 25-8 (2007).

13. Filipowicz, W., Bhattacharyya, S. N. \& Sonenberg, N. Mechanisms of posttranscriptional regulation by microRNAs: are the answers in sight? Nat Rev Genet 9, 102-14 (2008).

14. Eulalio, A., Huntzinger, E. \& Izaurralde, E. Getting to the root of miRNAmediated gene silencing. Cell 132, 9-14 (2008). 
15. Hofacker, I. L. Vienna RNA secondary structure server. Nucleic Acids Res 31, 3429-31 (2003).

16. Ambros, V. et al. A uniform system for microRNA annotation. Rna 9, 277-9 (2003).

17. Griffiths-Jones, S. The microRNA Registry. Nucleic Acids Res 32, D109-11 (2004).

18. Griffiths-Jones, S., Grocock, R. J., van Dongen, S., Bateman, A. \& Enright, A. J. miRBase: microRNA sequences, targets and gene nomenclature. Nucleic Acids Res 34, D140-4 (2006).

19. Bernstein, E. et al. Dicer is essential for mouse development. Nat Genet 35, 215-7 (2003).

20. Kanellopoulou, C. et al. Dicer-deficient mouse embryonic stem cells are defective in differentiation and centromeric silencing. Genes Dev 19, 489-501 (2005).

21. Wienholds, E., Koudijs, M. J., van Eeden, F. J., Cuppen, E. \& Plasterk, R. H. The microRNA-producing enzyme Dicer1 is essential for zebrafish development. Nat Genet 35, 217-8 (2003).

22. Ying, S. Y. \& Lin, S. L. MicroRNA: fine-tunes the function of genes in zebrafish. Biochem Biophys Res Commun 335, 1-4 (2005).

23. Van Rooij, E. \& Olson, E. N. MicroRNAs: powerful new regulators of heart disease and provocative therapeutic targets. J Clin Invest 117, $2369-76$ (2007).

24. Van Rooij, E. \& Olson, E. N. MicroRNAs Put their Signatures on the Heart. Physiol Genomics (2007).

25. Mishima, Y., Stahlhut, C. \& Giraldez, A. J. miR-1-2 gets to the heart of the matter. Cell 129, 247-9 (2007).

26. Chen, J. F. et al. The role of microRNA-1 and microRNA-133 in skeletal muscle proliferation and differentiation. Nat Genet 38, 228-33 (2006).

27. Chen, C. Z. \& Lodish, H. F. MicroRNAs as regulators of mammalian hematopoiesis. Semin Immunol 17, 155-65 (2005).

28. Micro-RNA's function to maintain stem cell phenotype. Cancer Biol Ther 6, 305 (2007).

29. Carleton, M., Cleary, M. A. \& Linsley, P. S. MicroRNAs and cell cycle regulation. Cell Cycle 6, 2127-32 (2007). 
30. Rogaev, E. I. Small RNAs in human brain development and disorders. Biochemistry (Mosc) 70, 1404-7 (2005).

31. Stefani, G. \& Slack, F. J. Small non-coding RNAs in animal development. Nat Rev Mol Cell Biol 9, 219-30 (2008).

32. Lynn, F. C. et al. MicroRNA Expression is Required for Pancreatic Islet Cell Genesis in the Mouse. Diabetes (2007).

33. Jeyaseelan, K., Herath, W. B. \& Armugam, A. MicroRNAs as therapeutic targets in human diseases. Expert Opin Ther Targets 11, 1119-29 (2007).

34. Asli, N. S., Pitulescu, M. \& Kessel, M. MicroRNAs in organogenesis and disease. Current Molecular Medicine (in press) (2008).

35. Pearson, J. C., Lemons, D. \& McGinnis, W. Modulating Hox gene functions during animal body patterning. Nat Rev Genet 6, 893-904 (2005).

36. limura, T. \& Pourquie, O. Hox genes in time and space during vertebrate body formation. Dev Growth Differ 49, 265-75 (2007).

37. Sessa, L. et al. Noncoding RNA synthesis and loss of Polycomb group repression accompanies the colinear activation of the human HOXA cluster. Rna 13, 223-39 (2007).

38. Lempradl, A. \& Ringrose, L. How does noncoding transcription regulate Hox genes? Bioessays 30, 110-21 (2008).

39. Rinn, J. L. et al. Functional demarcation of active and silent chromatin domains in human HOX loci by noncoding RNAs. Cell 129, 1311-23 (2007).

40. Woo, C. J. \& Kingston, R. E. HOTAIR lifts noncoding RNAs to new levels. Cell 129, 1257-9 (2007).

41. Tanzer, A., Amemiya, C. T., Kim, C. B. \& Stadler, P. F. Evolution of microRNAs located within Hox gene clusters. J Exp Zoolog B Mol Dev Evol 304, 75-85 (2005).

42. Lemons, D. \& McGinnis, W. Genomic evolution of Hox gene clusters. Science 313, 1918-22 (2006).

43. Lagos-Quintana, M., Rauhut, R., Meyer, J., Borkhardt, A. \& Tuschl, T. New microRNAs from mouse and human. Rna 9, 175-9 (2003).

44. Yekta, S., Shih, I. H. \& Bartel, D. P. MicroRNA-directed cleavage of HOXB8 mRNA. Science 304, 594-6 (2004).

45. Landgraf, P. et al. A mammalian microRNA expression atlas based on small RNA library sequencing. Cell 129, 1401-14 (2007). 
46. Mansfield, J. H. et al. MicroRNA-responsive 'sensor' transgenes uncover Hoxlike and other developmentally regulated patterns of vertebrate microRNA expression. Nat Genet 36, 1079-83 (2004).

47. Kloosterman, W. P., Wienholds, E., de Bruijn, E., Kauppinen, S. \& Plasterk, R. $\mathrm{H}$. In situ detection of miRNAs in animal embryos using LNA-modified oligonucleotide probes. Nat Methods 3, 27-9 (2006).

48. Darnell, D. K. et al. MicroRNA expression during chick embryo development. Dev Dyn 235, 3156-65 (2006).

49. Darnell, D. K. et al. GEISHA: an in situ hybridization gene expression resource for the chicken embryo. Cytogenet Genome Res 117, 30-5 (2007).

50. Antin, P. B. et al. Gallus expression in situ hybridization analysis: a chicken embryo gene expression database. Poult Sci 86, 1472-7 (2007).

51. Hornstein, E. et al. The microRNA miR-196 acts upstream of Hoxb8 and Shh in limb development. Nature 438, 671-4 (2005).

52. Stratford, T. H., Kostakopoulou, K. \& Maden, M. Hoxb-8 has a role in establishing early anterior-posterior polarity in chick forelimb but not hindlimb. Development 124, 4225-34 (1997).

53. Lee, S. K. \& Pfaff, S. L. Transcriptional networks regulating neuronal identity in the developing spinal cord. Nat Neurosci 4 Suppl, 1183-91 (2001).

54. Price, S. R. \& Briscoe, J. The generation and diversification of spinal motor neurons: signals and responses. Mech Dev 121, 1103-15 (2004).

55. Marquardt, T. \& Pfaff, S. L. Cracking the transcriptional code for cell specification in the neural tube. Cell 106, 651-4 (2001).

56. Shirasaki, R. \& Pfaff, S. L. Transcriptional codes and the control of neuronal identity. Annu Rev Neurosci 25, 251-81 (2002).

57. William, C. M., Tanabe, Y. \& Jessell, T. M. Regulation of motor neuron subtype identity by repressor activity of Mnx class homeodomain proteins. Development 130, 1523-36 (2003).

58. Tanabe, Y., William, C. \& Jessell, T. M. Specification of motor neuron identity by the MNR2 homeodomain protein. Cell 95, 67-80 (1998).

59. Jacob, J., Hacker, A. \& Guthrie, S. Mechanisms and molecules in motor neuron specification and axon pathfinding. Bioessays 23, 582-95 (2001). 
60. Graham, A., Maden, M. \& Krumlauf, R. The murine Hox-2 genes display dynamic dorsoventral patterns of expression during central nervous system development. Development 112, 255-64 (1991).

61. Dasen, J. S., Tice, B. C., Brenner-Morton, S. \& Jessell, T. M. A Hox regulatory network establishes motor neuron pool identity and target-muscle connectivity. Cell 123, 477-91 (2005).

62. Dasen, J. S., Liu, J. P. \& Jessell, T. M. Motor neuron columnar fate imposed by sequential phases of Hox-c activity. Nature 425, 926-33 (2003).

63. Shah, V., Drill, E. \& Lance-Jones, C. Ectopic expression of Hoxd10 in thoracic spinal segments induces motoneurons with a lumbosacral molecular profile and axon projections to the limb. Dev Dyn 231, 43-56 (2004).

64. Wu, Y., Wang, G., Scott, S. A. \& Capecchi, M. R. Hoxc10 and Hoxd10 regulate mouse columnar, divisional and motor pool identity of lumbar motoneurons. Development 135, 171-82 (2008).

65. Tiret, L., Le Mouellic, H., Maury, M. \& Brulet, P. Increased apoptosis of motoneurons and altered somatotopic maps in the brachial spinal cord of Hoxc8-deficient mice. Development 125, 279-91 (1998).

66. Song, M. R. \& Pfaff, S. L. Hox genes: the instructors working at motor pools. Cell 123, 363-5 (2005).

67. Farh, K. K. et al. The widespread impact of mammalian MicroRNAs on mRNA repression and evolution. Science 310, 1817-21 (2005).

68. Matise, M. P. \& Lance-Jones, C. A critical period for the specification of motor pools in the chick lumbosacral spinal cord. Development 122, 659-69 (1996).

69. Liu, J. P., Laufer, E. \& Jessell, T. M. Assigning the positional identity of spinal motor neurons: rostrocaudal patterning of Hox-c expression by FGFs, Gdf11, and retinoids. Neuron 32, 997-1012 (2001).

70. Lin, A. W. \& Carpenter, E. M. Hoxa10 and Hoxd10 coordinately regulate lumbar motor neuron patterning. J Neurobiol 56, 328-37 (2003).

71. Thaler, J. P., Lee, S. K., Jurata, L. W., Gill, G. N. \& Pfaff, S. L. LIM factor Lhx3 contributes to the specification of motor neuron and interneuron identity through cell-type-specific protein-protein interactions. Cell 110, 237-49 (2002).

72. Politis, P. K., Thomaidou, D. \& Matsas, R. Coordination of cell cycle exit and differentiation of neuronal progenitors. Cell Cycle 7, 691-7 (2008). 
73. Lobjois, V., Bel-Vialar, S., Trousse, F. \& Pituello, F. Forcing neural progenitor cells to cycle is insufficient to alter cell-fate decision and timing of neuronal differentiation in the spinal cord. Neural Develop 3, 4 (2008).

74. Perkins, A. C. \& Cory, S. Conditional immortalization of mouse myelomonocytic, megakaryocytic and mast cell progenitors by the Hox-2.4 homeobox gene. Embo J 12, 3835-46 (1993).

75. Aberdam, D., Negreanu, V., Sachs, L. \& Blatt, C. The oncogenic potential of an activated Hox-2.4 homeobox gene in mouse fibroblasts. Mol Cell Biol 11, 554-7 (1991).

76. Nieto, M. A., Patel, K. \& Wilkinson, D. G. In situ hybridization analysis of chick embryos in whole mount and tissue sections. Methods Cell Biol 51, 219-35 (1996).

77. Hamburger, V. \& Hamilton, H. L. A series of normal stages in the development of the chick embryo. J. Morph. 88, 49-92 (1951).

78. Obernosterer, G., Martinez, J. \& Alenius, M. Locked nucleic acid-based in situ detection of microRNAs in mouse tissue sections. Nat Protoc 2, 1508-14 (2007).

79. Brown, T. Analysis of RNA by northern and slot-blot hybridization. Curr Protoc Immunol Chapter 10, Unit 1012 (2001).

80. Andrews, N. C. \& Faller, D. V. A rapid micropreparation technique for extraction of DNA-binding proteins from limiting numbers of mammalian cells. Nucleic Acids Res 19, 2499 (1991).

81. Sharma, K. et al. LIM homeodomain factors Lhx3 and Lhx4 assign subtype identities for motor neurons. Cell 95, 817-28 (1998).

82. Das, R. M. et al. A robust system for RNA interference in the chicken using a modified microRNA operon. Dev Biol 294, 554-63 (2006).

83. Meister, G., Landthaler, M., Dorsett, Y. \& Tuschl, T. Sequence-specific inhibition of microRNA- and siRNA-induced RNA silencing. Rna 10, 544-50 (2004).

84. Krull, C. E. A primer on using in ovo electroporation to analyze gene function. Dev Dyn 229, 433-9 (2004).

85. Glover, J. C., Petursdottir, G. \& Jansen, J. K. Fluorescent dextran-amines used as axonal tracers in the nervous system of the chicken embryo. $J$ Neurosci Methods 18, 243-54 (1986).

86. Cao, X., Pfaff, S. L. \& Gage, F. H. A functional study of miR-124 in the developing neural tube. Genes Dev 21, 531-6 (2007). 
87. Wittler, L. Anteriore Musterbildung im Wirbeltierembryo - Die Induktion von Vorderhirn und Herz (Georg-August University, Goettingen, 2002).

88. Girish, V. \& Vijayalakshmi, A. Affordable image analysis using NIH Image/ImageJ. Indian J Cancer 41, 47 (2004). 


\section{CURRICULUM VITAE}

\section{Personal information:}

Name: Naisana Seyed Asli

Date of Birth: $3^{\text {rd }}$ Feb, 1979

Place of Birth: Tehran, Iran

Nationality: Iranian

\section{Education:}

Since Sep., 2003

2000- 2003

1996- 2000

\section{Fellowships:}

Oct 2003-Oct 2007
PhD studies in Molecular Biology (International Molecular Biology Program of Max-Planck Research Schools)

Master of Science in Cell \& Molecular Biology

Bachelor of Science in Biology
Max-Planck Institute of Biophysical Chemistry, Goettingen, Germany

Razi University, Kermanshah, Iran

Tehran University, Tehran, Iran

\section{Publications:}

- Regulation of geminin functions by cell cycle-dependent nuclear-cytoplasmic shuttling, Luo L, Uerlings Y, Happel N, Asli N.S., Knoetgen H, Kessel M; Mol Cell Biol. 2007 Jul;27(13):4737-44.

- MicroRNAs in organogenesis and disease, Asli N.S., Pitulescu M., Kessel M.; Current Molecular Medicine 2008 (in press)

- MicroRNA miR-196 functions in the Hox gene dependent maturation of lumbar motor neurons, Asli N.S., Marquardt T., Kessel M. 2008 (submitted) 